\title{
Chapter 11 \\ The German Case Study: Pioneer Projects of Aquaculture-Wind Farm Multi-Uses
}

\author{
Bela H. Buck, Gesche Krause, Bernadette Pogoda, Britta Grote, \\ Lara Wever, Nils Goseberg, Maximilian F. Schupp, \\ Arkadiusz Mochtak and Detlef Czybulka
}

\begin{abstract}
Most studies on multi-use concepts of aquaculture and wind farms explored cultivation feasibility of extractive species, such as seaweed or bivalves. However, recent studies also included the cultivation of crustaceans or fish culture in the vicinity of wind turbines. Consequently, new approaches combine fed and extractive species in integrated multi-trophic aquaculture (IMTA) concepts for offshore multi-use to reduce nutrient output and the overall environmental impact of aquaculture operations. In this chapter the findings of a series of mussel and oyster cultivation experiments over several seasons are presented, which were conducted at different offshore test sites in the German Bight. Sites were selected within future offshore wind farm areas for an explicit multi-use perspective. Results have demonstrated successful growth and fitness parameters of these candidates and
\end{abstract}

\footnotetext{
B.H. Buck $(\bowtie) \cdot$ B. Pogoda · B. Grote · M.F. Schupp

Alfred Wegener Institute Helmholtz Centre for Polar and Marine Research (AWI),

Marine Aquaculture, Maritime Technologies and ICZM, ZMFE Zentrum Für Maritime

Forschung und Entwicklung, Bussestrasse 27, 27570 Bremerhaven, Germany

e-mail: Bela.H.Buck@awi.de

B.H. Buck · B. Pogoda

Faculty of Applied Marine Biology, University of Applied Sciences Bremerhaven, An der Karlstadt 8, 27568 Bremerhaven, Germany

G. Krause

Alfred Wegener Institute Helmholtz Centre for Polar and Marine Research (AWI),

Earth System Knowledge Platform (ESKP), Bussestrasse 24, 27570 Bremerhaven, Germany

G. Krause

SeaKult - Sustainable Futures in the Marine Realm, Sandfahrel 12, 27572 Bremerhaven, Germany

L. Wever

Forschungszentrum Jülich GmbH, 52425 Jülich, Germany

N. Goseberg

Ludwig-Franzius-Institute for Hydraulic, Estuarine and Coastal Engineering, Leibniz University Hannover, Nienburger Str. 3, 30167 Hannover, Germany
}

A. Mochtak · D. Czybulka

University of Rostock, 18051 Rostock, Germany

(C) The Author(s) 2017

B.H. Buck and R. Langan (eds.), Aquaculture Perspective of Multi-Use Sites

in the Open Ocean, DOI 10.1007/978-3-319-51159-7_11 
therefore definitely proved the suitability of these bivalve extractive species for open ocean aquaculture. Another approach for multi-use in offshore wind farms is its use as marine protected area or even for reinforcement or restoration of endangered species, which need the absence of any fisheries activity for recovery. Current projects are testing this perspective for the native European oyster Ostrea edulis and the European lobster Homarus gammarus. From the technological point of view there are many options on how to connect aquaculture devices, such as longline and ring structures as well as different cage types, to the foundations as well as to install it in the centre of the free area between wind turbines. Next to the system design also experiments on drag forces originating from the aquaculture structure on the foundation and vice versa were investigated. Complementary to the biological, environmental end technical aspects, a number of studies were specifically targeted to address and include stakeholders, their attitudes, their interests and concerns over time. By this approach, the inclusion of stakeholders into the research process from its very beginning until today, co-production of knowledge could be fostered. Next to joint identification of the major impediments and concerns of offshore aquaculture under multi-use conditions, new issues and research questions were identified. Primary focus on the economic potential of aquaculture in offshore wind farms was shown for consumption mussels. The production of mussels using longline technology is sufficiently profitable even under the assumption of substantial cost increases. This is especially true, if existing capacities could be used. Last but not least, the EEZ is a special area-it is not a state territory even if a coastal state has its sovereign rights and jurisdiction. It is an area where three legal systems come together: international law, law of the European Union and national law. There are no mariculture projects in the German EEZ and no approval procedure has been completed so far. Some sites are not suitable for mariculture, especially because of nature conservation and shipping.

\subsection{Introduction}

The development of "offshore aquaculture" or "open ocean aquaculture" has often been described as the new challenging frontier of the "Blue Revolution", which puts current aquaculture efforts on the same level as the advances made in agriculture during the so-called "Green Revolution" in the onset of the 1950s (Krause et al. 2015). The motivation to foster this type of marine development roots against the backdrop of the rising concerns that the over-exploitation and economic inefficiencies in the capture-fisheries sector are leading to widespread severe decline of global food security. However, to date, the search for resilient solutions in the aquaculture sector to meet production, income, community development and food supply and security needs remains critical.

In contrast to nearshore aquaculture development, offshore aquaculture faces several additional challenges, one of which is that in Germany it is located in the EEZ, the Exclusive Economic Zone. The latter is defined by United Nations 
Convention on the Law of the Sea (UNCLOS) as a 200 nautical mile zone off the coast of a State, over which it has special rights regarding the exploration and utilization of marine resources. Thus, the EEZ is a special area-it is not a state territory even if a coastal state has there somewhat sovereign rights and jurisdiction, which refers to the coastal state's rights below the surface of the sea. As a case in point, in Germany, the EEZ is an area where three legal systems come together: international law, law of the European Union and national German law.

Indeed, the ocean space of the EEZ has been regulated or allocated in a number of different ways, but most importantly, this has been done predominantly within individual economic sectors. Obvious examples of "sectoral zoning" include waterways for shipping, disposal areas, military security zones, concession zones for mineral extraction, aquaculture sites, and most recently marine protected areas. Although the context and outcomes are different because of the dynamic and three-dimensional nature of marine environments, the land use planning concepts and techniques can be translated to the marine environment, thus leading to a contemporary rise in the development of Marine Spatial Planning (MSP) efforts. At present, there are few frameworks that facilitate integrated strategic and comprehensive planning in relation to all activities taking place in marine areas. This current stage of development of spatial planning of marine waters can be viewed somewhat in parallel to the past land use planning efforts. The latter arose in response to specific social and economic problems and later environmental problems that were triggered by the industrial revolution at the end of the 19th century.

Next to the problematic nature of marine spatial planning, the offshore realm is a place far off the coast, which bears challenges to the technological development of aquaculture systems that are able to withstand the harsh offshore conditions, vis á vis supporting feasible operation and maintenance demands. Candidate species must be tolerable to these exposed conditions whilst holding sufficient economic potential. Last, but not least, stakeholders and their interests, concerns, rights and duties must be taken into consideration.

In the following we illustrate these different aspects and challenges of offshore aquaculture in multi-use settings employing Germany's North Sea EEZ region as a case study. We draw here on research and experience from various research efforts in this areas since early 2000 until today (see Buck et al. 2008a). Figure 11.1 shows a summary of the projects conducted in the German Bight all led by the Alfred Wegener Institute Helmholtz Centre for Polar and Marine Research (AWI), which were related to the four main topics: (A) biology, (B) technology, (C) social science as well as (D) economics.

All projects are displayed in a chronological order by taking the scientific coherence into account. Project No. 1, the feasibility study, gave the basis for the following projects and the entire suite of aquaculture-wind farm multi-use research. The Coastal Futures Project (No. 4) acted as key node project, in which the other projects either have contributed to or have been stimulated by its transdisciplinary approach. Due to their problem-focused approaches and early and continuous integration of multiple stakeholder groups, these projects initiated and accompanied several activities and outcomes outside academia. For instance, it called for wind 


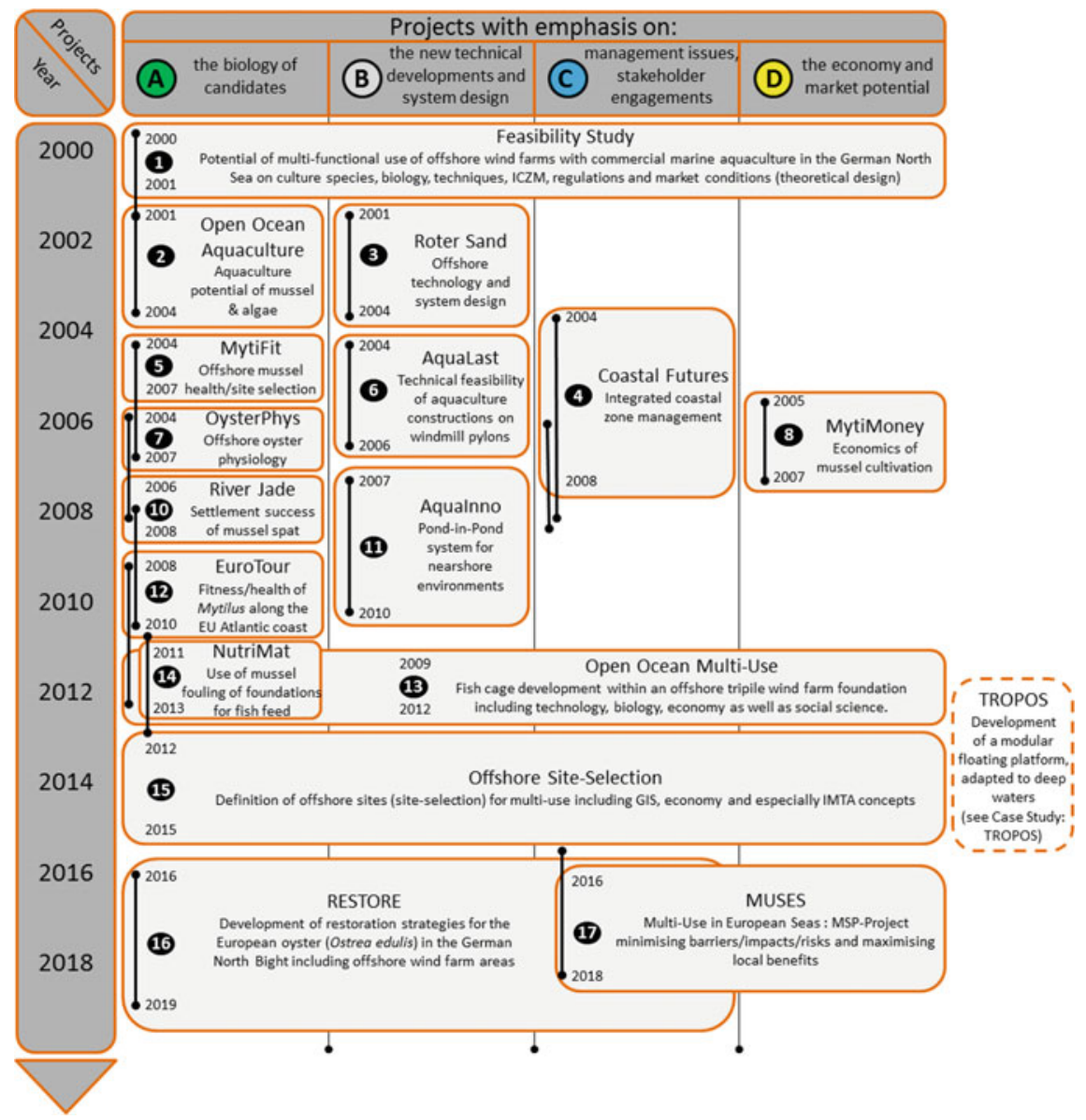

Fig. 11.1 Offshore aquaculture multi-use projects conducted in the German Bight under the guidance or participation of AWI from early 2000 ongoing. Next to the chronological order, all projects are configured in a scientific coherence manner. The project "TROPOS" is marked in a dotted line as it focused only partly on the German Bight. Additionally, there is a separate chapter in this book where this project is described in more detail. Project No. 11 "AquaInno" has only slight overlaps with multi-use aspects and therefore is not mentioned in detail. Project No. 12 "EuroTour" deals with site-selection and health status of offshore environments along the European Atlantic Coast. Project No. 16 focuses on restoration for nature conservation purposes. The Project No. 17 "MUSES" just started after submission of this book. Modified and updated after Buck et al. 2008a

farm planners attention to offshore aquaculture, included authorities and fishermen into the planning process for site-selection-criteria of appropriate aquaculture sites as well as stimulated the involvement of offshore engineers and wind farm operators into the technical part of an offshore aquaculture enterprise. Furthermore, it introduced fishermen to the co-management idea and appraised the potential economics 
of mussel cultivation, supplied authorities with maps and tools to limit regional stakeholder conflicts, and established an inshore reference station to support the data assessed offshore. All research undertakings over the entire period were conducted as follow-up projects resulting from addressing the issues of social acceptance, the demand for practical technical solutions and to fill some of the knowledge gaps in biology, social science and other related topics.

In the following sub-chapters, the central findings of these projects are discussed in more detail and the development of this contextual knowledge generation over time is synthesized. This will be done by starting with the potential species and their respective biological characteristics, which determine their feasibility for offshore aquaculture in the first place. In the successive sub-chapters, the prospective technologies to harness their potential as aquaculture products are discussed, as well as their likely economic potential for this contextual setting in the German Bight. The chapter closes with an overview over the existing stakeholder characteristics and their respective attitudes, perceptions and concerns and the respective regulatory framework.

\subsection{The Beginning}

The feasibility study (Project No. 1) (Buck 2000, 2001, 2002) aimed to ascertain the economic feasibility of an offshore marine aquaculture structure for breeding of marine organisms in the North Sea, predominantly in combination with an offshore wind farm. In the year 2000 several thousand wind-generators were planned for installation in the North Sea before the end of the decade. However, at that time, after completion of this feasibility study, no offshore wind farm was in use or in preparation. The major goal of this combination was to use environmentallyfriendly wind-driven power generation, or so-called renewable energy production, with the environmental enhancement that aquaculture offers as a very important opportunity. This feasibility study concentrated on Open Ocean Aquaculture (OOA) and its multi-use potential with offshore wind farms.

Most countries with access to the sea are engaged in aquaculture. Only rare cases, for example in developing nations, fundamentals of e.g. technical knowledge, resisting equipment and system design are lacking to successfully research and implement aquaculture. Although Germany has the above-mentioned factors in relative abundance, it can be counted with the few developing nations that have not adopted any form of aquaculture. The reasons for this stagnation are mainly as follows: Conflicts exist between interested parties on coastal land management issues. Such parties include commercial and pleasure boat traffic, gravel mining, marine and local fishing coops, and protected areas, such as national parks. Problems with regulation and assignment of areas in the North Sea and its near-shore waters arose due to these conflicts. In addition, complex local hydrodynamic conditions such as large wave heights and strong water currents have hindered the aquaculture development in Germany. 

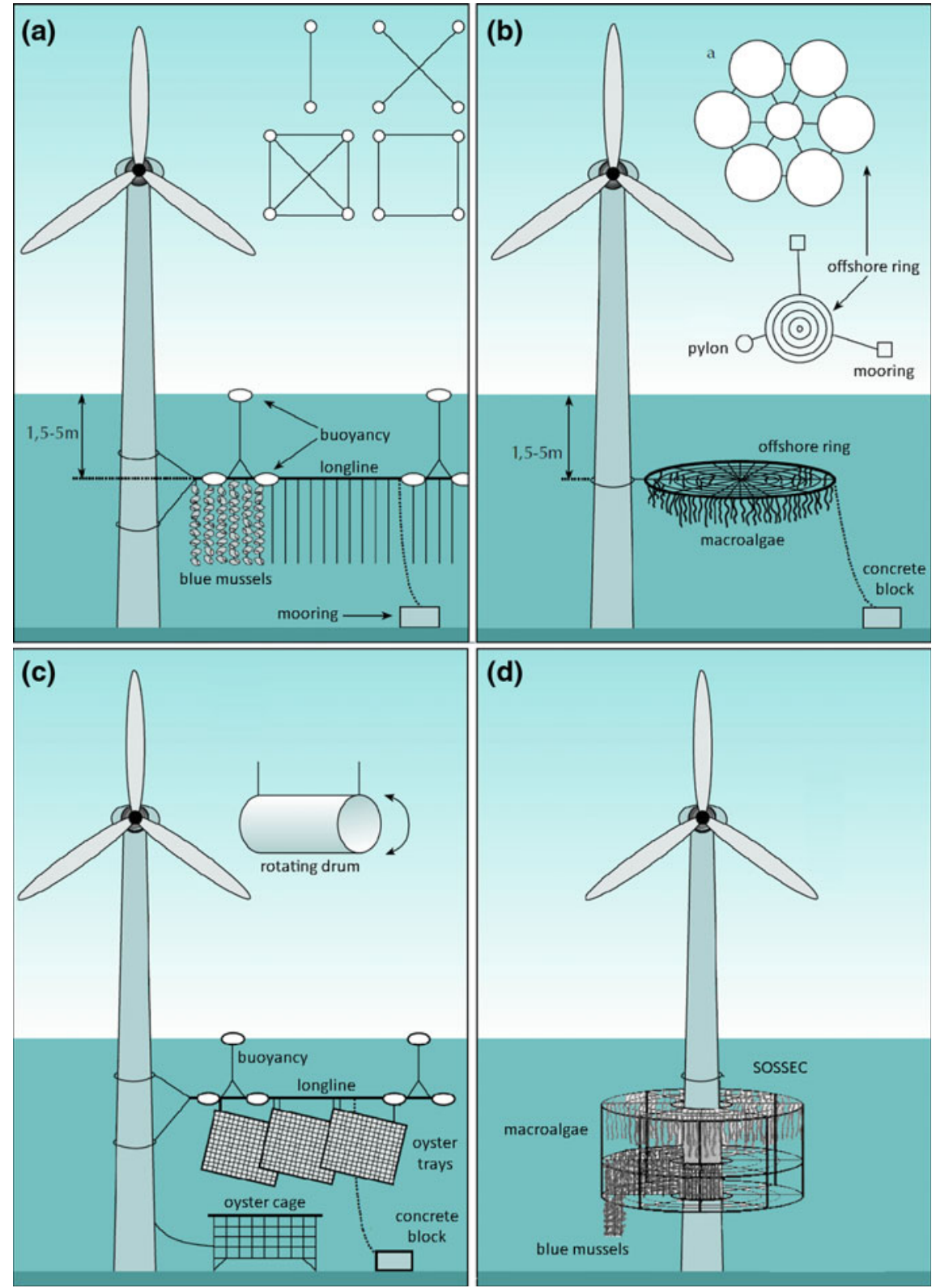
4Fig. 11.2 a-d First drawings to show the multi-use concept combining aquaculture with wind farms. a Top a birds-eye view of longline constructions. Special pylon anchorages ensure access and maintenance of the wind energy plants by ship; down Side view of a submerged mussel and seaweed longline culture. The wind energy plant pylon is used as the anchorage for one end of the longline. The line can reach a length of 100-300 m. Longer lines may be mounted to the next pylon; b Top A bird's-eye view of a ring construction. The combined rings are fixed around the pylon as well as a pylon with a single offshore ring construction using two anchorages; down Side view of a pylon with offshore ring construction used for cultivation of algae and mussels. An anchor stone is placed at the outermost point of the ring construction; c Side view of a pylon combined with an 'on bottom' cage for oyster culture and oyster trays fixed to a longline as well as a rotating oyster cage (drum); d SOSSEC design (Submersible Offshore Shellfish and Seaweed Cage), which is during culture in a submerged mode and can be lifted to the surface for harvest. Modified after Buck (2000, 2001); Images AWI/Prof. Dr. Bela H. Buck

"Offshore, Open Ocean, Far Out"-currently unknown or seldom used terms among the German public, have become since the mid-1990s common "catch-phrases" in Asia and the USA. In an effort to cover the immense demand for seafood products, new regions beneath the coastal waters were sought. However, at that time only a few world-wide Open Ocean Aquaculture businesses are in operation and are still a new method of aquaculture internationally. Main research efforts in an international perspective were placed in the provision of sturdy offshore technology, which resist the extreme environmental conditions and warrants safe utilisation of the installation. However, so far, little operational implementation of the results of extensive research has been undertaken.

Several types of cultivation in combination with the foundations of offshore wind turbines were suggested: (1) Predominately longline constructions for the cultivation of seaweed and mussels, by which submersible ropes provide the habitat on which the candidates can settle (Fig. 11.2a). (2) Other techniques, such as ring and cage constructions (Fig. 11.2b, c), which can be placed on the water surface and under water, as well as the construction SOSSEC (Submersible Offshore Shellfish and Seaweed Cage) (Fig. 11.2d) can be operated, too.

The advantage of submersible culture constructions is the avoidance of the impact of harsh weather conditions and strong wave mechanics. Thus, a combination of these techniques with the main pillar of the wind turbine installation dispenses the need for a sophisticated mooring of the aquaculture system, which would impact strongly on the benthic ecosystem. Due to the solid construction of the wind turbine, such systems would be very safe.

The feasibility study suggested a variety of candidates, which can be cultivated under such hydrodynamic and environmental conditions within the North Sea, and hold large potentials on the German market. Additionally, the study pointed to the technical challenges and the importance of the socio-economic drivers. All users have to be addressed at the beginning of a new project in order to find an overarching consensus of all parties thereto.

As predominately, already existing data sets were used in the feasibility study of offshore aquaculture potentials within the areas of wind farms in the German North Sea, this study was theoretical in nature. In order to determine the feasibility of 
aquaculture within the German North Sea, further experiments on a practical basis were conducted and led to the project development displayed in Fig. 11.1.

At the time when the study was published, we expected that the further development and modification of aquaculture systems would be directly dependent on the development of wind farms. Therefore, it was necessary that the development of future wind turbine techniques as well as aquaculture systems should not move ahead separately.

In summary, there was an ample need for practical research pertaining aquaculture development in the North Sea to overcome the current lack of knowledge in Germany in this sector.

\subsection{Potential Species for Offshore Aquaculture}

Suitable species for offshore aquaculture production in the German North Sea were identified during several scientific research projects. The selection was (1) based on literature research, (2) expert knowledge on candidate biology, (3) former projects as well as (4) confirmed by current practical research results. Accordingly, 21 aquaculture candidates of different trophic levels (extractive and fed species: seaweed, molluscs, crustacean and fish) are recommended for offshore cultivation in the German Bight (North Sea). In the following we present a collection of species tested starting with extractive species, followed by crustaceans and fish.

\subsubsection{Seaweed Species}

Seaweed aquaculture research in offshore sites focusses mainly on growth performance and culturing techniques. Various systems were installed in harsh offshore conditions, both at the wind farm foundation and at its vicinity (see subchapter on techniques and system design below), respectively. Following biological and ecological requirements, but also a regulatory and economic framework, five species of macroalgae were identified as potentially successful candidates for offshore cultivation in the German North Sea: Oarweed (Laminaria digitata), Sugar kelp (Saccharina latissima), Cuvie (Laminaria hyperborea), Dulse (Palmaria palmata), and Sea beech (Delesseria sanguinea).

\subsubsection{Candidate: Laminarian Species}

The genus Laminaria is one of the most important macroalgal genera in temperate coastal ecosystems, especially in the northern hemisphere. This is amongst other things reflected by its high species numbers, its considerable overall biomass, its 
dominance, and its economic significance (Bartsch et al. 2008). The utilisation of algal products plays an essential role in many fields of modern everyday life. Laminariales offer a variety of goods used in human and animal consumption, in industrial products or for bioremediation (Bartsch et al. 2008).

In the German North Sea, vital abundance of L. hyperborea, L. digitata and S. latissima is reduced to the rocky shore of the Island of Helgoland as the remaining coastline is characterized by soft-bottom substrate, not suitable for the fixation of Laminaria rhizoid holdfasts. For aquaculture production, Laminaria plants are "seeded" on ropes, which are subsequently fixed to various suspended or floating culture devices. Detaching L. digitata and S. latissima blade portions from the meristem induces them to become sporogenous far ahead of their natural reproductive season, making mature sporophytes available all year round (Buchholz and Lüning 1999; Lüning et al. 2000; Pang and Lüning 2004) (Fig. 11.3a-e).

In general, Laminaria in the German North Sea show a period of rapid growth from January to June and one of slow growth from July to September (Kain 1979).
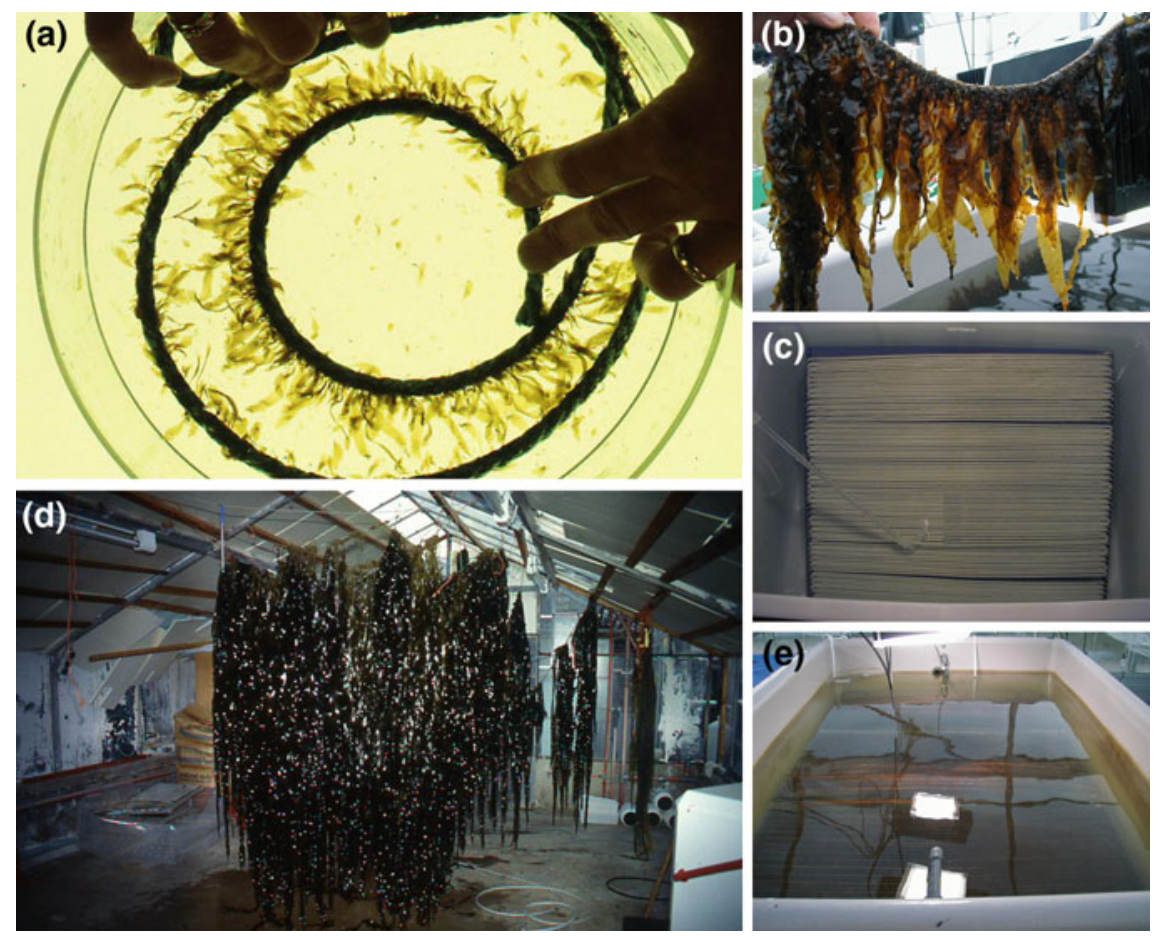

Fig. 11.3 a Rope with young Saccharina latissima 6 weeks after seeding; b Laminarian plants after 10 weeks cultivation in land based facilities; c Seeding rope used for offshore cultivation arranged in a "curtain"-mode before seeding; $\mathbf{d}$ Large S. latissima harvested from an offshore site after 5 months cultivation ready for the drying procedure; e Tank for seeding procedure and day-length adaptation. Photos a and d AWI/Dr. Cornelia Buchholz; b-c and e AWI/Prof. Dr. Bela H. Buck 
Helgolandic S. latissima and L. hyperborea predominantly grow in winter and early spring similarly as in Norway (Bartsch et al. 2008). While growth of L. hyperborea totally stops in July, growth of S. latissima decreases substantially but does not cease. In contrast, the growth period of $L$. digitata from Helgoland extends from spring to summer and in September, it exhibits a growth rate of still $50 \%$ of the optimum (Lüning 1979). The seasonal variations in abiotic conditions affect growth performance, particularly in algae from high latitudes with a more pronounced seasonality of temperature, irradiance and photoperiod (Bartsch et al. 2008).

Exploring the feasibility of offshore kelp cultures, potential forces experienced by the attached algae were studied extensively. Sporophytes were seeded on ropes, which were designed for the use in offshore environments (Fig. 11.3a, c). Land-based cultivation took place in tank devices, where the day length could be adapted according to the development of sorus (Fig. 11.3b, e). When Laminarian thalli reached market size $(1.5-2.0 \mathrm{~m}$ in length) plants were harvested and transferred to the lab to test its dry weight ratio (Fig. 11.3d).

The degree of exposure influenced morphology and shape of the algae and their resistance to environmental forcing considerably. Laminaria originating from sheltered conditions had wider blades with thick and undulate margins, while offshore sporophytes grown at exposed sites were thin and streamlined (Bartsch et al. 2008; Buck and Buchholz 2005). S. latissima sporophytes pre-cultivated onshore but transferred to the sea at very early stages developed a streamlined blade and resisted current velocities up to $2.5 \mathrm{~m} \mathrm{~s}^{-1}$. If grown singly in currents of $>1 \mathrm{~mm} \mathrm{~s}^{-1}$, $S$. latissima can withstand the high energy environment experienced in offshore cultivation (Buck and Buchholz 2005). These experiments on Laminaria species show that adapted to strong currents as young individuals, they will grow well and produce large amounts of biomass at exposed sites of the German Bight (Buck and Buchholz 2005; Fig. 11.4a, b).

When combining Laminaria aquaculture with offshore wind farms, the foundations would provide a stable fixing structure for the seaweed cultivation systems (e.g. Buck 2002; Krause et al. 2003; Buck et al. 2004). These ideas led to several multi-use projects in the German Bight, such as No. 1-4, 9, 13, 15 (see Fig. 11.1) (Buck 2002; Michler-Cieluch et al. 2009a, b, Buck and Buchholz 2004a, 2005; Buck et al. 2012), where for the first time Laminaria species were tested in an IMTA approach with partners from the offshore wind industry.

Mass culture of Laminaria sp. and Saccharina latissima under the high energy offshore environment in the North Sea requires a rigid cultivation system for withstanding rough conditions, which can be handled while retaining the macroalgae. Buck and Buchholz (2004a) tested various carrier constructions and different mooring systems and their results led to a new patented ring carrier for macroalgae offshore cultivation (see subchapter on techniques and system design below) (Figs. 11.32 and 11.33).

For IMTA approaches in the German Bight, the three native Laminaria species are ideal extractive candidates: Laminaria cultivation brings clear advantages for the environment. Apart from their $\mathrm{CO}_{2}$-consumption, kelps are also able to absorb large amounts of nitrogen and phosphate, thus helping to abate coastal 


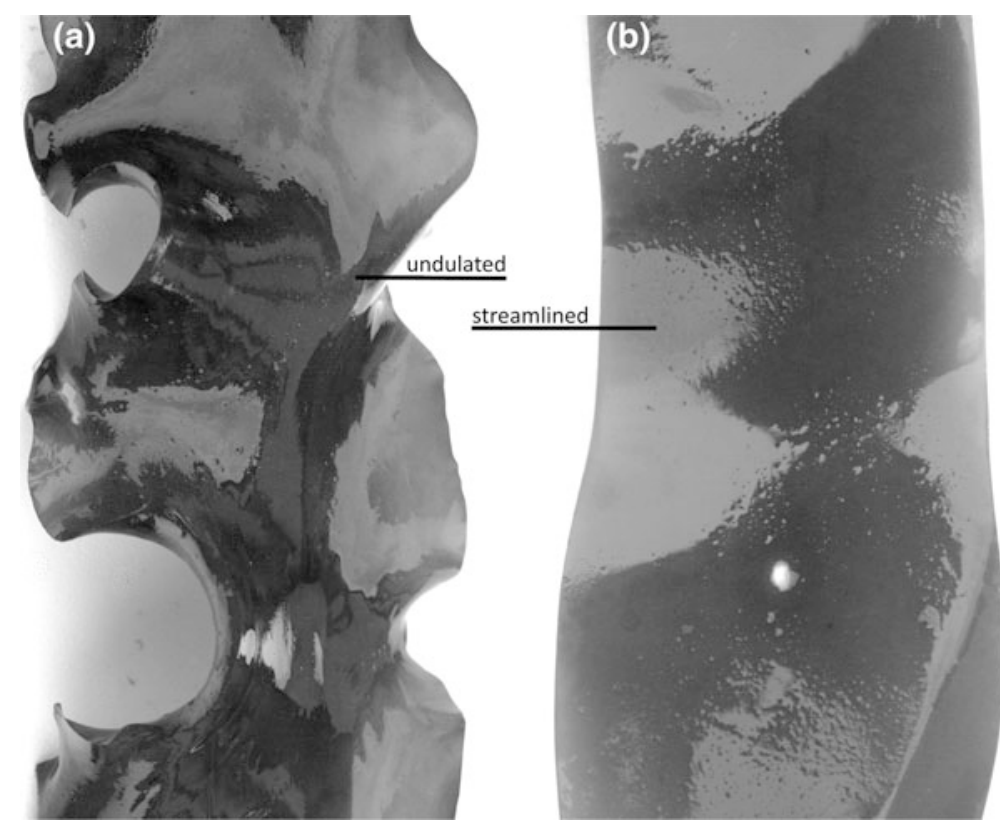

Fig. 11.4 a Saccharina latissima originating from a sheltered site with a wider blade and ruffled margins and $\mathbf{b}$ cultivated $S$. latissima from the offshore site with a streamlined shape (modified after Buck and Buchholz 2005). Photos AWI/Prof. Dr. Bela H. Buck

eutrophication (McHugh 2003; Lüning and Pang 2003; Fei 2004) (see Chapter Offshore Aquaculture with Extractive Species: Seaweed and Bivalves). This feature of Laminaria and other seaweeds qualifies them for use in sustainable maricultures. Modern integrated aquaculture systems have been developed and are constantly improved. The combination of seaweed culture with land-based fish culture or open marine cage culture has found great acceptance (Subandar et al. 1993; Petrell and Alie 1996; Ahn et al. 1998; Troell et al. 1999; Chopin et al. 2001; Neori et al. 2004). Macroalgae, including Laminaria, may act as biofilters for finfish aquaculture at offshore sites in the German Bight, removing dissolved excretions and surplus nutrients and providing extra oxygen and biomass.

\subsubsection{Candidate: Palmaria palmata}

Dulse is an edible intertidal or shallow subtidal red alga (Rhodophyta) of the Atlantic and North Pacific and its culture methods are well known (Browne 2001; Le Gall et al. 2004; Pang and Lüning 2004, 2006) (Fig. 11.5a).

$P$. palmata has been proven to be a good candidate for integrated multi-trophic aquaculture (IMTA) in the projects SEAPURA (Lüning 2001) and "Offshore Site Selection" (Project No. 15; Matos et al. 2006; Grote 2016; Grote and Buck 2017) 

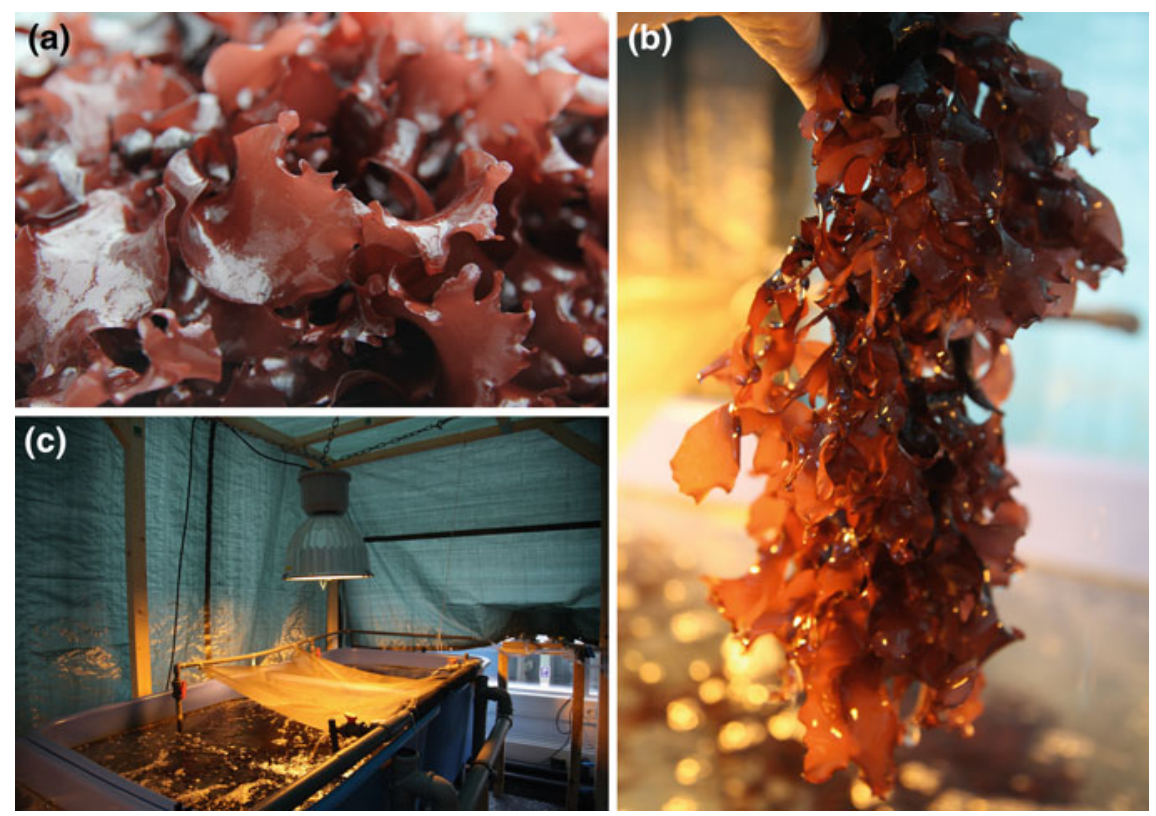

Fig. 11.5 a-c Dulse (Palmaria palmata) grown in a land-based IMTA-system in co-culture with turbot for nutrient budget calculation for the multi-use of offshore wind farms. a Palmaria palmata (Photo AWI/Sina Löschke); b Palmaria palmata from IMTA tank culture (Photo AWI/Dr. Britta Grote); c IMTA tank system for cultivation of Palmaria palmata in project No. 15 "Offshore Site Selection". The red macroalgae were grown in tumble culture (Photo AWI/Dr. Britta Grote)

and is thought to be a suitable species for cultivation in multi-use approaches in offshore wind farms (Grote and Buck 2017) (Fig. 11.5b, c). The red alga can reach specific growth rates (SGR) between $1.1 \% \mathrm{~d}^{-1}$ at $14{ }^{\circ} \mathrm{C}, 13-14 \mathrm{~h}$ daylight and varying radiation in co-culture with halibut (Corey et al. 2014) and $6.18 \% \mathrm{~d}^{-1}$ at $14{ }^{\circ} \mathrm{C}, 16 \mathrm{~h}$ daylight and constant radiation in co-culture with turbot (Grote and Buck 2017). Latter results are similar to the maximum SGR of $P$. palmata reaching $7 \% \mathrm{~d}^{-1}$ at $6-14{ }^{\circ} \mathrm{C}$ and $16 \mathrm{~h}$ daylight with nutrients added (Morgan and Simpson 1981). In an IMTA-system with turbot, the excess $\mathrm{N}$ of $1 \mathrm{~kg}$ fish supported the growth of more than $6.5 \mathrm{~kg}$ of dulse, which removed a maximum of $0.76 \mathrm{mg} \mathrm{N} \mathrm{mg} \mathrm{DW}^{-1} \mathrm{~d}^{-1}$ at $14{ }^{\circ} \mathrm{C}$ (Grote and Buck 2017). Conservative estimates of yields of $P$. palmata at about $300 \mathrm{t}^{\text {year }}{ }^{-1}$ are expected to remove up to $30 \%$ of $\mathrm{N}$ excreted by 500 tonnes of salmon within two years (Sanderson et al. 2012).

Since $P$. palmata is one of the few seaweed in Europe used for food, its chemical composition has been investigated (Morgan et al. 1980a). In recent years, interest in health foods, food supplements, new protein sources and novel bioactive compounds led to further research of the chemicals found in seaweeds (Løvstad-Holdt and Kraan 2011; Indergaard and Minsass 1991). The red alga has also a relatively high protein content, which can be increased by IMTA cultivation, as the ammonium leads to increased $\mathrm{N}$ storage in the algal tissue (Grote 2016). 
P. palmata requires a site with high water current for nutrient and $\mathrm{CO}_{2}$ exchange across the surface of the fronds as well as for prevention of fouling (Werner and Dring 2011), thus making it a good candidate for offshore cultivation. Currents with flow rates of minimum 5-10 $\mathrm{cm} \mathrm{s}^{-1}$ are needed for Palmaria cultivation. However, the exposure of the site to wave action should be moderate (Werner and Dring 2011). Therefore, for offshore cultivation of dulse wave exposure and current velocities need to be considered to reach optimal growth conditions and to reduce loss of biomass.

Another limiting factor for growth of $P$. palmata in the wind farms of the German Bight is the relatively high water temperatures in summer. Grote and Buck (2017) found reduced SGRs of $2.2 \% \mathrm{~d}^{-1}$ at $16.5^{\circ} \mathrm{C}$. Minimum winter temperatures are not considered to be damaging unless there is the unlikely threat of ice-formation which could cause abrasion of the cultures. Growth of P. palmata is optimal at temperatures between $6^{\circ}$ and $12{ }^{\circ} \mathrm{C}$, but the red alga will grow well to temperatures up to $15^{\circ} \mathrm{C}$ (Morgan et al. 1980b; Morgan and Simpson 1981) or $17{ }^{\circ} \mathrm{C}$ (Grote and Buck 2017), with these differences probably resulting from different temperature ranges for different populations.

The size at which $P$. palmata should be harvested is a frond length of $30-40 \mathrm{~cm}$ (Werner and Dring 2011). It is crucial to monitor the algae during spring and especially during the summer months to ensure that the dulse is harvested before the fronds are overgrown by fouling organisms (Werner and Dring 2011). This is very important when $P$. palmata is grown for human consumption, which requires high quality harvests. As growth is expected to be reduced during the summer months due to higher temperatures in the German Bight, the optimal time for harvest would be in June (Grote and Buck 2017). As the growth of P. palmata was enhanced in the vicinity of fish farms at sea (Sanderson et al. 2012) and as it is an robust alga thought to withstand strong forces, $P$. palmata is thought to be an ideal extractive candidate for offshore IMTA (Grote and Buck 2017). However, the potential forces experienced by the attached algae offshore need to be studied in more detail.

\subsubsection{Candidate: Delesseria sanguinea}

Sea beech is an European endemic, sublittoral red alga with a distribution range from northern Spain and Portugal to northern Norway and Iceland (Lüning 1990). It is thought to be a candidate for offshore aquaculture systems due to its biological tolerance to environmental conditions (Lüning 1990); however, biological studies on multi-use and offshore aquaculture success of this species are still missing. The reproductive season of $D$. sanguinea lasts from October to February/April at Helgoland (Molenaar and Breeman 1997) and the red alga can tolerate temperatures between 13 and $23{ }^{\circ} \mathrm{C}$, but temperatures for optimal growth lie between 10 and $15^{\circ} \mathrm{C}$ (Lüning 1990). D. sanguinea is used in the cosmetics industry for its anticoagulant properties and vitamin $\mathrm{K}$ content; the active principle being termed delesserine (Guiry and Blunden 1991). 


\subsubsection{Bivalve Species}

Following mainly biological and technical requirements, but also a regulatory and economic framework, three filter-feeding bivalves were identified as potentially successful candidates for offshore cultivation in the German Bight: Mytilus edulis, Crassostrea gigas and Ostrea edulis (Buck et al. 2006a).

$M$. edulis and $O$. edulis are native species while $C$. gigas was introduced to German waters in the 1960s due to aquaculture activities in the Netherlands (Diederich et al. 2004; Smaal et al. 2009). By now C. gigas is distributed all over the German North Sea coastline and is commercially cultured since the 1980s. All three species are classified as extractive species in aquaculture and are therefore ideal candidates for offshore cultivation with IMTA concepts. They reduce nutrient emissions of higher trophic species by filter-feeding and require low maintenance as they do not require additionally feed (Pogoda et al. 2011).

During several studies, these candidates have been cultivated at various offshore sites and approved their suitability for offshore aquaculture operations in the future. Results of these studies clearly elucidated that all three bivalve species grow successfully under exposed conditions in offshore environments (e.g. Buck 2007; Brenner et al. 2012; Pogoda et al. 2011, 2013). As the "multi-use" of offshore wind farms for aquaculture installations will facilitate the further expansion of environmentally friendly and sustainable aquaculture, most test sites of the described cultivation experiments were conducted in North Sea areas of two offshore wind farms (OWF): "Butendiek" (in operation since 2015) and "Nordergründe"1 (currently under construction in late 2016, Fig. 11.6).

\subsubsection{Candidate: Mytilus edulis}

Biological conditions: Blue mussels cultivated in offshore areas of the German North Sea, for the most part, show high growth rates compared to those grown in nearshore sites (e.g. Buck 2004, 2007). This is due to the fact that water quality (e.g. less urban sewage) and oxygen concentrations are more suitable and the infestation of parasites is low or non-existent (Buck et al. 2005; Pogoda 2012). However, in areas under estuarine influence and/or exposure to fluvial transport point to a comparable probability for high contamination loads similar to nearshore areas, thus potentially reducing fitness (Brenner et al. 2012). In Project No. 2 "Open Ocean Aquaculture" mooring devices were deployed to test the feasibility of mussel and seaweed aquaculture at offshore sites within areas of planned wind farms (Fig. 11.7a). Larval abundance of mussels tended to decrease with increasing distance from shore (Walter et al. 2002; Buck 2017). However, several offshore sites were identified, where larval concentration was sufficient enough to facilitate adequate natural seeding (Buck 2007) (Fig. 11.7b). Alternatively, limited spat

\footnotetext{
${ }^{1}$ Nordergründe is an area in the Weser estuary off the German Coast in the German Bight (Fig. 8).
} 


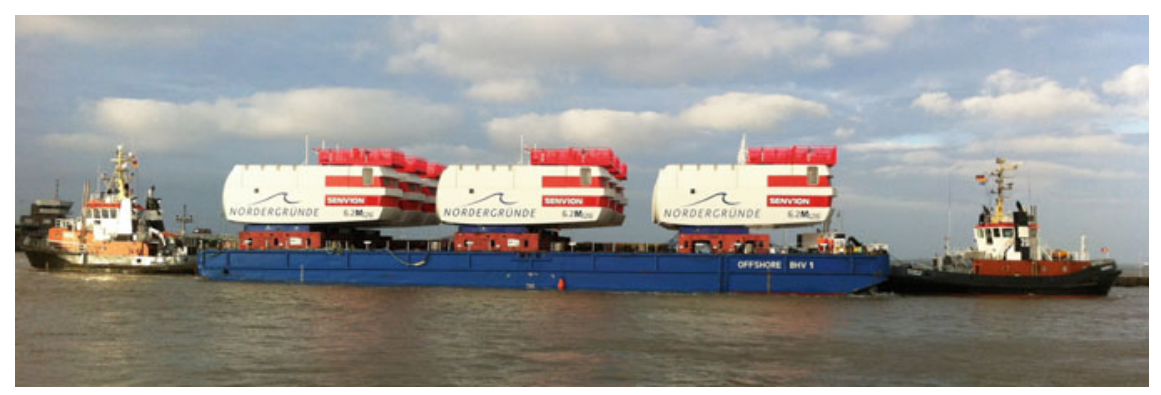

Fig. 11.6 Transfer of offshore wind farm turbines to the OWF Nordergründe by tugboats. Nordergründe area, as part of the multi-use concept, was used for extractive species test sites, especially for bivalves and Laminaria sp. (Photo AWI/Dr. Bernadette Pogoda)

availability may be viewed as an advantage when moving offshore. The benefit for a low settlement can lead to a one-step cultivation technique (no thinning procedure) if collecting and grow-out sites are within the same region in the vicinity of offshore structures. The lower settlement success on one hand results in a limited commercial potential, but on the other hand eases handling and maintenance (Fig. 11.7c). During Project No. 3 "Roter Sand" different types of submerged longline systems were developed and tested: a conventional polypropylene longline as well as a steel hawser longline, both with different versions of buoyancy modes. Spat collectors and grow-out ropes were suspended perpendicular from the horizontal longline for several months. These multi-use experiments have shown a massive settlement at offshore cultivation lines, making thinning essential (Buck 2007) (Fig. 11.8).

Resistance of mussels to severe conditions: The resistance of mussels to strong currents as well as high waves and swell depends on the degree and duration of these forces (Project No. 5 "MytiFit" and Project No. 10 "River Jade"). Information on hydrodynamic conditions is important due to the fact that e.g. mussels and oysters do adapt to harsh conditions but do not automatically grow fast. Even when flow rates are increasing and consequently deliver more food, which stimulates mussels and oysters to feed intensively, at a certain current velocity threshold growth is reduced due to a pressure differential between inhalant and exhalent siphons (Wildish and Kristmanson 1984, 1985; Rosenberg and Loo 1983). Further, exposure to high waves/swell also reduces production rates due to the loss of mussels through detachment (Scarratt 1993). Even if mussels cultivated in high energy environments are able to adapt to the permanent physical stress by increasing the strength and number of byssal-thread attachments, system design adapted from sheltered environments, such as collector devices, have to be modified to prevent detachment (Brenner and Buck 2010).

\footnotetext{
${ }^{2}$ Roter Sand is an offshore lighthouse located in an area called Nordergründe in the Weser estuary, German Bight/North Sea 17 nautical miles off the coast of the city of Bremerhaven (Fig. 8).
} 


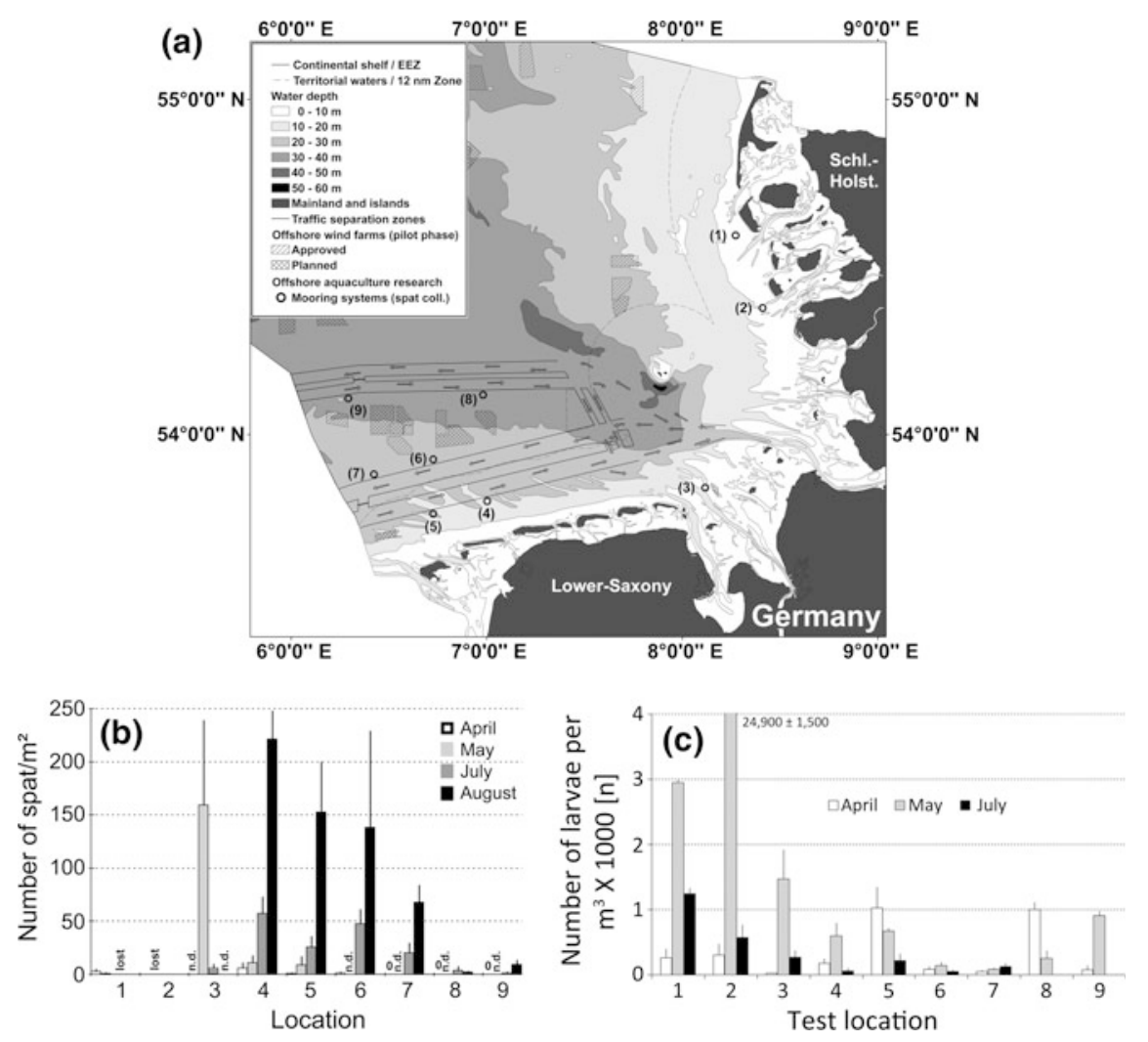

Fig. 11.7 a Shows the map indicating the stations where offshore test installations were moored; b displays the concentration of mussel larvae in the water column at the respective site and c represents the number of mussels settling on ropes (Buck 2017)

To follow the idea of multi-use of sites and support the co-existence of mussel cultivation off the coast in severe conditions where wind farms occur the attachment and detachment of mussels and their byssus threats from their holding devices were tested (Figs. 11.9a-c, 11.10 and $11.11 \mathrm{a}-\mathrm{m}$ ). Collector types for larval settlement attraction, good foothold and interweaving abilities, or collectors combining these properties should be developed and applied depending on the use for seed mussel collection or grow-out as well as for a one-step or a two-step (including thinning) cultivation method. Due to the harsh conditions in the open ocean collector surfaces should be precisely tailored to avoid loss of mussels. It may happen that not only one collector type for all purposes is the solution. Changing collector surfaces according to the prevailing conditions (current velocity, waves, size of the mussel, etc.) may be most beneficial.

Use of fouling organisms originating from foundations: In Project No. 14 "NutriMat" the use of harvested Mytilus edulis, originally settling in vast amounts on the foundations of offshore wind farms, was investigated (Weiss et al. 2012). The removal of fouling organisms at regular intervals due to regulated 

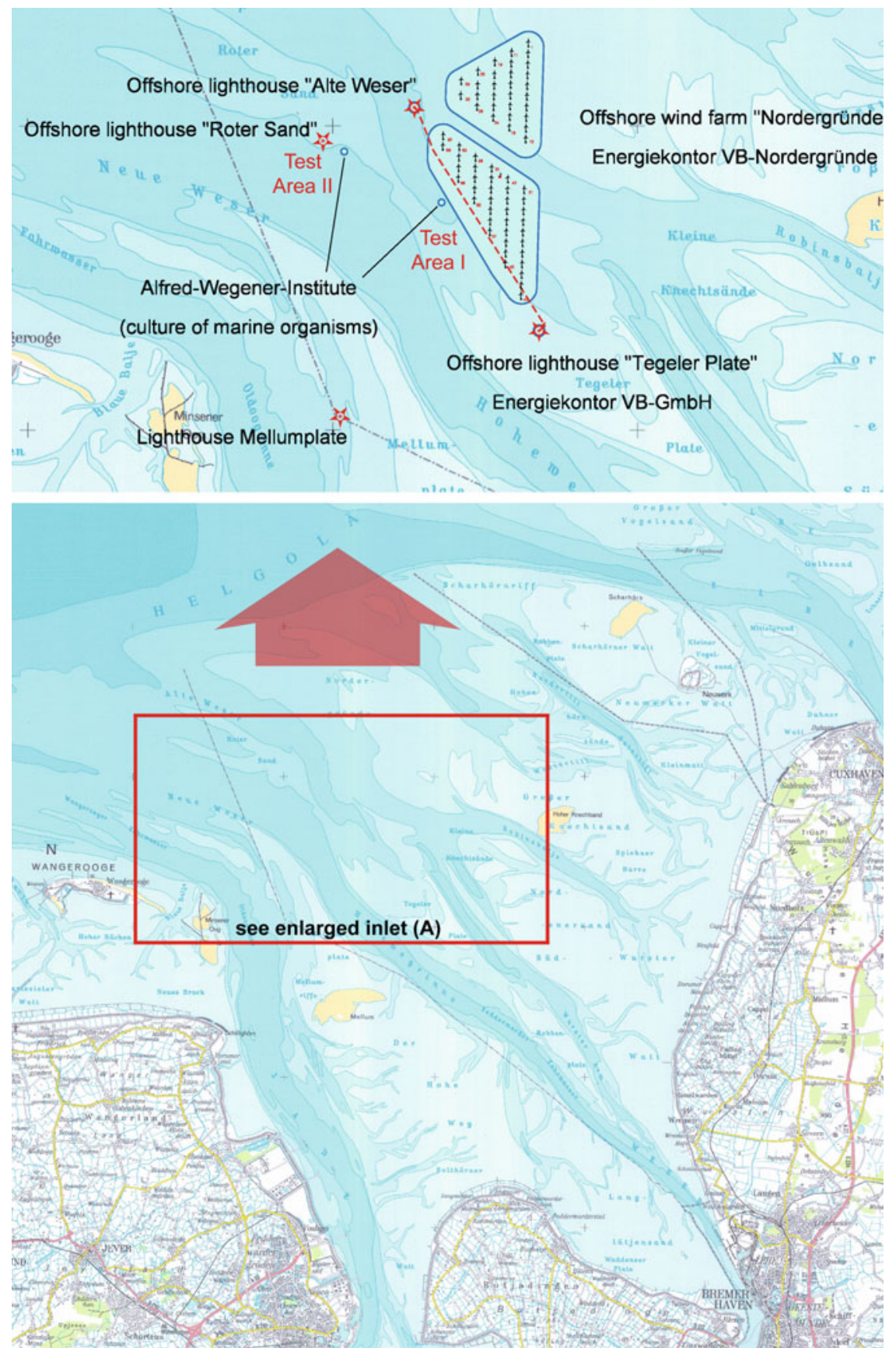

Fig. 11.8 Map of the southern German Bight. The enlarged upper Inset illustrates the test area No. I, Nordergründe, and the test area No. II at the offshore lighthouse Roter Sand. The wind turbines indicate the planned offshore wind farm "Energiekontor" (modified after Buck 2007) 

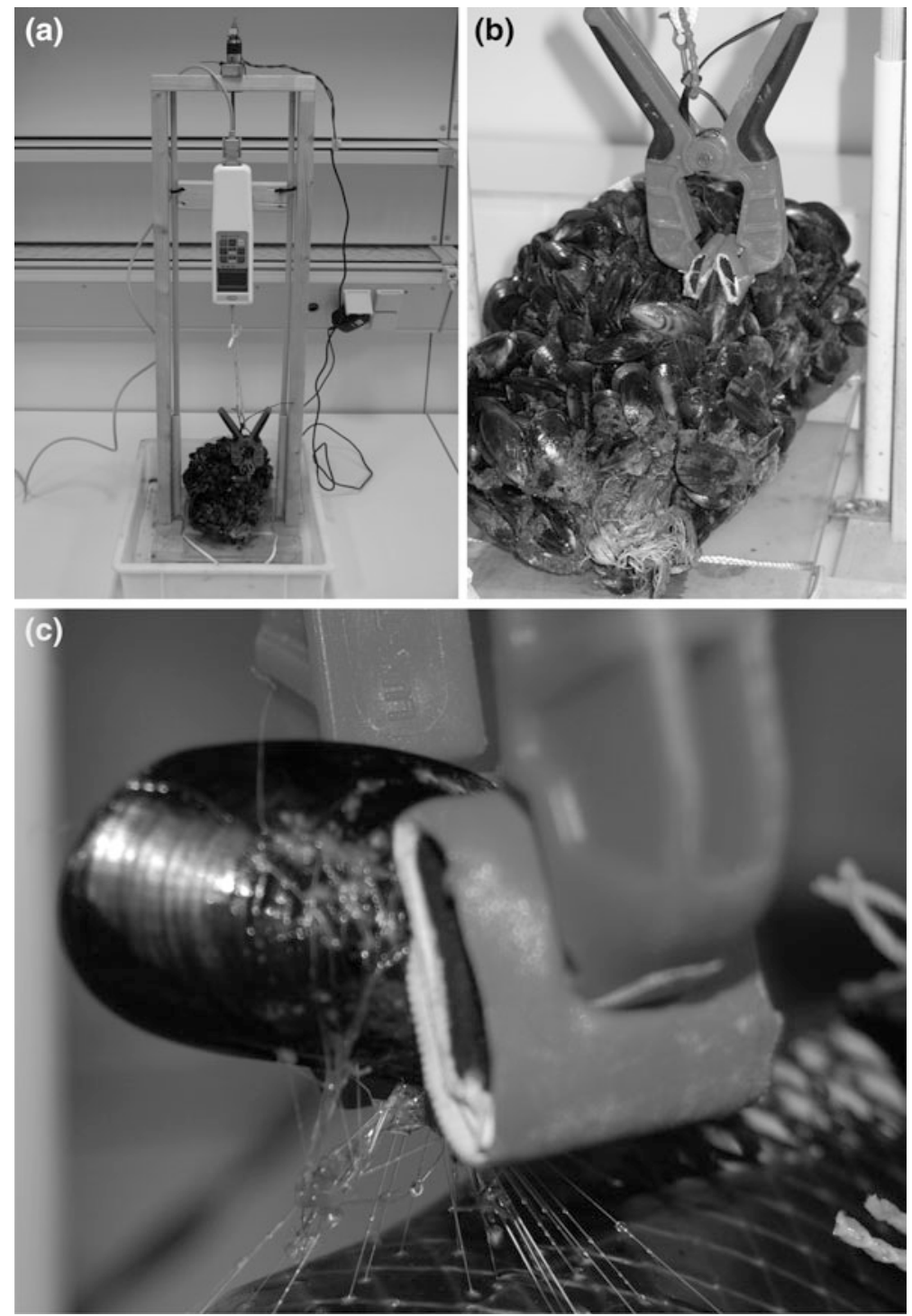

Fig. 11.9 a-c Investigation of the forces needed to detach mussels/byssus threads from substrates. a Dislodgement device with a force gauge; b sample and clamp to pick up a single mussel from a mussel conglomerate; $\mathbf{c}$ visible are various byssus threats when lifting up the clamp (modified after Brenner and Buck 2010)

construction surveys is mandatory to get an insight into corrosion, cuts or any other potential damage on the wind turbine foundation surface. However, the inspection and resulting removal opens an access to a high quality protein and lipid source. The meat of harvested Blue mussels as alternative protein source in aquaculture 

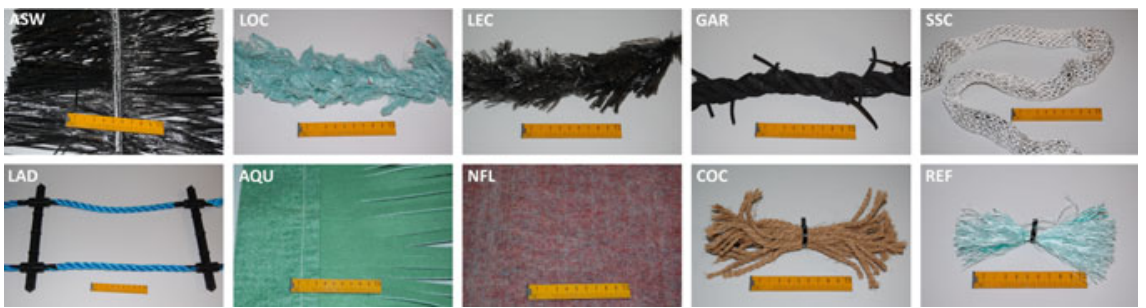

Fig. 11.10 Collector types used for the detachment test. ASW Artificial Seaweed Collector (Size $[S]: 10 \mathrm{~mm}$; Material $[M]$ : nylon rope as back bone with $10 \mathrm{~cm}$ long PP-leaves attached at both sites; Origin [O]: Japan); $L O C$ Looped Christmas Tree ( $M$ Extruded polypropylene with a straight trim, strands of lead in the centre help sinking; $O$ New Zealand); $L E C$ Leaded Christmas Tree ( $M$ Extruded polypropylene with a looped trim, strands of lead in the centre help sinking; $O$ New Zealand); GAR Galician Rope ( $M$ Rough surfaced nylon-PE ropes with strands; $O$ Spain); SSC Self-Sinking Collector ( $M$ Polyester net formed as a tube, small stones help sinking; $O$ Norway); $L A D$ Ladder Collector ( $S 16 \mathrm{~mm}$; $M$ Parallel running PP-ropes connected every $35 \mathrm{~cm}$ by a plastic bar; $O$ Norway); $A Q U$ Aquamats ${ }^{\circledR}(M$ Strands of PP-fleece material with ballast sleeve; $O$ USA); $N F L$ Naue ${ }^{\circledR}$ Fleece ( $M$ PP-fleece, cost-saving alternative to AQU; $O$ Germany); $C O C$ Coconut Rope ( $S 24 \mathrm{~mm}$; $M$ rope of coconut fibres; $O$ India); $R E F$ Reference Collector ( $M$ Bushy tufts of a unravelled $10 \mathrm{~mm}$ PP-rope; $O$ Germany) (modified after Brenner and Buck 2010)
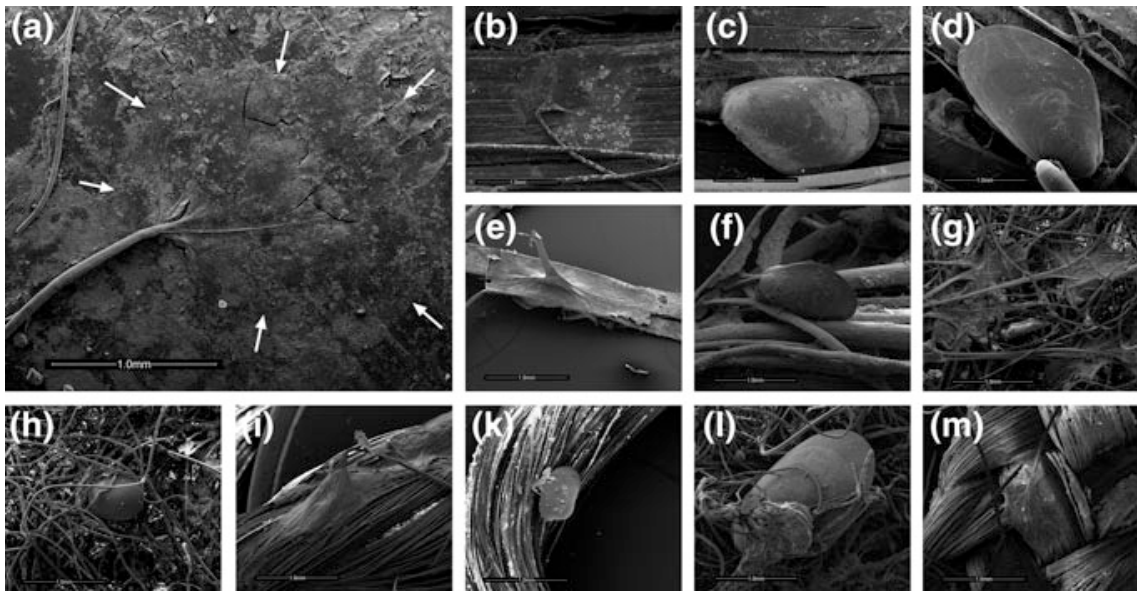

Fig. 11.11 a-m EM-photos (100-fold magnification) of mussel byssus threats/plaques attached to substrates. a Byssus plaque attached to a mussel shell. White arrows demonstrate the outstretched size of the plaque. $\mathbf{b}$ Byssus plaques on an ASW collector; $\mathbf{c}$ attached post-larvae on LEC collector and on $\mathbf{d}$ LAD collector; $\mathbf{e}$ byssus plaques on LEC collector; $\mathbf{f}$ attached post-larvae on COC collector; $\mathbf{g}$ byssus plaques and $\mathbf{h}$ attached post-larvae on NFL collector; $\mathbf{i}$ byssus plaques and $\mathbf{k}$ attached post-larvae on an SSC collector; $\mathbf{m}$ byssus plaques on an GAR collector (modified after Brenner and Buck 2010)

feeds was tested for the feeding of farmed turbot (Scophthalmus maximus) (Fig. 11.12a-e). For this purpose, mussels were scraped off the foundation and transferred to the land-based facilities to produce feed in various mixtures with 

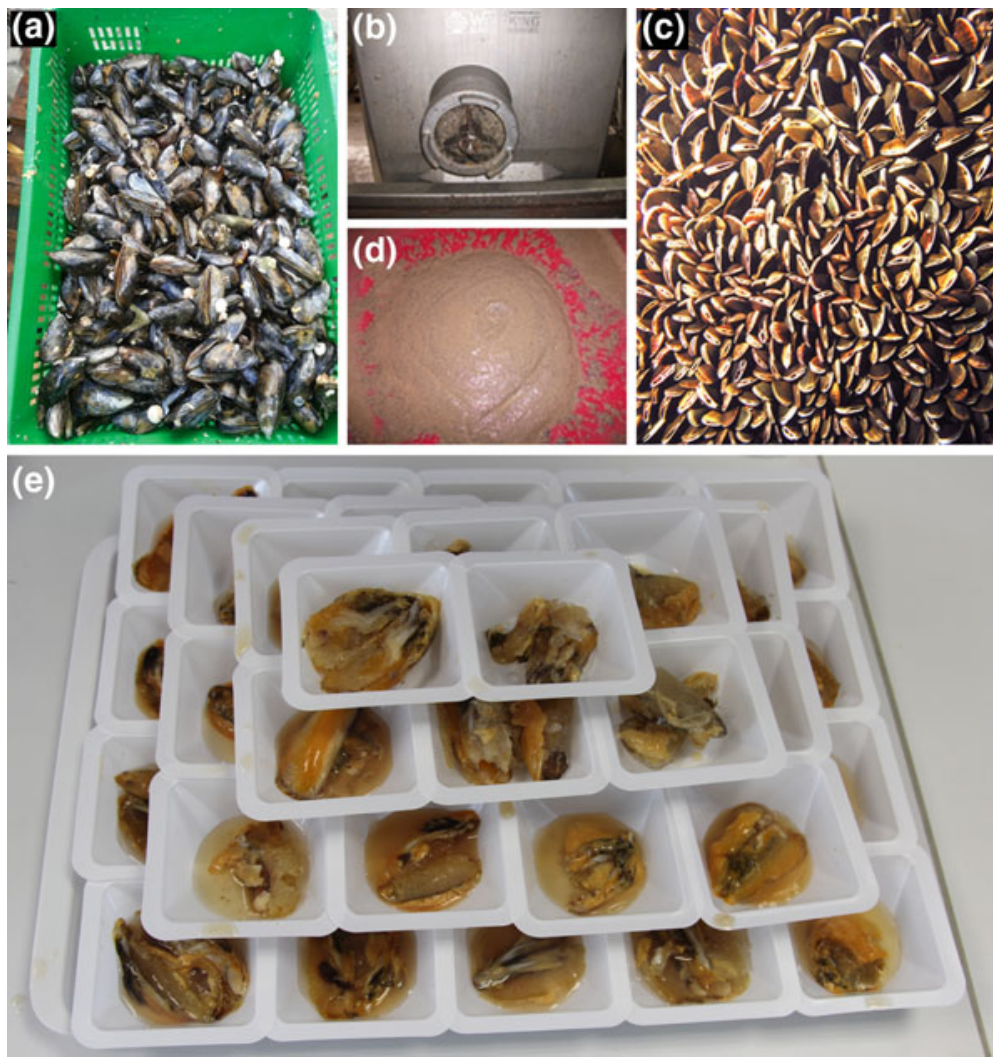

Fig. 11.12 a-e Mussels (Mytilus edulis) from offshore foundations to be used as fish feed. a Harvested mussels scrapped from the foundation; $\mathbf{b}$ grinder to chop the mussel meat; $\mathbf{c}$ Blue mussels attached to a foundation surface underwater; $\mathbf{d}$ mussel meat after grinding; $\mathbf{e}$ mussels to be tested for parasite infestation. Photos a-b and d-e AWI/Dr. Monika Weiß; c AWI/Prof. Dr. Bela H. Buck. Modified after Weiss et al. 2012

common fish feed and then fed to turbot, which was cultivated within a Recirculating Aquaculture System (RAS). These mixes of feed all containing different concentrations of mussel meal were tested and the resulting growth, acceptance, welfare and digestibility observed. The experiments revealed that a replacement of fish meal with mussel meal of $100 \%$ and $50 \%$ resulted in depressed growth; while a fish meal replacement with $10 \%$ and $25 \%$ of mussel meal did not reduce growth or negatively affect the health of the tested turbot. The outcome of this project was that mussel meal has a high potential to serve as supplement or fish meal replacement in feed for turbot raised in aquaculture systems and therefore reduces the impact of fisheries for fish meal production (Weiss and Buck 2017). 

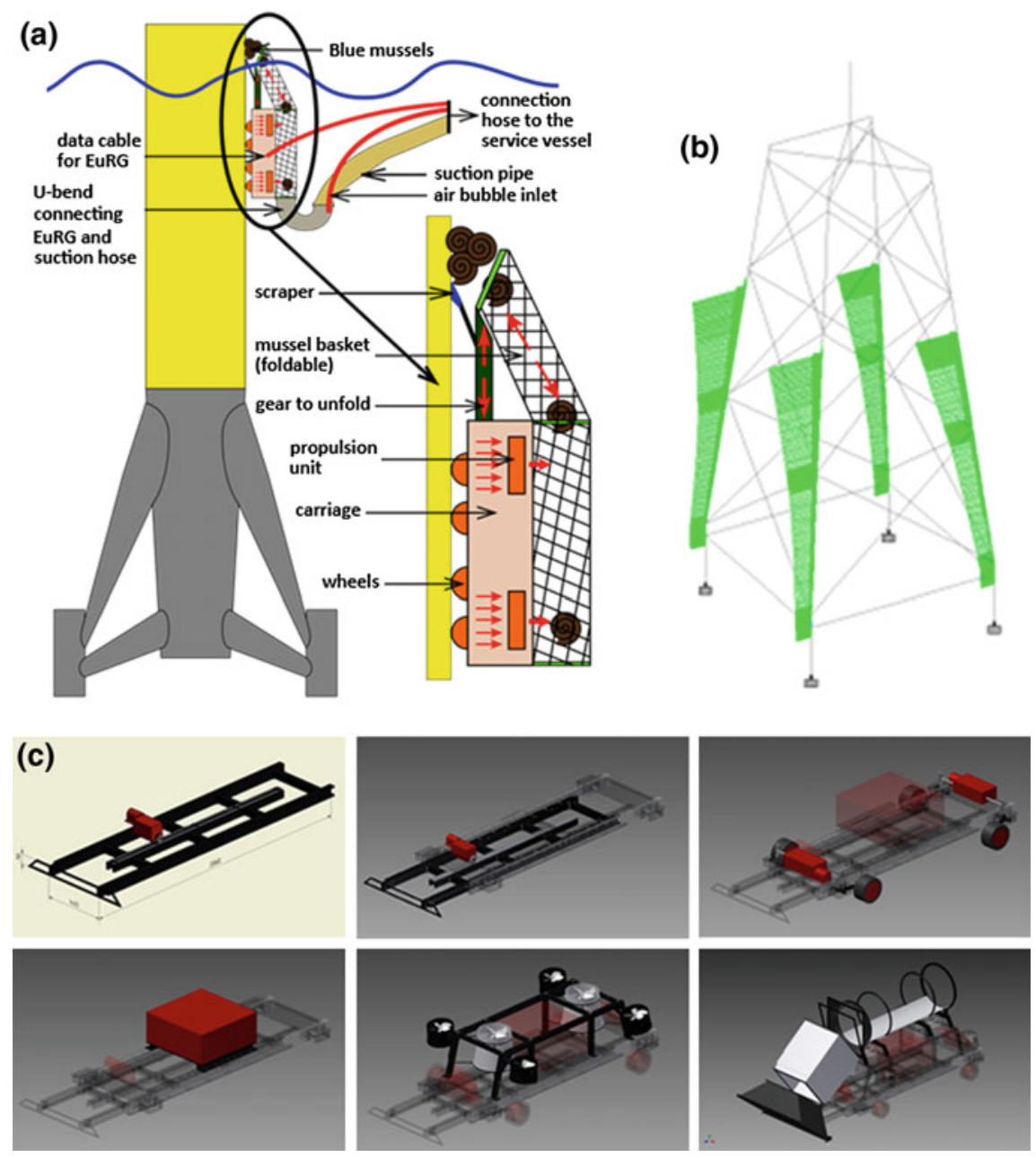

Fig. 11.13 a-c Harvest and cleaning device. a Side view of a foundation and an attached EuRG; the enlargement of the EuRG shows the structure in more detail; $\mathbf{b}$ is a computer model, which shows the load forces on the foundation and the carriage. $\mathbf{c}$ show some details of the development progress of the carriage and its superstructure. Modified after Weiss et al. 2012

Additionally, an automatic mussel harvesting technique by designing a remotely operating robot was developed (Fig. 11.13a-c), called EuRG (Ernte- und Reinigungsgerät, Harvest and cleaning device). It was used for harvesting mussels from the surface of the foundation. However, this vehicle was only designed on paper and never built. 


\subsubsection{Candidates: Crassostrea gigas and Ostrea edulis}

Health conditions: In contrast to Blue mussel cultivation, which can rely on natural spatfall in offshore areas of the German Bight, offshore oyster cultivation depends on purchasing seed oysters and caging of animals. The biological performance of Pacific and European oysters was investigated at three different offshore sites in the German Bight during the first multi-use aquaculture project "Open Ocean Aquaculture" as well as in the project "Offshore Oyster Physiology" (OysterPhys) (Project No. 2 and No. 7, Fig. 11.1). Young oysters were cultivated in the open ocean 10-40 nautical miles off the coast in 2001-2003 and from April to October 2004 and 2007 in oyster lanterns (Fig. 11.14). Research focused on growth performance, condition and survival rates in these high-energy environments. For a higher resolution of overall condition, elemental and biochemical compositions as well as macroparasitic burden were analysed.

$O$. edulis and C. gigas obtained positive growth rates in terms of shell length (Fig. 11.15a) and dry mass outside their natural coastal habitat, which is normally

Fig. 11.14 Oyster lanterns filled with spat of Ostrea edulis and Crassostrea gigas for grow-out at offshore cultivation test sites (Photo AWI/Dr. Bernadette Pogoda)

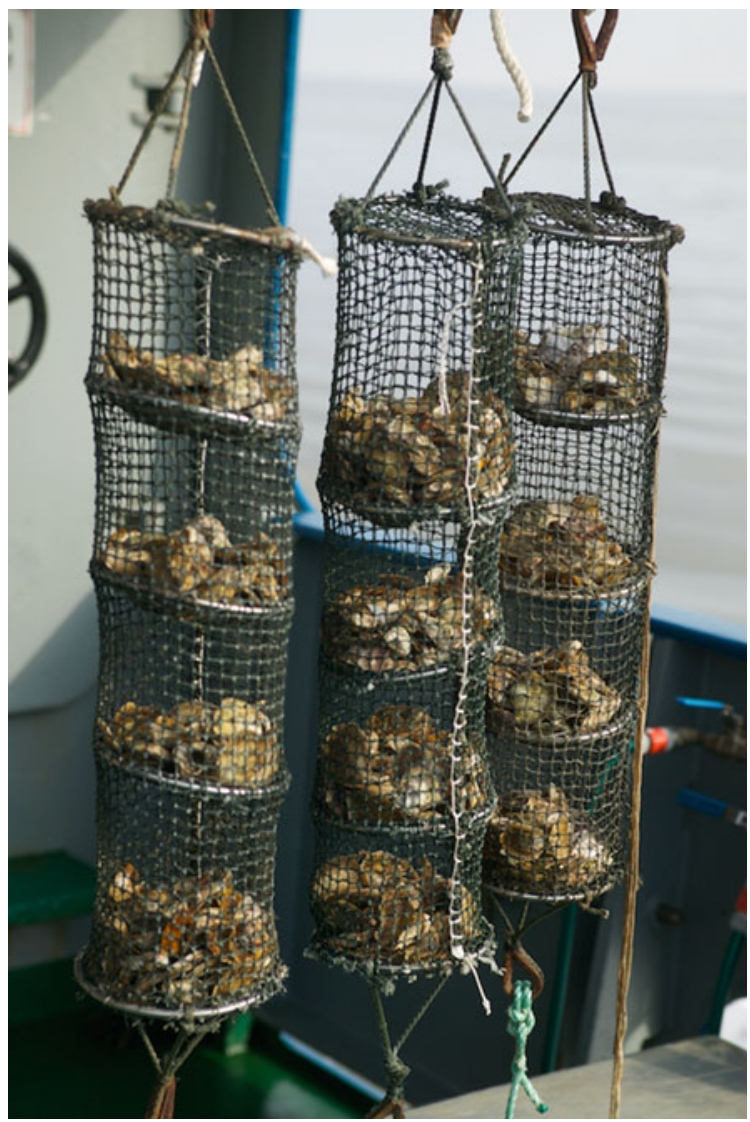




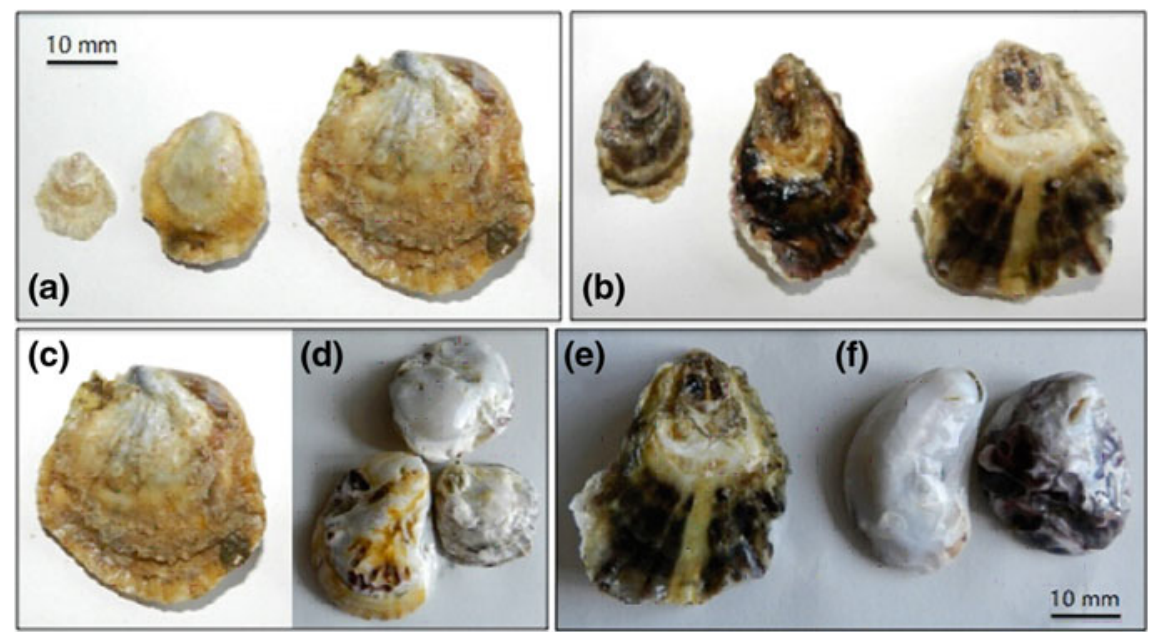

Fig. 11.15 a-f Shell growth of the European oyster Ostrea edulis a and the Pacific oyster Crassostrea gigas b during one offshore cultivation season (mid-April-mid-October); $\mathbf{c} O$. edulis and $\mathbf{e}$. gigas showing normal shell growth from offshore sites in contrast to $\mathbf{d}$ and $\mathbf{f}$ with strong shell abrasion from an exposed cultivation site where tidal currents are high. Modified after Pogoda et al. 2012. Photos AWI/Dr. Bernadette Pogoda

located on the seabed of coastal seas. In general, growth rates were similar to those of oysters from nearshore coastal areas (Pogoda et al. 2011). This documents that offshore-cultivated oysters are able to achieve a "normal" or "natural" growth performance.

Furthermore, oysters developed their species-specific morphology and produced an "aesthetic" shell, which plays an important role for their market value (Matthiessen 2001) (Fig. 11.15a). Only oysters grown at sites where daily tidal currents and sediment loads are high developed a different shape (Fig. 11.15b). Thicker shells and a very compact appearance indicate that these animals strongly invested energy in shell growth to withstand the strong currents as well as to prevent shell abrasion (Newkirk et al. 1995; Pogoda et al. 2011). This emphasizes the importance of a detailed and thorough site selection prior to the start of offshore oyster cultivation or any aquaculture operation in general (see Pogoda et al. 2011).

According to typical size classes used in commercial aquaculture farms larger $O$. edulis spat from a Norwegian producer was used in the experiment of 2007 (Newkirk et al. 1995; Matthiessen 2001; Pogoda et al. 2011). These animals yielded significantly higher growth rates $(p<0.0001)$, even beyond those of Pacific oysters. The superior condition of these European oysters was reflected by an even higher condition index (Pogoda et al. 2011). Accordingly, oyster cultivation in harsh environments could benefit from using a bigger spat size class regarding physical constraints through high current velocities and wave action, as smaller animals, in a very sensitive growing phase, grow slower under severe conditions. 
The European oyster showed constant increases in shell length and dry mass during the cultivation periods (Pogoda et al. 2011). This implies a high ability of dietary assimilation of the native European oyster, even when food availability is low in summer (Rick et al. 2006) and a good adaptation to this offshore environment (Newkirk et al. 1995; Matthiessen 2001; Laing et al. 2006). In contrast, seasonal variations with reduced growth rates in summer were observed for the Pacific oyster. Interestingly, this species-specific difference is also clearly reflected in parallel changes of the biochemical compositions.

The biochemical and elemental compositions were analysed to characterize the nutritional condition and for a better understanding of related energetic processes. Accumulation and depletion of metabolic energy reserves depend primarily on food quantity and quality, environmental effects on metabolic processes, and reproductive activities (Beninger and Lucas 1984; Whyte et al. 1990; Ruíz et al. 1992). Therefore, investigations focused on seasonal dynamics of the major energy storage products, namely carbohydrates, proteins and lipids, on the compositions of lipid classes and fatty acids as well as on carbon and nitrogen.

Both species utilized primarily glycogen as energy store during times of high food availability. After the phytoplankton spring bloom, when reduced growth rates were observed for $C$. gigas, glycogen contents were drastically depleted, whereas lipid contents increased. In contrast, $O$. edulis kept on growing and accumulating glycogen, while lipid contents remained relatively constant. These different strategies may be explained by the earlier maturity of Pacific oysters and the resulting conversion of carbohydrates to lipids to enhance the production of eggs, which are rich in lipid (Gallager and Mann 1986; Whyte et al. 1990; De la Parra et al. 2005).

In shellfish production, the condition index is commonly used to evaluate the effects of the surrounding environment on these organisms. It is an adequate parameter to describe the commercial quality, physiological state and health of bivalve molluscs. The most commonly applied condition index (CI) is the ratio of flesh mass to shell mass (e.g. Walne and Mann 1975; Davenport and Chen 1987). Condition indices for all three offshore-cultivated bivalve species support the positive results already observed for the growth performance at offshore sites. CI values for Blue mussels, European and Pacific oysters indicated excellent conditions (Pogoda et al. 2011).

Seasonal variations in lipid class compositions of offshore-cultivated oysters were essentially similar to those of nearshore-grown individuals (Pogoda et al. 2013). Triacylglycerols (TAG) are the main lipid stores in the investigated oysters and serve as short-term energy reserves. Together with glycogen, they accumulate during periods of high food availability and are depleted in periods of food paucity. Accordingly, the amount of TAGs is a sensitive indicator of the nutritional condition of an animal (Fraser et al. 1985). Expressed as the ratio of phospholipids to triacylglycerols (PL:TAG), values $\leq 1$ indicate a good nutritional state (Abad et al. 1995; Caers et al. 2000) and European and Pacific oysters clearly improved condition during offshore-cultivation. PL and TAG levels reached equal proportions of 
1 in summer, which indicate well-fed animals and excellent growing conditions at offshore cultivation sites in the German Bight (Pogoda et al. 2013).

Also the amount of essential fatty acids greatly affects growth and condition of oysters (Pazos et al. 1996). The fatty acid compositions of the European and the Pacific oysters were dominated by $16: 0,20: 5(n-3)$ and $22: 6(n-3)$, major components of phospholipids of typical marine organisms. Both species of offshore-cultivated oysters showed the accumulation of lipids as energy reserves during high food availability from spring to early summer. Diatom markers increased during spring and early summer in both oyster species and suggest a diet rich in diatoms (Pogoda et al. 2013). Increasingly high ratios of $(n-3) /(n-6)$ during the cultivation experiment underline the excellent physiological condition of both offshore-cultivated oyster species (Pogoda et al. 2013; Pazos et al. 1996).

The combination of successful growth performance and obviously excellent overall condition of offshore-cultivated oysters resulted in insignificant mortalities. In contrast to commercial oyster production in nearshore environments, which often suffer from high mortalities, offshore survival rates for both oyster species were high (>96\% in 2004, >99\% in 2007) and encourage open ocean cultivation (Pogoda et al. 2011).

Parasite infestation: Studies on the macroparasite burden of offshore-cultivated European and Pacific oysters and Blue mussels reported a zero infestation at offshore locations in the North Sea (Fig. 11.16a-c). In general, parasites can affect condition and health of host animals. Buck et al. (2005), Brenner (2009) and Pogoda et al. (2012) have shown that offshore grown mussels and oysters were free of macroparasites and that infestation rates increased with proximity of the sites to shore, respectively; intertidal mussels and oysters showed the highest numbers of parasites. The debate over the effects of parasites on the energy status and overall health of the host is still open as robust data to elucidate these issues is still lacking. Three major groups of macroparasites are known to infest North Sea mussels and oysters: shell-boring polychaetes, trematodes and mytilicolid copepods. Absence of trematodes at offshore locations can be explained by their complex life cycle: they often infest intertidal gastropods as first intermediate hosts (e.g. Littorina littorea and Hydrobia ulva). These are typical macroparasites of inshore bivalves, which, however, are completely absent in offshore cultivated oysters and mussels.

Due to the absence of these exclusively coastal organisms the parasite's life cycle cannot be completed in offshore regions (Buck et al. 2005). Mytilicolid copepods and shell-boring polychaetes (e.g. Polydora ciliata) are abundant in inshore waters (Thieltges et al. 2006). However, their short planktonic larval phase restricts successful dispersion to coastal waters. Larvae drifting away from the coast are bound to die due to predation or starvation in the absence of hosts, which are only available at very few selected offshore culture locations (Buck et al. 2005). These results present a commercial advantage of such offshore shellfish cultures.

All known micro- and macroparasites found in European coastal waters are harmless to consumers, but may have negative condition effects (macroparasites) and cause higher mortalities (microparasites) in infested hosts (Brenner et al. 2012). 

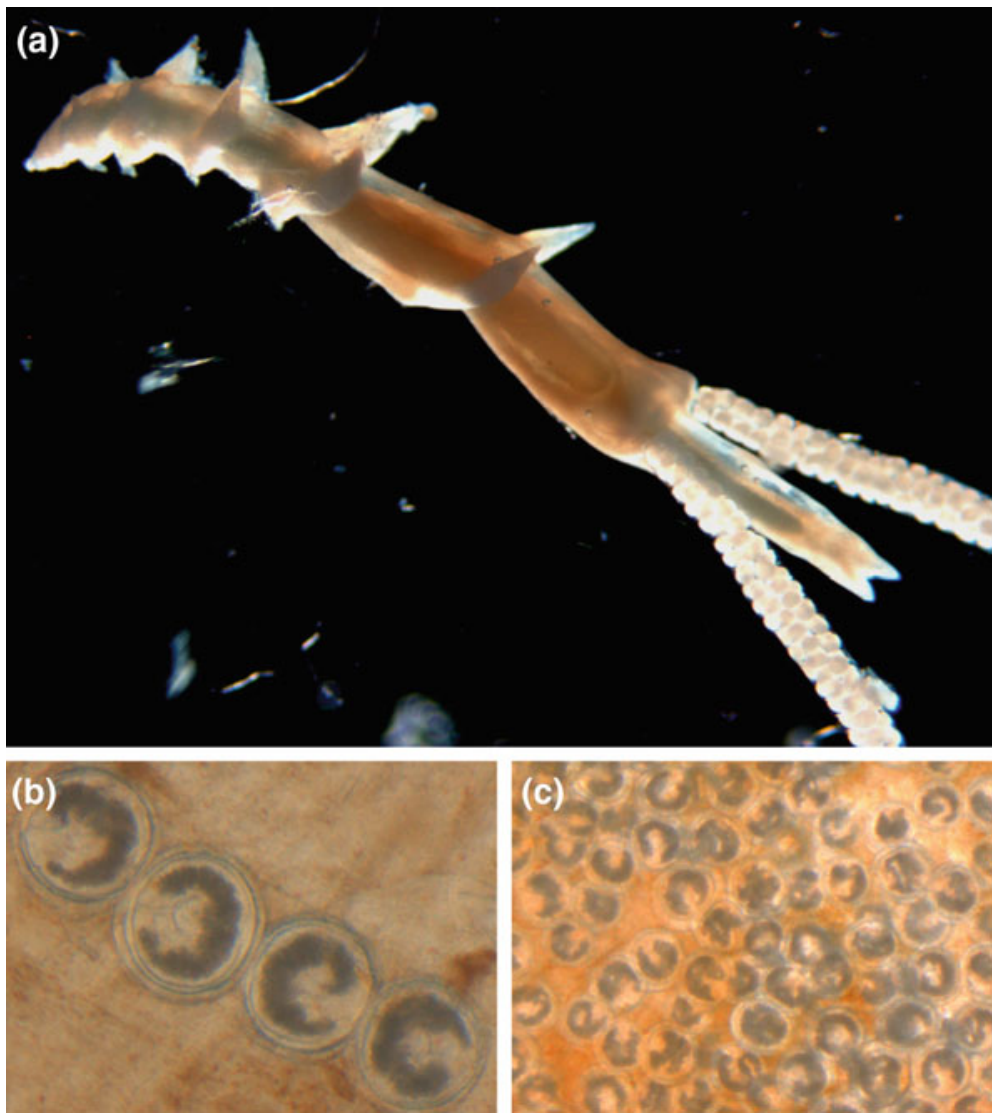

Fig. 11.16 a Mytilicolid copepod parasite Mytilicola orientalis; $\mathbf{b}$ trematode parasite Renicola roscovita located in the palps and $\mathbf{c}$ within the digestive gland (Photo a: AWI/Dr. Bernadette Pogoda, Photo b-c: AWI/Prof. Dr. Bela H. Buck)

Beside the potential harmful effect, some macroparasites cause aesthetic risks, since they are visible due to their colour (Mytilicola intestinalis) (Fig. 11.16a) or size (Pinnotheres pisum). Oysters are commonly eaten raw and consumers would not accept the appearance of e.g. parasitic copepods, as they are easy to recognize due to their bright red colour and size (up to $25 \mathrm{~mm}$ ). This is an issue, as it would result in a serious commercial decrease of the shellfish value. Some macroparasites could also evoke a deteriorated morphological appearance, e.g. shell-boring polychaetes. As oysters and mussels represent high-value seafood products, an aesthetic appearance of the shell — especially on the oyster half-shell market - and meat is rather important. From an economic point of view the absence of macroparasites in shellfish products is certainly favourable. Furthermore, parasite infestations could reduce harvests and severely deplete local populations. Understanding the 
development of infestation patterns is therefore crucial for the successful site-selection in shellfish cultivation.

Restauration and ecosystem services: Because of their high ecological value oyster stocks are now in the focus of European conservation efforts. In the context of cooperation within the Oslo-Paris Commission (OSPAR), the native oyster was identified as a severely endangered habitat creating species and its protection in its area of distribution was concluded. According to the Habitats Directive for the protected habitat type "reef", a favourable conservation status has to be preserved or restored. In view of the ecosystem-related benefits of oyster reefs, especially the high biodiversity of species found in reefs, the Federal Agency for Nature Conservation (BfN) is engaged with the possibilities of a potential reintroduction of native European oysters in the North Sea. The recently launched Project No. 16 "Restore" aims at the development of strategies for a sustainable restoration of Ostrea edulis in the German Bight. Methods and procedures will be tested at experimental scales at different locations in the field. As fishery is completely prohibited within offshore wind farm areas in German waters, these are in the focus for first restoration sites and resemble yet another type of multi-use. Results of this investigation will support the future development and implementation of a German native oyster restoration program to re-establish a healthy population of this highly endangered oyster species in the German North Sea.

\subsubsection{Crustacean Species}

\subsubsection{Candidate: Homarus gammarus}

Krone and Schröder (2011) and Krone et al. (2013) investigated various artificial reefs (e.g. wind farms, wrecks) to proof if these new hard substrate structures, which are placed on the sand and silt dominated seabed of the German Bight, would provide a habitat for a hard bottom dweller like the European lobster. From these insights Krone (2012a) developed various habitat designs connected to foundations of offshore wind foundations, which allow mobile reef fauna, such as lobsters, to live in or hide. These new designs could be beneficial to reef fauna stocks.

The population of the European lobster H. gammarus in the German Bight is currently limited to the rocky area around the island of Helgoland. Despite management and reinforcement actions, the lobster population has still not recovered from a severe collapse in the 1950s and 1960s (Schmalenbach et al. 2011). A successful settlement of the animals in the stone fields that surround the individual wind turbines, could possibly contribute to the long-term stabilization of the population. Researchers are now exposing lobsters in this emerging habitat (Schmalenbach and Krone 2011). The project will investigate the feasibility and environmental consequences of such a lobster transaction. 2,400 animals were raised in a rearing facility on Helgoland in 2013/2014. Young lobsters, about five $\mathrm{cm}$ size, were then relocated by divers to the hard substrate surrounding wind 
(a)

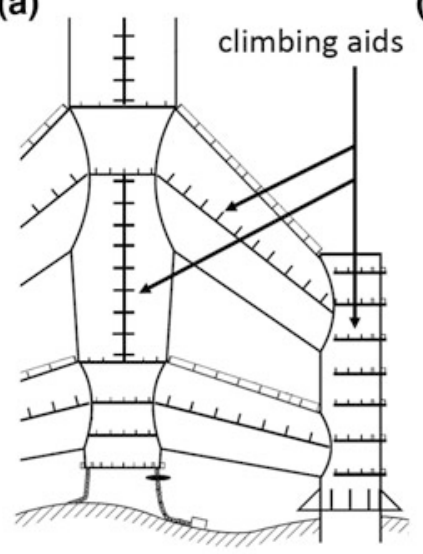

(b)

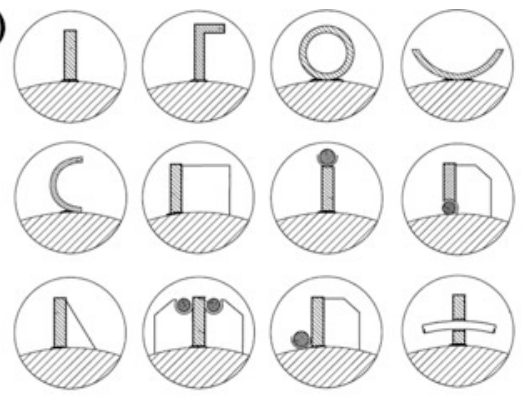

(d)

(c)
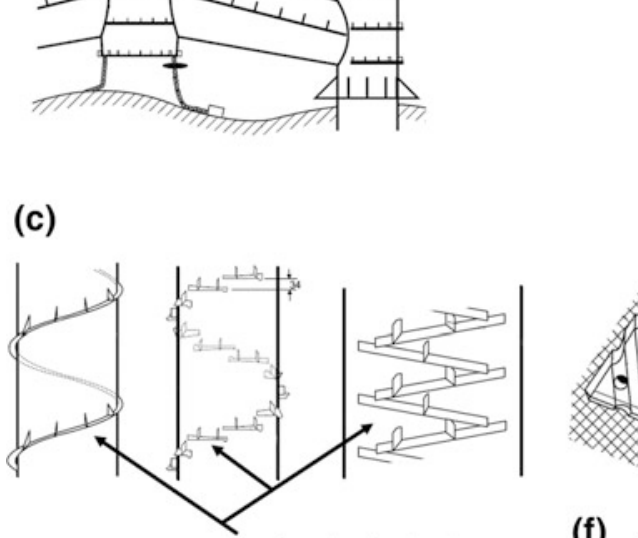

(e) circular/spiral

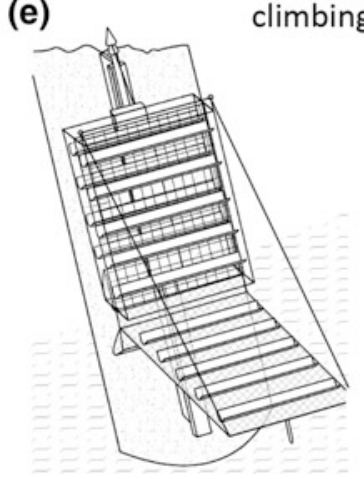

ral

(f)

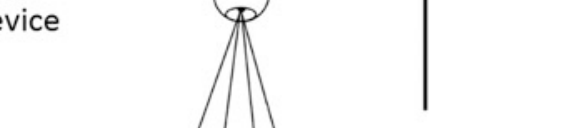

seabed

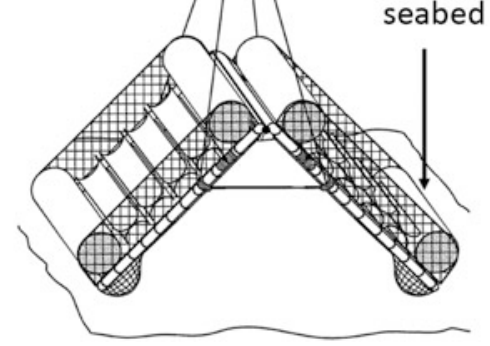

Fig. 11.17 a-d Wind farm foundations as artificial reefs. a shows a tripod foundation with climbing aids; $\mathbf{b}$ are potential guide profiles for the target species in a flat, round or even structured mode; $\mathbf{c}$ profiles attached to a foundation piece in a circular and spiral manner; $\mathbf{d}$ artificial habitat in polyhedron form for crustaceans; e scavenging carriage to harvest target species; $\mathbf{f}$ device for colonizing and harvesting marine hardground animals (all images modified after Krone (2012a); Krone et al. 2012; Krone and Krämer (2012) and Krone and Krämer (2011) 
turbines in the Borkum Riffgat offshore wind farm $70 \mathrm{~km}$ off the German-Dutch coast. Researchers will survey the ecological habitat and how many of the juveniles settle successfully in the stone fields (Krone et al. 2013).

The shown foundation has climbing aids in the form of guide profiles, which are fastened in some sections to the offshore construction in a vertical, horizontal, and/or diagonal direction (Fig. 11.17a-c). These profiles are designed as rib-shaped flat or round profiles as well as structured by flat transverse profiles, which are also used for making breeding places (Krone et al. 2012). The pyramid-like structure (polyhedral form) relates to an artificial habitat to crustaceans on soft bottoms (Fig. 11.17d; Krone 2012b). Lobsters and other crustaceans as basically hard substrate animals also settle on soft soils when suitable habitats are available. This device can be placed next to wind turbine foundations. Another device is a scavenging carriage including a basic unit and a running unit that is configured to detachably couple the scavenging carriage with a rail device to be movable. The scavenging carriage is configured to detachably couple with the habitat carriage and the lifting device (Fig. 11.17e; Krone and Krämer (2011). Finally, one more device was invented to be used to establish and harvest a colony of benthic animals, in particular crabs. The device is hoisted and lowered in the folded form, and is laid out in the folded or fully open form. Tubular components improve drift and are particularly attractive as a habitat for crabs. This device can be used as an artificial reef to establish a colony and as a trap for effectively harvesting crabs in the immediate surroundings of wind turbines in offshore areas (Fig. 11.17f; Krone and Krämer (2012).

\subsubsection{Candidate: Cancer pagurus}

The edible crab or brown crab is a potential candidate for multi-use by passive gear fishery within offshore wind farms (OWF). As this species covers fairly the same niche as the European lobster and is also a high value seafood product on the market, it is another promising candidate that should be examined. Passive fishery on brown crab is very common along Northern European coasts and also in several offshore areas of the German Bight and reduces the ecological pressure on the endangered lobster population. Clear positive effects on the potential of OWFs to function as refuge for fish and marine animals were observed for crustacean species such as brown crab (Cancer pagurus) due to increased opportunities for shelter and food availability (Stelzenmüller et al. 2016).

\subsubsection{Fish Species}

Fish as a candidate for offshore multi-use concepts is new. Most of the studies on aquaculture in offshore wind farms concentrated on invertebrates and algae. In recent years, interest in offshore fish cultivation is increasing (Buck and Krause 
2012). By now, only few studies focused on culture techniques, system design as well as on the commercial potential and the management of fish cultivation in wind farms (Buck et al. 2012). Existing studies on the biology of offshore fish cultivation, however, did not directly deal with fish cultivation in co-use with wind farms. Hundt et al. (2011) and Buck et al. (2012) provided a list of potential candidates for the cultivation in wind farms in the EEZ of the German Bight, such as European sea bass (Dicentrarchus labrax), cod (Gadus morhua), Atlantic halibut (Hippoglossus hippoglossus), turbot (Scophthalmus maximus), haddock (Melanogrammus aeglefinus), and Atlantic salmon (Salmo salar).

This selection of candidate species for offshore aquaculture in the German Bight was based on mainly four criteria: (1) natural occurrence in the North Sea (absolutely no introduction of non-native species), (2) physical requirements of candidates match the conditions in the German Bight, (3) current status of farming knowledge and available techniques, and (4) its economic feasibility (Buck et al. 2012). Generally, the harsh offshore conditions of the North Sea, namely strong tidal currents and wave heights, and the wide temperature difference in the shallow marginal sea limit the candidate list to few fish species. For the German Bight, the strong temperature difference lies between $<6{ }^{\circ} \mathrm{C}$ in winter and $>21{ }^{\circ} \mathrm{C}$ in summer and is probably the most limiting factor for cultivation of many fish species (Buck et al. 2012). Furthermore, Buck et al. (2012) conducted studies on the welfare of fish within net pens in RAS conditions that were similar to exposed conditions offshore. These results demonstrated, that a clear understanding of the dependence of fish fitness on strong hydrodynamic conditions is paramount.

\subsubsection{Candidate: Dicentrarchus labrax}

The European sea bass is a well-established species in aquaculture and with a production of over 60,000 tons per year one of Europe's most cultured marine fish species (FAO 2005). The on-growing usually takes place in coastal surface cages (FAO 2005), but the successful rearing under more exposed conditions was proven in flexible surface cages in the Mediterranean (Sturrock et al. 2008), which is the main site of production of European sea bass. Since sea bass is a physoclist species, in which the swim bladder is closed and pressure compensation is only possible by slow gas exchange, the ascent and decent of the cage has to include sufficient breaks to prevent a barotrauma of the fish's swim bladder (Korsøen 2011). However, the eurythermal species is capable to tolerate temperatures below $5{ }^{\circ} \mathrm{C}$ (FAO 2005), which would enable on-growing in the offshore regions of the German North Sea. Nonetheless, the average temperature of $10^{\circ} \mathrm{C}$ in the North Sea (Wiltshire and Manly 2004) is below its optimum temperature range of $22-28{ }^{\circ} \mathrm{C}$ for growth (Lanari et al. 2002), which will result in an extended on-growing phase. A rough approximation of the actual length at the end of the on-growing can be based on the growth models by Lanari et al. (2002) and the annual temperature of the water in the German Bight (data BSH-German station bay, $10 \mathrm{~m}$ depth, daily mean values of 2009, www.bsh.de). The model suggests that an approximately $3 \mathrm{~g}$ fingerling 

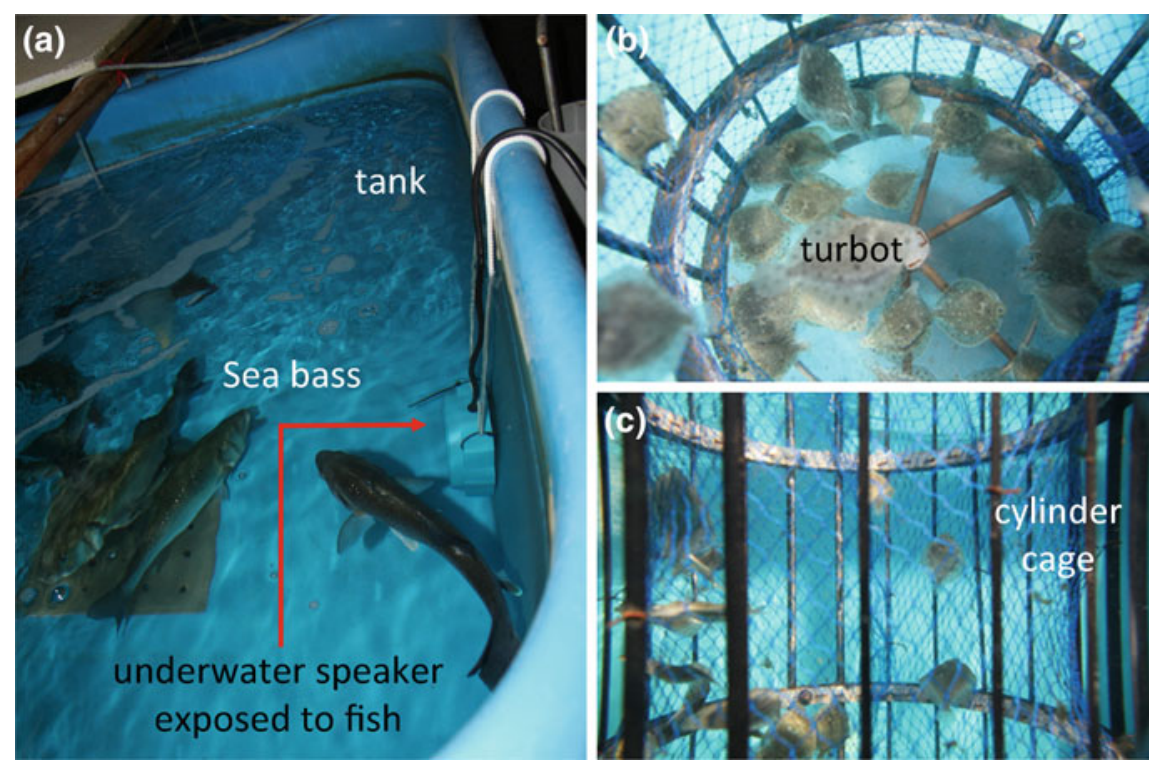

Fig. 11.18 a-c European seabass (Dicentrarchus labrax) and turbot (Scophthalmus maximus) for welfare experiments. a Sea bass in a tank of a recirculating system with speakers at the side wall of the tank to induce noises imitated of offshore wind turbines; $\mathbf{b}$ Juvenile turbots swimming in a cylinder-like cage model with a current velocity of $0.5 \mathrm{~m} / \mathrm{s}$ to test welfare and behaviour and $\mathbf{c}$ in a current velocity of $0.9 \mathrm{~m} / \mathrm{s}$. Photos a University of Applied Sciences Bremerhaven/Gerrit Fiedler modified after Fiedler et al. 2011, b-c AWI/Jan Schmidt and Tim Heusinger modified after Buck et al. 2012

would need 31 months to reach the $300 \mathrm{~g}$ harvest weight (Buck et al. 2012). This exceeds the production of $D$. labrax in cages in the Mediterranean by $4-8$ months (FAO 2005) making an offshore cultivation in the North Sea economically not feasible.

During a subproject of Project No. 13 "Open Ocean Multi-Use", the welfare of European seabass was tested by exposing fish in a tank device to loud noise using underwater speakers (Fig. 11.18a) (Fiedler et al. 2011). The noise was equivalent to the sound, which originated from offshore wind turbines in $2 \mathrm{~m}$ depth of the surrounding water column. Next to welfare observation and the fish behaviour regarding acceptance of feed, excitability, escape, aggression among fish of the stock as well as taking cholesterol samples to measure stress were conducted. Interestingly, fish did accept the loud noise in short time of 1-2 days. After adaption of the noise the fish showed no abnormal behaviour as well as cholesterol concentrations was within a threshold of fish not exposed to the noise.

However, at this stage it is important to understand that this test was just a preliminary work, which has to be conducted again in full scale, which means: more replicates, better infrastructure and experienced personal. The presented work was conducted during a student's project with limited access to specific infrastructure 
and financial support. Nevertheless, even if not planned under best conditions, the work shows a trend, which requires more research on this topic.

\subsubsection{Candidate: Gadus morhua}

Declining catches of Atlantic cod lead to a growing interest in aquaculture of this species. For more than thirty years, the intensive production of cod has been established (Moksness et al. 2004). The rearing of G. morhua requires the production of live food of different sizes and feeding protocols need to be followed strictly (Moksness et al. 2004). Of all the gadoid species, cod is thought to have the greatest potential for future development for aquaculture and some scientists believe that within the next 20 years similarly high production levels can be achieved as for the Atlantic salmon (Rosenlund and Skretting 2006). The suitability of $G$. morhua for offshore aquaculture has been successfully demonstrated in $3000 \mathrm{~m}^{3}$ submersible cages including automatic feeding buoys by the company Sea Station $^{\mathrm{TM}}$ off the coast of New Hampshire (Chambers and Howell 2006). As G. mоrhua is a physoclist species, necessary pauses need to be included during vertical movements of the cage (Korsøen 2011). One major problem for cod aquaculture is their ability to bite through the mesh or other materials, which makes them the fish species with the highest escapee rate (Jensen et al. 2010), which could have a negative impact on wild population by cross-breeding (Davies et al. 2008). The extreme temperature tolerance range from -1 to $23{ }^{\circ} \mathrm{C}$ and an optimum temperature range from 8 to $12{ }^{\circ} \mathrm{C}$ (Jobling 1988) make this species a candidate for aquaculture in the German Bight. However, aquaculture companies should be aware that the relatively high summer temperatures in the German Bight could enhance the risk of infections, as G. morhua is prone to bacterial fish pathogens such as Franciscella spec. or Aeromonas salmonicidae at prolonged temperatures of more than $12{ }^{\circ} \mathrm{C}$ (Buck et al. 2012).

\subsubsection{Candidate: Hippoglossus hippoglossus}

The Atlantic halibut is a much valued aquaculture candidate as the species is resistant to several common fish diseases, has high food conversion efficiency and a good meat quality due to its firm texture and long shelf life (Daniels and Watanabe 2010). However, the rearing of fingerlings is difficult as larvae need the right composition of live feed after the yolk sac stage and a precise temperature regime. The on-growing of $H$. hippoglossus takes place either in land-based tanks or troughs, or in net cages in the sea (Daniels and Watanabe 2010). The use of submersible cages was successfully demonstrated for halibut (Howell and Chambers 2005; Daniels and Watanabe 2010), offering significant advantages in contrast to surface culture, such as avoidance of the exposure to the seasonal high water temperatures and to the effect of UV radiation at the surface. The temperature tolerance range for the Atlantic halibut reaches from -1.3 to approximately $18-20{ }^{\circ} \mathrm{C}$, 
depending on the oxygen saturation of the water (Daniels and Watanabe 2010). Although the oxygen saturation in the German Bight is very high below $10 \mathrm{~m}$ depth, temperatures in extreme years can reach values outside of the physiological capacity of $H$. hippoglossus. Furthermore, Atlantic halibut is sensitive to strong currents and turbidity (Buck et al. 2012). For offshore site selection, it is important to identify an area with a sufficient supply of oxygen, a moderate temperature regime as well as low current flow and turbidity.

\subsubsection{Candidate: Scophthalmus maximus}

The turbot is one of the most valuable food fish of the North-East Atlantic. Since the 1990s, intensive production methods are established for all stages of life of this species (Moksness et al. 2004). Today, the on-growing of turbot takes place mainly in land-based recirculating aquaculture systems. S. maximus can be held in very high stocking densities at optimum parameters (Daniels and Watanabe 2010). The culture in surface cages, or submersible cages, was successfully demonstrated at moderate velocities and a constant temperature regime (Daniels and Watanabe 2010). Since the growth of turbot rapidly decreases below $14{ }^{\circ} \mathrm{C}$ and above $20{ }^{\circ} \mathrm{C}$ and it stops feeding below $8{ }^{\circ} \mathrm{C}$ and above $22{ }^{\circ} \mathrm{C}$, the temperature conditions in the German-Bight do not favour on-growing year-round (Person-Le Ruyet et al. 2006; Daniels and Watanabe 2010). In addition, this species is sensitive to the tide flow rates of up to $1.2 \mathrm{~ms}^{-1}$ (Buck 2002), which plays an important role for site selection in the German Bight (Buck et al. 2012).

Taking the results of current velocities and waves on cages and the nets (see Sect. 11.4 "Technologies" below) into account a further test was conducted to proof the behaviour of the culture candidates living in these high energy environments. These tests were conducted at the ZAF (Zentrum für Aquakulturforschung/Center for Aquaculture Research) under the umbrella of the AWI. A cage prototype (Fig. 11.18b, c) was manufactured and installed in a large raceway of a RAS (Recirculating Aquaculture System) including a water treatment device (drum filter, nitrifying and denitrifying filter, and protein skimmer) to guarantee best water quality during the experiment. This cylindrical cage (see section above) was mounted in a way that an adjustable pump (Hydor Koralia magnum 5, flow rate $6,500 \mathrm{l} / \mathrm{h}$ ) induced a certain current velocity on the cage and its inner culture space. The cylinder cage in a size of 1:40 was taken from the current flume/wave tank investigations in Hanover.

The challenge in the subproject of Project No. 13 "Open Ocean Multi-Use" was to find fish species in small size to be used as model organism, such as juvenile turbots with a mean size of approx. $10 \mathrm{~g}$ (Scophthalmus maximus) (Buck et al. 2012). This fish size of the "model organism" would in terms of scaling correspond to a market sized adult turbot, which would be farmed in real offshore cages.

After acclimatizing the fish in the cage model after several hours the pump was switched on for a short term to induce a current velocity of $0.9 \mathrm{~ms}^{-1}$ at the exhaust pipe. The pump was adjustable in the tank so that the distance to the cage could be 
within a range of $25-150 \mathrm{~cm}$. This distance to the cage and the resulting current velocity was calculated by using a corresponding situation as it occurs at the offshore site. After starting the experiment fish behaviour, escape response, welfare, and reaction at feeding were recorded using an underwater video camera.

The results of these investigations show a strong impact of strong current velocities on farmed turbot within the cage. Juvenile turbot are unharmed at velocities of $0-1.0 \mathrm{~ms}^{-1}$. However, the fish are affected by stronger currents in a way that the fish will be transferred from their resting area on the bottom of the cage resulting in more activity of the fish swimming against the current trying to resettle on the bottom. At very strong current velocities of $1.5 \mathrm{~ms}^{-1}$ and higher it might happen that young turbots are pressed against the net of the cage leading to the risk to obtain skin injuries.

To summarize, these results show that turbot cultivation offshore is not suitable if current velocities exceed a certain value, making a site-selection-criteria process necessary. However, we have to take into account that we used small fish - the model organism - in the experiment, which allowed the upscaling to a size corresponding with real fish sizes to be farmed at offshore sites. As fish in a size we used in this investigation will never be transferred to offshore sites as it is described in this book we assume that larger fish, which normally will be cultured in offshore cages, will act differently.

\subsubsection{Candidate: Melanogrammus aeglefinus}

The haddock is a valued food fish on both sides of the North Atlantic, but its wild catches stagnate, so that haddock is an interesting candidate for aquaculture (Moksness et al. 2004). In recent years, the cooperation of a large commercial salmon production (Heritage Salmon Limited) with various Canadian research institutes lead to great advances in the management of broodstock, the feed of larvae, as well as the weaning and on-growing methods (Chambers and Howell 2006). Same as cod, haddock is a physoclist species and breaks in descents and ascents need to be included to prevent barotraumas due to rapid pressure changes by vertical movement of the cages. (Buck et al. 2012). Moreover, M. aeglefinus has the ability to penetrate even tight mesh (Özbilgina and Glass 2004), precaution needs to be taken to prevent escapes. The on-growing of $M$. aeglefinus in submersible offshore cages has proven to be very promising, reaching good growth rates in a $600 \mathrm{~m}^{2}$ Sea Station at the temperature conditions off the coast of New Hampshire (Chambers and Howell 2006). However, the similarly high growth rates as cod in the first year decreased slightly and the growth potential over longer periods of time must be considered to be lower than in cod (Treasurer et al. 2006). Haddock can tolerate temperatures between 1 and $20^{\circ} \mathrm{C}$ (Chambers and Howell 2006), making it a potential aquaculture species for the offshore area in the German Bight. 


\subsubsection{Candidate: Salmo salar}

With an annual production of 1,244,637 t (Bilio 2008), the Atlantic salmon, Salmo salar, is by far the most produced marine species. Although $S$. salar is an anadromous species, which is spending a part of its live in freshwater (FAO 2004), it is an excellent candidate for aquaculture in marine waters and has its highest growth rate at salinities between 33 and 34\%o. The temperature range for this species is $6-16{ }^{\circ} \mathrm{C}$ (FAO 2004), with temperatures optimal for growth between 8 and $12{ }^{\circ} \mathrm{C}$ (Boghen 1991). Although the temperature minima and maxima of this species can be exceeded in the surface waters of German North Sea, the Atlantic salmon is thought to be suitable for aquaculture in the German Bight (Buck et al. 2012).

\subsubsection{Various Species in One Habitat-Managing Reef Effects}

Following Krone (2012b), it is currently difficult to judge the ecological consequences associated with the introduction of the artificial reef type "wind power

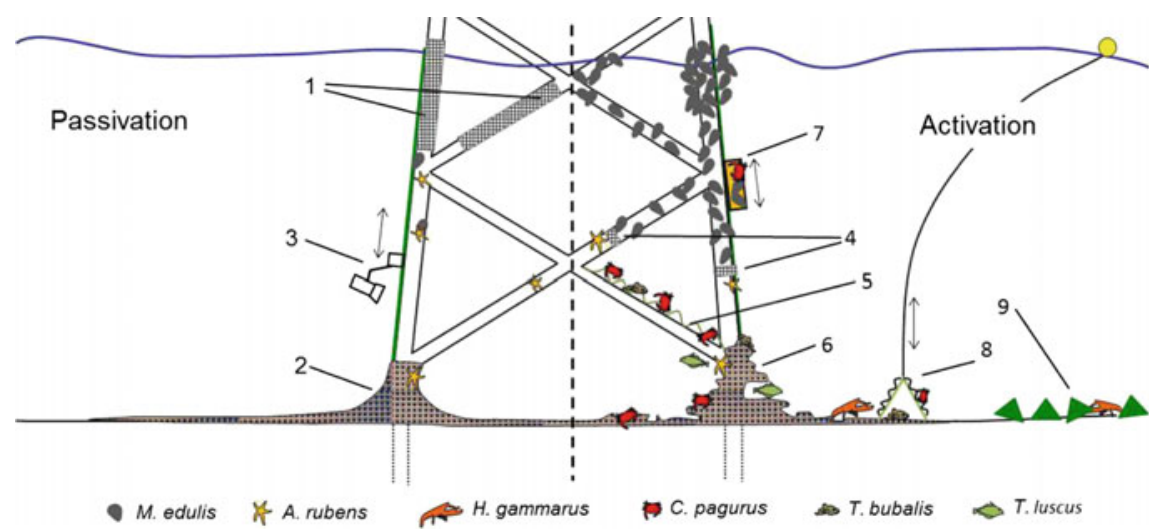

Fig. 11.19 Techniques for passivation and activation of wind power foundations and artificial reef fauna examples. 1 Electrochemical anti-fouling system for structures wetted by sea water; 2 Calcareous EAT-material designed to reduce structural diversity and as scour protection; 3 Device for using technical devices underwater, equipped with a camera; 4 The electrochemical anti-fouling system applied to prevent sea stars (A. rubens) to climb up to feed on the Bivalvia M. edulis; 5 Device for developing habitats in the underwater area of an offshore construction, paths and hideouts for crabs and demersal fish; 6 EAT-material used to create reef-like structures to enhance the reef species; 7 Device for colonizing and harvesting marine hard ground animalssuch as $M$. edulis and large vagile megafauna; 8 Transportable device for colonizing and harvesting invertebrates in the vicinity of offshore constructions; 9 Artificial habitat in polyhedron shape used as a fishing net barrier which is at the same time habitable for lobsters (modified after Krone 2012b) 
foundation" and its reef effects on fish and benthos. The question whether the impact is positive, negative or negligible remains unanswered and depends on the emphasis one places on the different implications of the reef effect. The present findings, however, enable the designed structure to increase or to reduce biofouling and megafauna settlement at offshore wind power foundations (Fig. 11.19). Krone (2012b) defines it as "reef passivation". Alternatively, all potential reef functions could be activated if the development of a highly valuable artificial reef fauna is intended, such as "reef activation" (for more details see Krone 2012b).

\subsection{Technology}

\subsubsection{Longline-Techniques and Combination to Wind Farm Turbines}

In the coastal sea of Germany, there are some limitations to allow the expansion of mussel culture activities. First, nearly $98 \%$ of the coastal sea has a nature reserve status. Culture plot sizes are decreasing in order to follow the mussel management plans of Schleswig-Holstein and Lower-Saxony (e.g. CWSS 2002; Buck 2002) with no new licenses being approved in the future. Second, moving more seawards to abandon the preserved areas, environmental conditions in the North Sea are harsh and protected bays for safe mussel longline cultivation is inexistent. However, exposed locations off the coast are in the focus for many aquaculture activities worldwide (e.g. Polk 1996; Hesley 1997; Stickney 1998; Bridger and Costa-Pierce 2003) and generated a vast quantity of projects in high energy environments. With this in mind, a multiple use concept for another newcomer, the offshore wind farm operator, has been developed (Buck et al. 2004). The offshore wind farm turbines provide space and attachment devices for mariculture installations and therefore minimize the risks originating from high energy environments (Buck et al. 2006b). The viability of a mussel cultivation enterprise within offshore wind farm areas was intensively studied following various factors, such as (1) the technological and biological feasibility, (2) the legislative and regulatory constraints, (3) the environmental sustainability of farming aquatic organisms at all, and (4) the profitability of this potential commercial operation (for review see Buck et al. 2008a). However, without the solid foundations of the wind turbines as anchor or connection points, economic viable installations of equipment for an extensive mariculture would decrease in view of the high-energy environment in this part of the North Sea. 


\subsubsection{Mussel Longlines: Design}

In Project No. 3 (Roter Sand) different anchored longlines were installed in order to test their suitability under open sea conditions in terms of material and functionality and to obtain insights on how to connect these systems to wind farm foundations. Various test devices of horizontal ropes anchored to the seafloor with buoys to provide flotation and vertical droppers for spat collection and/or mussel grow-out were deployed offshore in multi-use with the wind farm "Energiekontor" 17 nautical miles off Bremerhaven.

The first system had a polypropylene (PP)-based design (Fig. 11.20a) and was deployed by the Water and Shipping Agency (WSA) Bremerhaven in 2002. The 3 -stranded polypropylene-based longline $(\varnothing=32 \mathrm{~mm})$ was made of two $35 \mathrm{~m}$ long segmental parts connected to each other. To keep the longline afloat each segment was equipped with one $80 \mathrm{~kg}$ buoyancy barrel in the centre and with $115 \mathrm{~kg}$ barrels at the coupling to the anchor-line. Further, a few $35 \mathrm{~kg}$ ball-like surface marker floats were fixed to a $5 \mathrm{~m}$ rope, which was connected to the longline. Three steel barrels filled with concrete $(200 \mathrm{~kg})$ tightened the longline to the sea bottom at the coupling to the anchor-line and in the centre. Another design was the steel hawser-based design (Fig. 11.20e), which was deployed a year later. The 3 -stranded steel hawser-based longline $(\varnothing=20 \mathrm{~mm})$ had a similar set up as it was described for the polypropylene line, however, the longline consisted of more sections: seven $10 \mathrm{~m}$ long segments with each three $10 \mathrm{~kg}$ submersed floats in the centre and at each coupling elements $21 \mathrm{~kg}$ submersed floats. All floats were connected to a short wire element, which itself was spliced perpendicularly into the hawser and squeezed by one of the hawser's strands. An alternative attachment was the use of flat steel panels tightly fixed to the longline to which both, the floats and the collectors, were attached. Due to the weight of the steel wire, the longline had more floats than the polypropylene-based longline and no additional weights were attached to the longline. At all coupling elements pencil-like fenders $(28 \mathrm{~kg})$ were attached to mark the longline at the surface. The third system was based on the initial PP-design (Fig. 11.20f) but was equipped with V-shaped collector pairs.

All longline designs and moorings were based on the same fundamental setup having longlines operating in a submerged mode at a depth of about $5 \mathrm{~m}$ horizontally below the surface to avoid the destructive effects of surface waves. All longlines had a $10 \mathrm{~m}$ "undisturbed end" at both sides, which could not be retrieved when sampling or harvesting. Buoys were fixed along the longline in combination with suspended mussel spat collectors. The three-stranded collectors (Galician type, $2.5 \mathrm{~m}$ long), equipped with horizontal inserted pegs to prevent attached mussels to be shaken off through current and wave forces, were suspended every $2 \mathrm{~m}$ perpendicular from the longline in a parallel manner in the first two longline set-ups. In the third design $\mathrm{V}$-shaped pairs consisted of two $2.5 \mathrm{~m}$ side pieces and were connected in series in a suspended manner and in perpendicular fashion from the longline. Each collector had an additional weight of approximately $3 \mathrm{~kg}$ at the bottom end and was on the top end hooked into the longline by shackles to ease the maintenance during harsh conditions. Tufts of unravelled polypropylene lines 
(a)

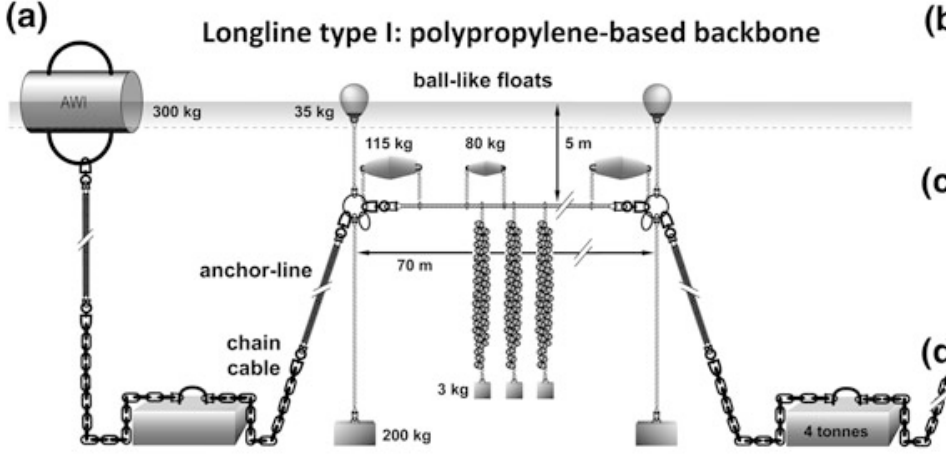

(b)

(c)

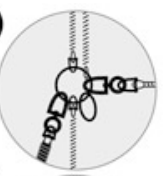

(d)

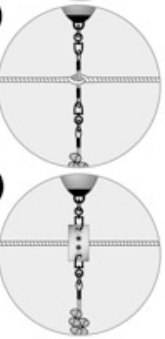

(e)

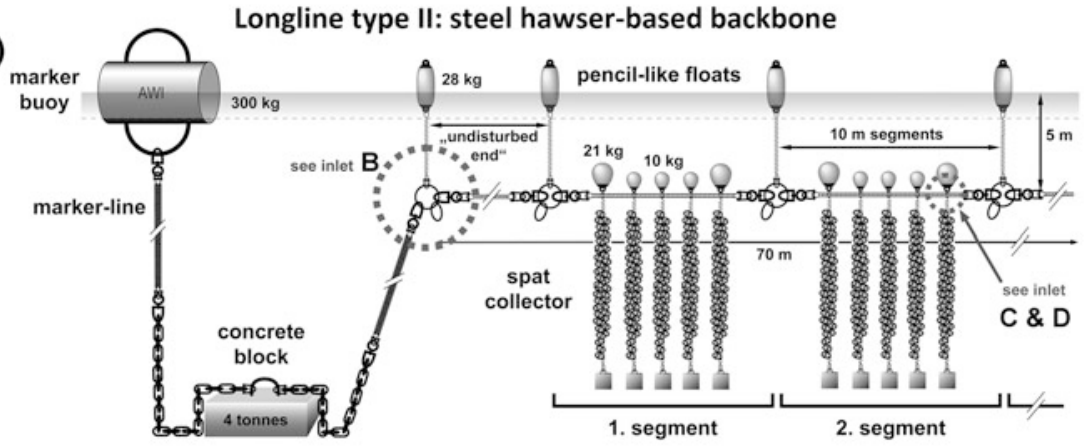

(f)

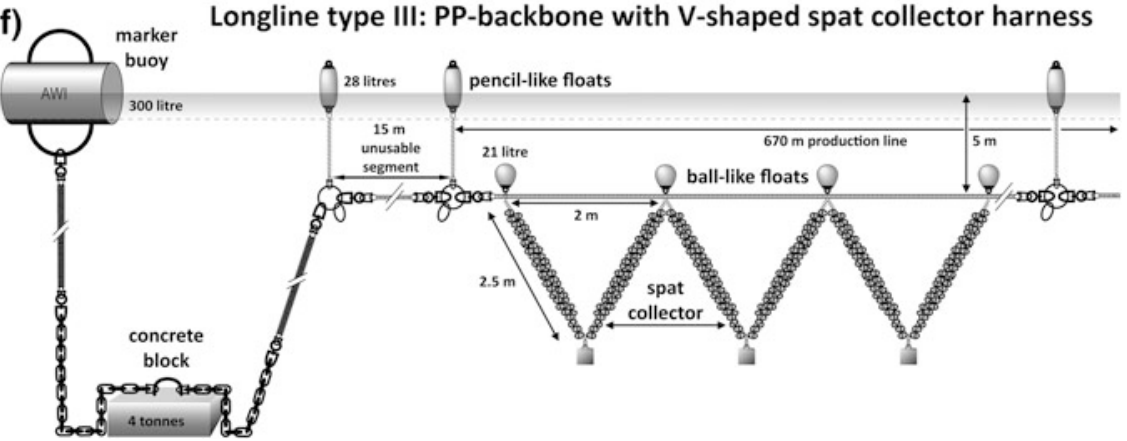

Fig. 11.20 a-f Submerged longline devices and the collector harnesses, which were developed at sea. One end of the backbone was attached to the wind turbine foundation. a Shows a polypropylene-based longline with coupling elements $\mathbf{b}$ and its equipment and connection with floats/collectors (c-d); e displays a steel hawser-based longline; f shows a longline with polypropylene (PP) as a backbone and V-shaped spat collectors. Images were modified after Buck 2007 and Buck et al. 2010. All images are not to scale 
(Tortell 1976) were also connected to the longline to determine the settlement of mussel post-larvae. The longline was secured at each end with an anchor consisting of a $4 \mathrm{t}$ concrete block. A chain cable attached to the concrete block was connected to the anchor-line, which itself held one end of the longline. Additionally, each concrete block was equipped with a marker-line and a marker buoy (300 kg). The marker line had a service load of several tonnes that it could be used to tauten the longline and to retrieve the concrete block at the end of the project. All mooring components were selected and sized for the use in muddy sea bottom and for long term durability. All longline segments had spliced eye loops with embedded galvanized thimbles at the ends and at all coupling elements shackles and swivels were used (Fig. 11.20b-d).

All longline systems and their mooring devices were first modelled and designed with the WSA. A local cable and wire manufacturer supported the engineering development for the culture design. All components were selected and procured to start the preparation and assemblage of the longline during wintertime.

After installation all longlines and their collectors were fully overgrown by mussels. Heavy mussel growth was found also on all mooring components and a lot of mussels were recorded on the undisturbed ends of the longline at each side. From the farmer's perspective, the offshore site was suitable in terms of settlement and grow-out. Problems encountered during the test trials included material failure, heavy fouling on the collector lines and other infrastructural units resulting in large ballast weights, while heavy predation on mussel seed by sea stars and Eider ducks also happened. Another difficulty was maintaining proper headline depth and its management with the right buoyancy due to mussel growth. This added drag forces to the entire longline, which in turn complicated the handling during hostile sea conditions.

The PP-longline design was resistant to the high energy environment of the North Sea, but chafed within the inner parts of the eye loops and therefore some of the thimbles were lost. These stress forces affect the lifetime greatly. The segmentation set-up in the second longline design allows the replacement of spare parts. The weight of the suspended collector harness increased significantly with time, and extra floatation had to be added to support the buoyancy of the longline. However, the time intervals chosen for service were too long (particularly during the summer growing season) so that parts of the collector harness including the floats submersed fully and partly touched the seafloor. Additionally, this process was exacerbated by the fact that the loss of buoyancy resulted in a further lowering of the total construction. When the longline was retrieved the concrete blocks were broken easily out of the clay at the site and raised by the anchor chain. Most of the mooring system, in particular the longline and its harness, was later inspected onshore. On a few spots near the eye loops some slight damage of the material was found, but, after removing the fouling, most of the line looked intact and almost new. 


\subsubsection{Mussel Longlines: Forces Induced by Collectors}

As the distance between wind turbine foundations within an offshore wind farm are expected to be between 700 and $2500 \mathrm{~m}$, the forces induced by the longline can be estimated to be very high. Additionally to the investigation on forces impinging on the foundations by the attached longlines, the forces induced by the hundreds of fully grown, market-sized Blue mussel collectors was calculated as well. To get more insight into these forces the drag coefficient of this type of collector had to be investigated. First tests were conducted in a towing tank of the Hamburg Ship Model Basin (HSVA, Hamburg) to determine the drag coefficient $\left(C_{D}\right)$ for the collectors (Fig. 11.21a-i). The length of the tank allowed sufficiently long measuring times (length $80 \mathrm{~m}$, width $3.8 \mathrm{~m}$, and depth $3 \mathrm{~m}$ ). Mussel collectors, with mussels and without mussels (naked) were prepared for measurements of drag by attaching the proximal end of the collector to a string. This string was directed over a guide reel fixed to the bottom of a beam. A cavity within the beam allowed the thread to be hooked onto the digital gauge, which was placed on the control panel of the carriage. The beam was fastened to the base frame of the towing tank's carriage. It was lowered $1 \mathrm{~m}$ deep into the tank filled with water. Collectors tied to
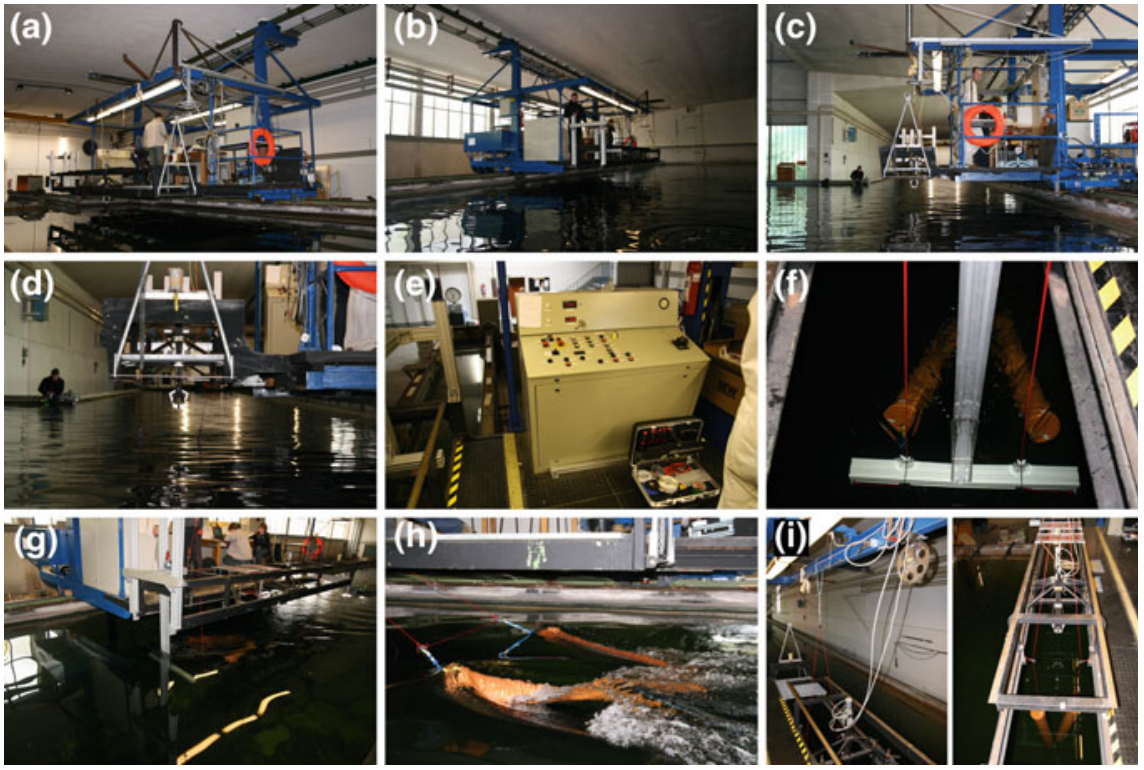

Fig. 11.21 a-i Towing tank at the HSVA (Hamburg Ship Model Basin). a Main carriage with the operation desk and the equipment holding the collectors; $\mathbf{b}$ carriage under way; c carriage displaying the Bosch-profile, which holds the experimentals; $\mathbf{d}$ single holdings device to which different collector types (artificial, mussel) in various modes (single, double, V-shape) can be attached; e operation desk controlling the speed of the carriage; $\mathbf{f} \mathrm{V}$-shape artificial collector pair to be tested; $\mathbf{g}$ carriage with V-shape artificial collector pair under way; $\mathbf{h} \mathrm{V}$-shape artificial collector pair during high speed under way; $\mathbf{i}$ walkable platform to manage the experimentals. Images AWI/Prof. Dr. Bela H. Buck and Björn Hendel 
the thread of the gauge were towed through the tank by the carriage at velocities of $0.5,1.0,1.5,2.0$, and $2.5 \mathrm{~m} \mathrm{~s}^{-1}$, respectively.

The drag measurements of each collector were used to calculate the dimensionless coefficient of drag $\left(\mathrm{C}_{\mathrm{D}}\right)$ by applying the equation:

$$
C_{D}=\frac{2 F_{D r g}}{\rho \cdot A \cdot v^{2}}
$$

$F_{D R G}$ denotes the measured drag, $\rho$ the density of water, $A$ is the surface area exposed to the current of velocity $v$. While for relatively rigid or bluff organisms the projected area of the organism across the flow is generally used, we decided to test an artificial test body (collector) and a fully grown mussel collector as well. For solid objects being accelerated in fluid in addition to drag a force occurs which is, commonly described as acceleration reaction (e.g. Daniel 1984; Denny et al. 1985; Denny 1988). In order to take orbital motions into account the drag $F_{D r g}$ from Eq. (11.1) has to be written in vector notation, and an acceleration term is added (Morison et al. 1950):

$$
\vec{F}_{D r g}=C_{D} \cdot A \cdot \frac{1}{2} \cdot \rho \cdot \overrightarrow{|v|} \cdot \vec{v}+C_{M} \cdot \rho \cdot Q \cdot \frac{d \vec{v}}{d t}
$$

where $C_{M}$ is the dynamic drag coefficient and $Q$ the volume of water displaced by the object. In order to initially avoid uncertainties with $C_{D}$ and the area $A$ for flexible organisms it is useful to write the first term in Eq. (11.2) in terms of dynamic pressure $\left(\overrightarrow{F^{*}}\right)$, which can be exactly computed from current measurements:

$$
\overrightarrow{F^{*}}=\frac{\vec{F}_{D r g}}{C_{D} \cdot A}
$$

i.e.

$$
\overrightarrow{F^{*}}=\frac{1}{2} \cdot \rho \cdot \overrightarrow{|v|} \cdot \vec{v}
$$

For a detailed demonstration of the time history of drag forces occurring under the action of tidal currents, wind wave and swell model calculations were carried out using the software "WaveLoads" developed by Mittendorf et al. (2001), which solves Eq. (11.2) for offshore structures. The forces were computed for a hypothetical (artificial) test body (cylinder) of $2.5 \mathrm{~m}$ in length and such a diameter that the area exposed to the current corresponded with that of the plan area of a typical fully grown mussel collector as determined before. The drag coefficients measured in the towing tank experiments were used instead of the ones determined for cylinders (Fig. 11.22a-f). The cylinder was exposed perpendicular to the flow direction. The results render information on the distribution of horizontal and vertical forces which act on the test bodies and mussel collectors. 

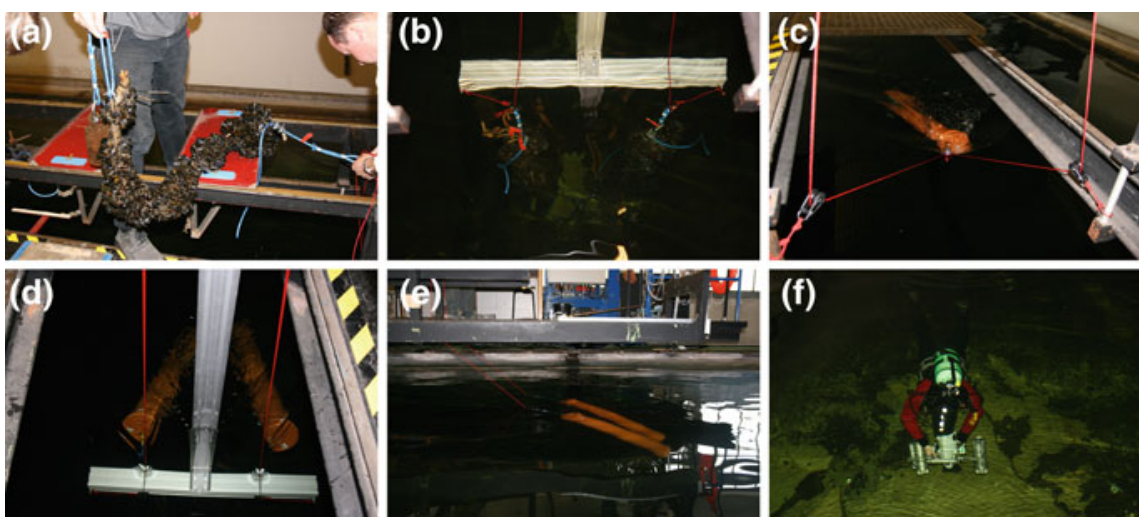

Fig. 11.22 a-f Mussel collectors and artificial test bodies in the towing tank. a Mussel (Mytilus edulis) collector in preparation for the towing experiment; $\mathbf{b}$ crossbeam with two mussel collectors in a V-shape; c single test body in test mode; two test bodies (V-shape) in test mode at the crossbeam (d) and from side view (e); f scuba diver in the towing tank to monitor the behaviour of test bodies during towing. Images AWI/Prof. Dr. Bela H. Buck and Björn Hendel

The drag coefficient $C_{D}$ of the artificial test body as well as the fully grown mussel collector was calculated at velocities of $0.5,1.0,1.5,2.0$, and $2.5 \mathrm{~m} \mathrm{~s}^{-1}$ to range between 0.2 and 1.15 . The graphs for moth collector types show a pronounced bend at a velocity of $1 \mathrm{~m} \mathrm{~s}^{-1}$. This appears to approximately mark the minimum speed required for orientation of the collectors within the water column into the downstream direction. At higher velocities $\geq 1.5 \mathrm{~m} \mathrm{~s}^{-1}, \underline{\mathrm{C}_{\mathrm{D}}}$ was almost a constant.

\subsubsection{Mussel Longlines: Attachment to Foundations}

The development and the conceptual design of offshore foundation structures are complex and require an interdisciplinary approach. One of the most important questions pertains whether it is technically possible and economic feasible to use offshore foundation structures as fixation device for aquaculture operations, such as a longline construction as one possible culture design. Therefore, wind energy converters in offshore sites do need an exact description of the loading on the plant. In general, these loads are caused and influenced by the environmental conditions such as wind, wave, currents and the soil properties (GL 2005). From the engineers point of view it is indispensable to have an estimation of the additional loadings caused by attached longline constructions.

In Project No. 6 "AquaLast" supplemental loads on the support structures of offshore wind energy converters (OWEC) caused by attached longlines were investigated. Several alternative connection points were tested. As monopile and tripod foundations are the most common foundation structures to date, these both were considered within the modelling approach calculating the respective loads 
from wind and waves. Both foundation structures are in the dimension of 4-5 MW wind turbines. While the monopile design was calculated for a water depth of $10 \mathrm{~m}$ the tripod design was computed for a water depth of $30 \mathrm{~m}$.

The monopile was calculated and designed with the representative environmental loads from the area of the planed wind farm Nordergründe (see Fig. 11.8). For the static calculation of the monopile we use the structural analysis program RSTAB in the version 5.14.191 and the add-on module STEEL from IngenieurSoftware Dlubal GmbH. The 2nd order theory is used to get the results. In Fig. 11.23a, b the static system, the bending moments and the transverse loads based on the maximum loads from the wind energy converter are plotted.

(a)

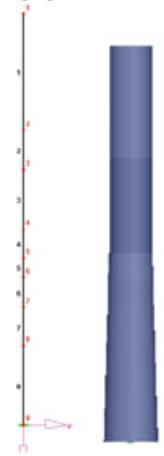

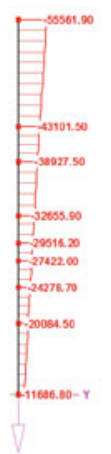

(b)

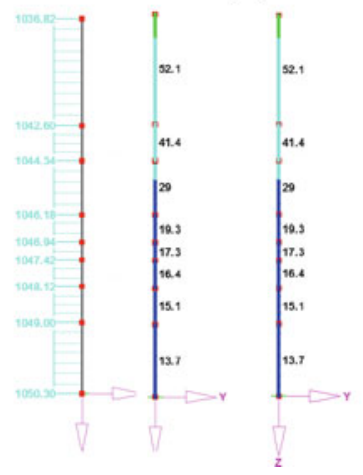

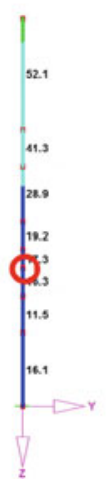

Fig. 11.23 a Static system of a monopile, moments and transverse loads including the distribution of stress; $\mathbf{b}$ diagram of the maximum tension at the monopole at different potential longline connection points. Modified after Buck and Wiemann (unpublished data)

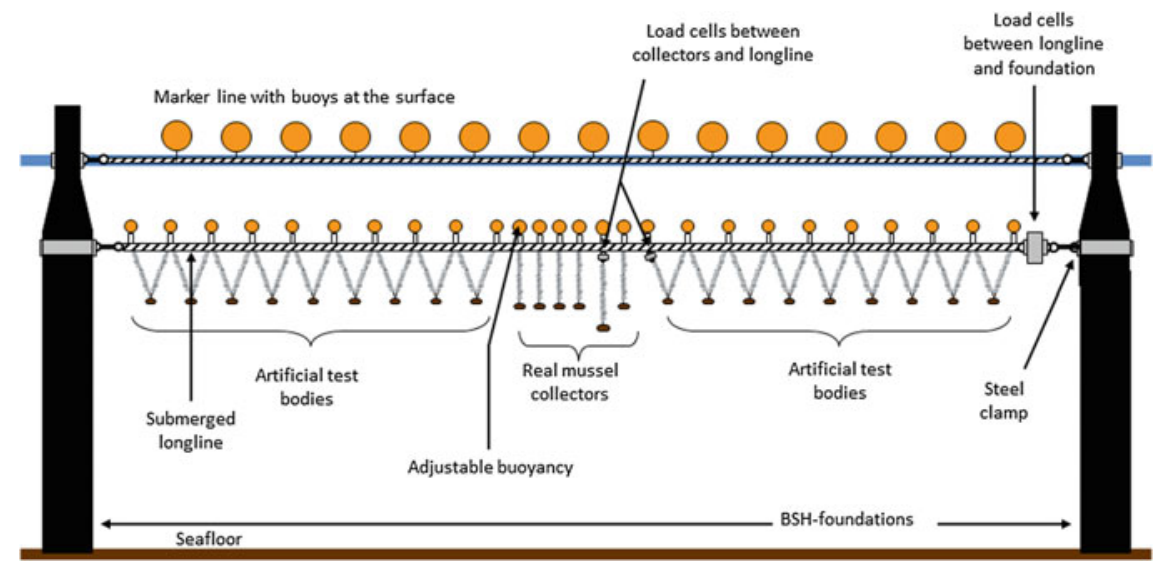

Fig. 11.24 First submerged test longlines in a multi-use-concept by using former ODAS-foundations, which are located in the vicinity of the offshore wind farm Butendiek. Modified after Buck et al. 2006b 
(a)

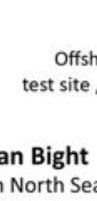

German Bight

(southern North Sea)

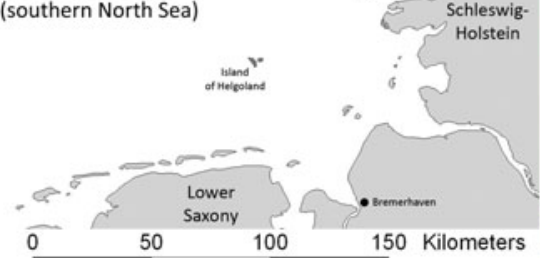

(c)
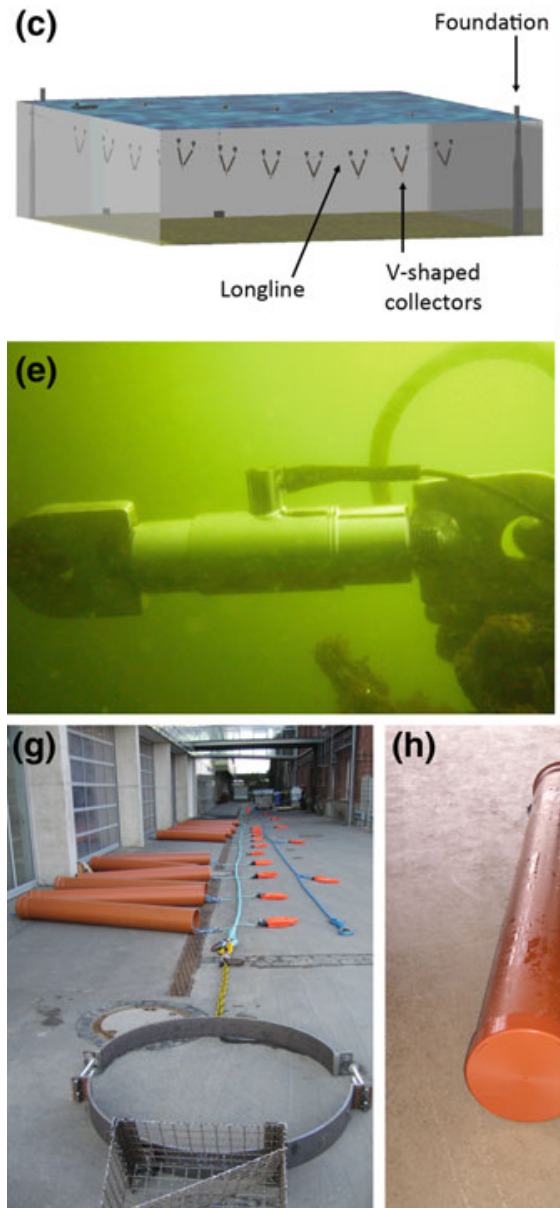

(h)

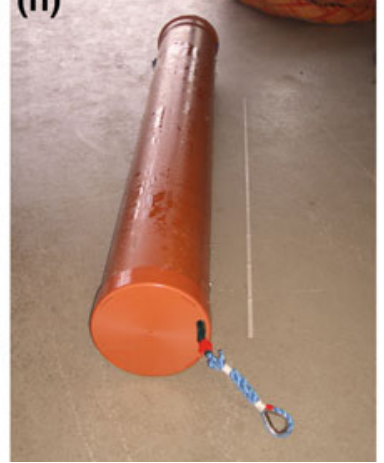

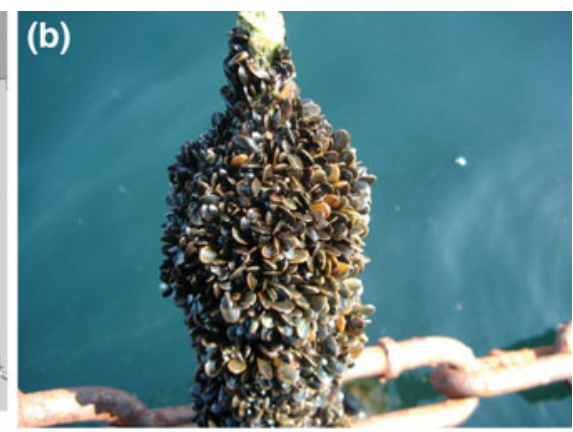

(d)
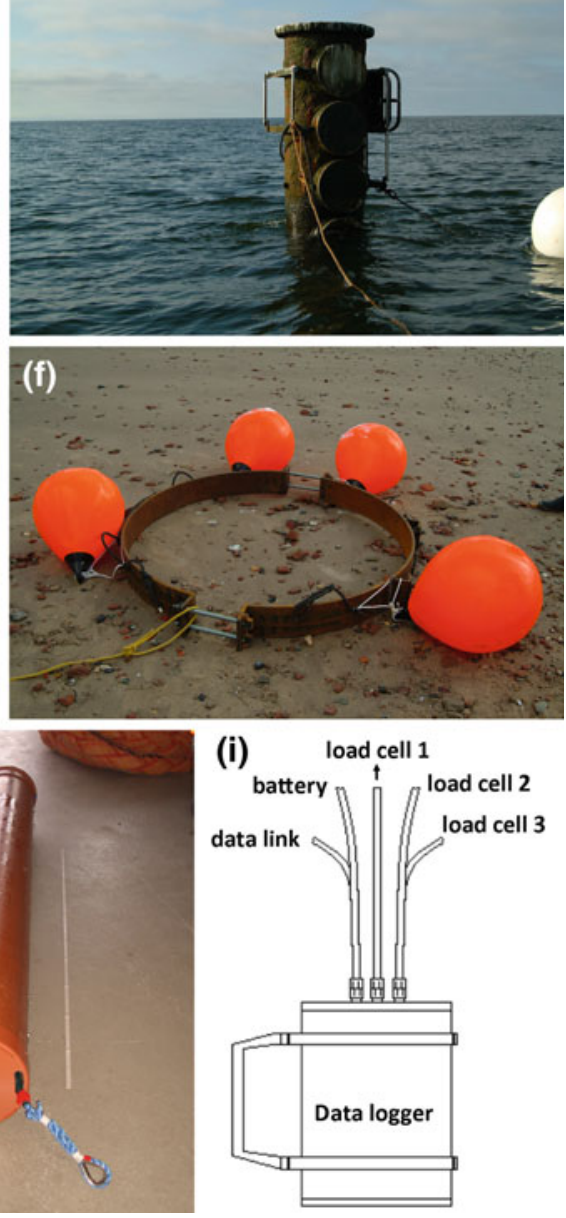
4Fig. 11.25 a Location of the test site 16 nautical miles off the island of Sylt (ODAS-foundation); b fully overgrown collector with mussels (Mytilus edulis); c Drawing of the longline device connected in between two foundations showing the V-shaped collector types; d former ODAS-foundation simulating the wind turbine monopile foundation, to which one end of the longline was connected; $\mathbf{e}$ underwater load cell; $\mathbf{f}$ steel clamp to connect one end of the longline to the foundation (the buoys were only fixed to the clamp during transfer from the vessel to the foundation); $\mathbf{g}$ complete longline harness on land; $\mathbf{h}$ artificial test body; $\mathbf{i}$ drawing of the underwater data logger. Images AWI/Prof. Dr. Bela H. Buck

\subsubsection{Mussel Longlines: Attachment to a Monopile}

For the connection of a longline and a monopile foundation a numerical model was built up to provide information of the parameters influencing the reactions at the longline fixation. The analysed load cases were quasi-static calculations for extreme loads. In support of the model approach, an entire monopile-longline-monopile construction was set up in the offshore waters 16 nautical miles off the Island of Sylt at a water depth of about $17 \mathrm{~m}$ (Figs. 11.24 and 11.25a-i). Loads at one junction of the longline with the foundation as well as in between various collector types and the longline were measured and environmental conditions were assessed by sensors installed on site over a period of 5 months (May-September 2006).

For the test period a submerged longline design was chosen due to its ability to withstand strong oceanographic conditions (Buck 2007, Langan and Horton 2003). The submerged construction consisted of a buoyed, horizontal running backline, which is commonly described as a back-bone of the entire harness (Figs. 11.24 and $11.25 \mathrm{c}$ ). This back-bone (polypropylene, $32 \mathrm{~mm} \mathrm{Ø)} \mathrm{was} \mathrm{fixed} \mathrm{via} \mathrm{spliced} \mathrm{ends}$ (including thimbles) to a $1.5 \mathrm{~m}$ chain with shackles and swivels (service loads above 20 tons) at both ends to the test piles in a depth of about $5 \mathrm{~m}$ (low tide level). In this project the investigation of the settlement success of mussel larvae on artificial collector substrates was not the main objective. Moreover, the concentration of mussel larvae in the water column even in June to July, which is the main peak season for drifting mussel larvae (Buck 2017), was already determined to be very low at the study site. Thus, artificial test bodies were introduced, which had a similar diameter, shape and weight to simulate a fully colonized market-sized mussel collector. For this purpose, $22 \mathrm{~V}$-shaped test bodies were fastened perpendicular to the longline and served as "non-collecting" collector harness.

The mechanical loads were measured at three strategically important positions along the line using submersible force sensors (Althen TCA-256). One sensor acquired the tension of the main leash rated for a load of $200 \mathrm{kN}$ was located directly at the attachment of the long line. Two additional force sensors each ruggedized for $10 \mathrm{kN}$ of load were placed above the $\mathrm{V}$-shaped mussel collectors in order to confirm the charge on a single mussel collector.

Data from the force sensors was recorded on a custom made submersible data logger (iSiTEC) located in a cage fixed to one pile in $5 \mathrm{~m}$ water depth. The measurement was accomplished in a $1 \mathrm{~h}$ interval, whereby 180 measurements were noted within a 3 min burst. This cage also held a battery supplying energy for the 
sensors and the logger for roughly 3 month together with an autonomous underwater tide and wave recorder (RBR TWR-2050). The tide and wave recorder was used, to meet exact statements about the arising wave spectra during the test period. Data noted during the trial period were acquired all $30 \mathrm{~min}$ in one burst with a 512 sample measurement length and were averaged afterwards. This power saving strategy allowed for a time span of approx. 3 months before the inbuilt batteries were exhausted.

Measurements of currents in the plane of the collectors, approx. $7 \mathrm{~m}$ below water surface was achieved by applying a current meter (AADI RCM-9LW) at a mooring site in approximately $30 \mathrm{~m}$ distance from the longline demonstrator. The current meter was additionally equipped with pressure, temperature and conductivity sensors to address the oceanographic conditions as well as a turbidity probe and a shallow water oxygen sensor, both to account for growth parameters of the biological setup. Due to the high capacity of the $R C M-9 L W$ batteries no power saving precautions had to been taken and a sample interval of $10 \mathrm{~min}$ was realized. Table 11.1 summarizes the applied sensors and acquired parameters during the test construction.

The longline (LL) was represented by finite elements (FE) and the calculation was done by commercial FE software. The FE were realised by 3D tension-only spar elements. These elements only considered axial tension forces and had three translational and no rotational degrees of freedom. No bending moments could be transferred. The ends of the longline model were fixed in all three translational degrees of freedom. There was no mass for the longline added because it was small compared to external loading and the mussel collectors were assumed to be floating, thus only hydrodynamic forces were applied on the collectors. The mussel collectors were represented by points, which were in this case FE nodes between the 3D spar elements.

The complex dynamic behaviour of a floating longline (Raman-Nair and Colbourne 2003) and the load calculation based on statistic wave and current fields

Table 11.1 Overview of the applied sensors used in the longline demonstrator setup

\begin{tabular}{l|l|l}
\hline Applied sensor and the acquired parameters \\
\hline Device & Parameter & Unit \\
\hline \multirow{2}{*}{ Aanderaa } & Current speed & $\mathrm{cm} / \mathrm{s}$ \\
\cline { 2 - 3 } & Current direction & ${ }^{\circ} \mathrm{deg}$ \\
\cline { 2 - 3 } & Temperature & ${ }^{\circ} \mathrm{C}$ \\
\cline { 2 - 3 } & Conductivity & $\mathrm{mS} / \mathrm{cm}$ \\
\cline { 2 - 3 } & Depth & $\mathrm{kPa}$ \\
\cline { 2 - 3 } & Turbidity & $\mathrm{NTU}$ \\
\cline { 2 - 3 } & Oxygen & $\mu \mathrm{M}$ \\
\hline \multirow{2}{*}{ RBR TWR 2050 } & Tide spectrum, $\mathrm{T}^{\frac{1}{3}}$ & $\mathrm{~s}$ \\
\cline { 2 - 3 } & Wave spectrum, $\mathrm{H}^{\frac{1}{3}}$ & $\mathrm{~m}$ \\
\cline { 2 - 3 } & Temperature & ${ }^{\circ} \mathrm{C}$ \\
\hline Althen TCA-256 & Stress loads & $\mathrm{kN}$ from mA \\
\hline
\end{tabular}


(GL 2005) are reduced to a static worst case consideration. This was done to give a first approximation of the additional loading on OWEC support structures. In the OWEC dimensioning process extreme load cases like the 50 year wave or emergency stops were taken into account. Thus, the extreme load case of the 50 year wave was simulated as a quasi-static simulation. No dynamics and thus no inertia forces were taken into account. The very time consuming process of dynamic modelling would be necessary for fatigue analysis. In that case, the varying loads caused by the longline were of interest. Modal analysis of these loads was also important on the support structure to avoid excitation in or near the eigenmodes of the plant. In any case, the dynamics were highly depending on the sea state. This was modelled by wave theories and current assumptions. These were highly statistic inputs and could only be a rough approximation of reality.

For these reasons, a static analysis of the problem was a reasonable first approach to the complex problem. The forces of the longline were depending on the single collector forces. These were considered to be concentrated loads, which were all applied in the same angle of attack relative to the longline and with similar force value. In this case, the reactions were maximal because there was no neutralization of the forces taking place. The longline was oriented in one plane. In consequence the LL could be approximated by a 2D model as shown in Fig. 11.26a.

The schematic 2D LL picture in Fig. 11.26a shows the pre-deformed model as a starting point of simulation. This deformation was the approximate form of a catenary curve. A curve like that would be obtained for a cable under self-weight or in a uniform loading caused by even very low currents perpendicular to the LL. The pre-deformation was needed to define the maximum sag without loading. It was also needed for better convergence of the numerical calculation.

The following parametric studies for this model were conducted: First, a single load was applied vertically in the middle of the LL. The maximum sag was variable. For this case an analytical calculation was carried out to validate the model itself and to understand the main parameters of interest in the problem.

The second parametric study was made for forces on each FE node that represents a single or V-mussel collector under varying angles of attack. The loads in both parametric studies were applied as ramped loads to ensure convergence. The reaction forces in both supports were calculated. All simulations were quasi-statically calculations for the worst case loading investigated.

According to theoretical analysis, a single load in the middle of the longline led to a V-like deformation (Fig. 11.26b). The relative force in a single loaded cable in equilibrium without consideration of strain and mass is defined as

$$
\frac{F_{s}}{F}=\frac{1}{2 \sin (\beta)}
$$

where $F_{s}$ is the force in the cable and $F$ is the external load. $\beta$ is the angle between cable and horizontal axis. $F_{s}$ equals the absolute value of the reactions. This formula shows the fundamental difference between cables and beams. Beams could carry bending moments and cables could not. This was due to the fact that at angle $\beta$ of $0^{\circ}$ 
Fig. 11.26 a Schematic longline with nodes representing the mussel collectors; $\mathbf{b}$ free body diagram of a single loaded cable

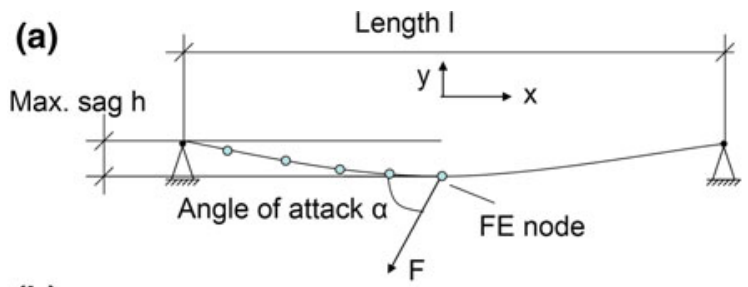

(b)

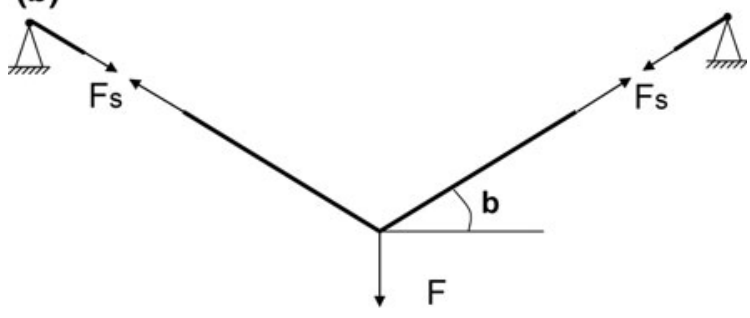

the vertical reactions in a beam were a half of the applied load and for a theoretic cable the reactions were infinite.

In the following graph, the theoretical and simulated values for the relative force were shown as a function of the relative maximum sag $h /$. The relative maximum sag $\mathrm{h} / \mathrm{l}$ was the ratio of the maximum sag to total distance between the supports (Fig. 11.27a). The theoretical values for $h$ were based on curve length of the pre-deformed model. The curve length was then used to get the maximum sag of the foreseen V-form after loading. That value of $h$ was then used with the formula described above. The theoretical and simulated values for the relative force are shown in Fig. 11.27a, b.

With values for $h / l$ bigger than 0.05 the relative force was smaller than 4 and was approaching 1 with increasing $h / l$ ratio at nearly 0.25 . The more the longline was tightened and the $h / l$ ratio was decreasing the numerical model of the longline shows an increasing relative force in the supports. In Fig. 11.28a the pre-deformed model is shown and the deformed model under single load depicted as an arrow is also sketched. The deformed model had a V-form similarly to the theoretical cable under the same loading. The second parametric study for different angles of attack and different maximal sags is shown (Fig. 11.28b). As an example the deformed and not deformed model of a longline loaded at equally spaced points with a loading angle of $60^{\circ}$ is shown in Fig. $11.28 \mathrm{~b}$. The forces are depicted separately in their coordinate direction components. In the middle part smaller loads represent the single mussel collectors whereas the rest represents V-collectors. A deformation of the LL model in force direction was observed. Figure $11.28 \mathrm{c}$ shows the results for the second parametric study. The relative force in the right and left support was calculated for different values of angle of attack and varying maximal sags. In this case the relative force was the reaction at the end of the longline divided by the sum of total collector forces that were applied. In general the reactions in the left support were bigger than in the right except for angles of $90^{\circ}$ where the loading was 

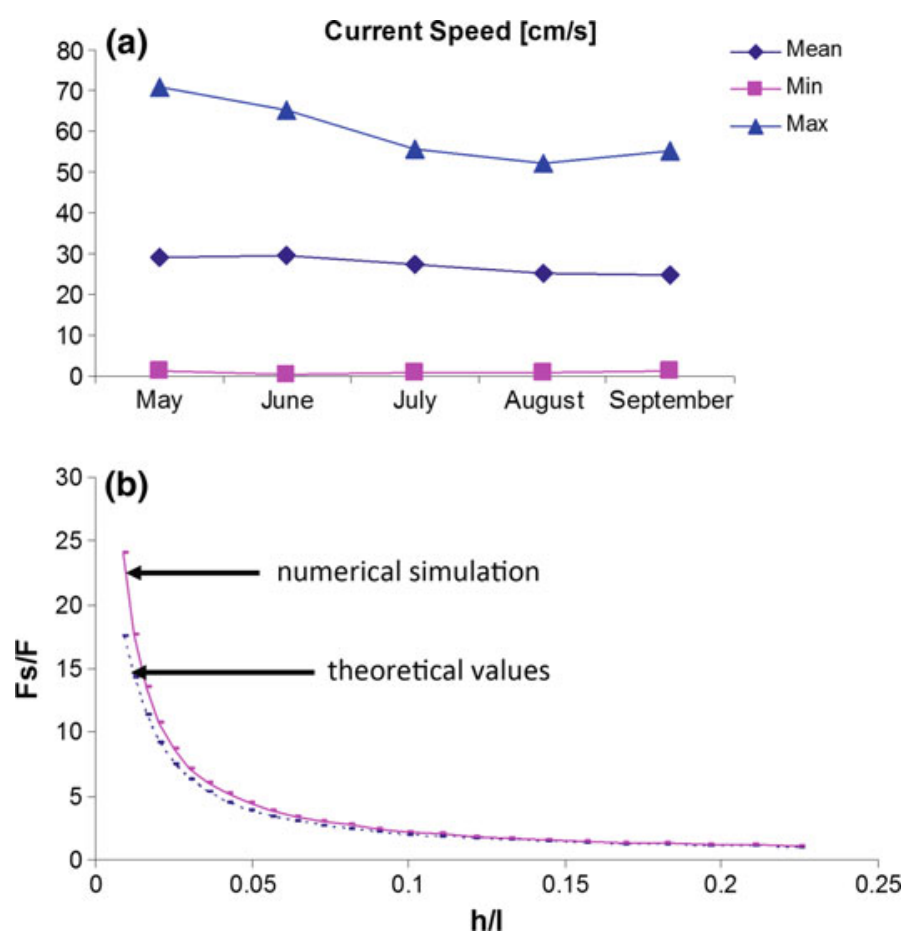

Fig. 11.27 a Results of the current-meter at site; $\mathbf{b}$ free body diagram of a single loaded cable. Buck and Wiemann (unpublished data)

symmetric thus the relative forces are equal. Depending on the angle the loads in the right support increased with decreasing angle to a certain point and then decrease again. In the right support the reaction decreased for angle smaller than $90^{\circ}$. With increasing $h / l$ ratio the reactions decreased as well.

\subsubsection{Mussel Longlines: Attachment to a Tripod}

In a final approach, a tripod construction was chosen as a potential connection point for aquaculture devices. A tripod is an offshore foundation construction for water depths of more than $25 \mathrm{~m}$. The weight of a tripod for a 4-5 MW turbine is up to 1000 tons of offshore steel S355 NL/ML. The tripod considered within this project is constructed and calculated for the area "Borkum Riffgrund", where the German research platform FINO 1 (N54 ${ }^{\circ} 0.86^{\prime}$ E $\left.6^{\circ} 35.26^{\prime}\right)$ is located. We employed the common wind loads and the waves for this position to create a tripod model, which was used as basis for the following investigations. Figure 11.29a-f shows the construction and the static model for the calculated tripod as well as loads on the tripod and the tension of the steel induced by a connected longline device. A tripod 
(a)

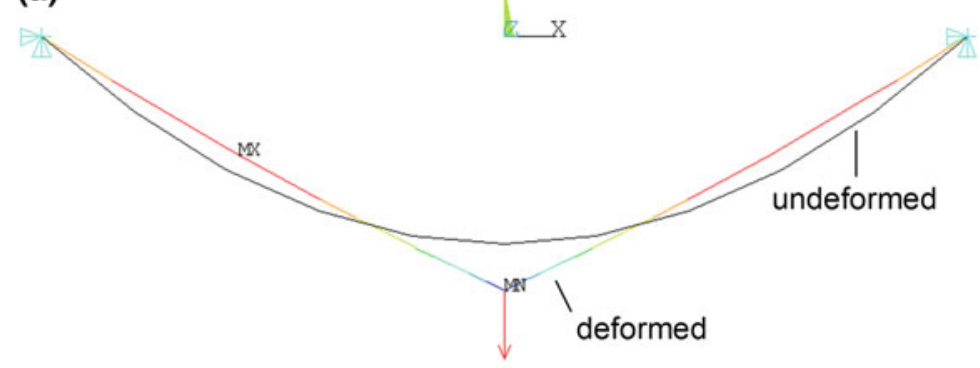

(b)
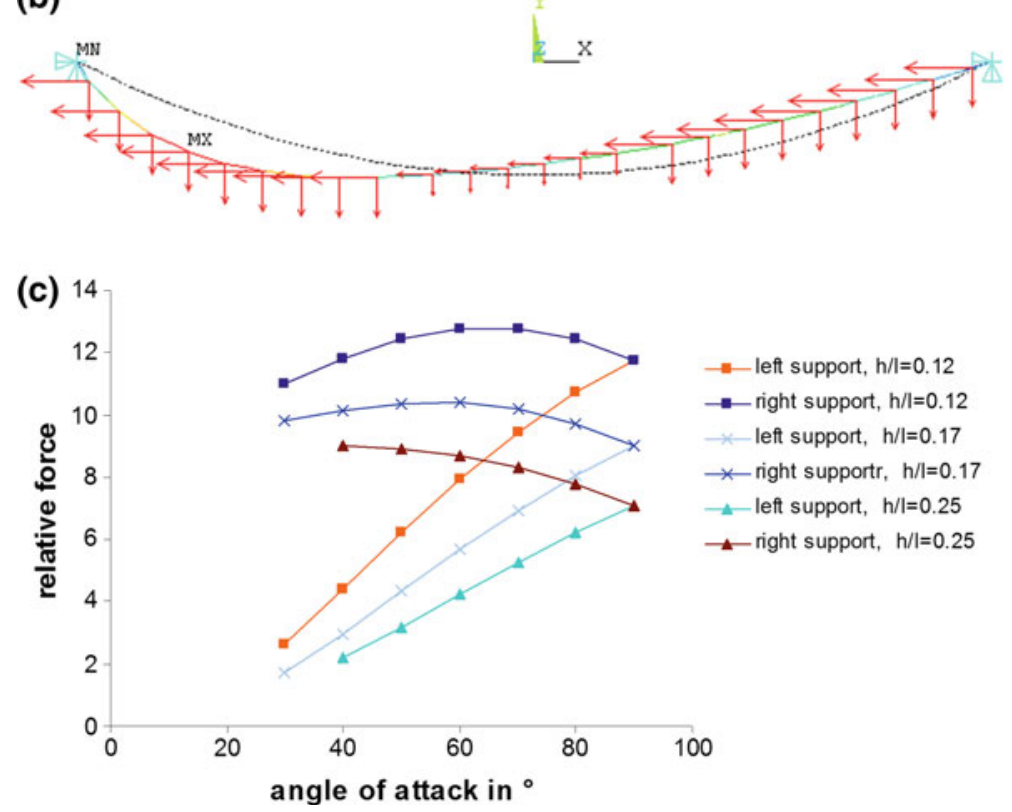

Fig. 11.28 a Preformed and deformed numerical model of the single loaded longline; b Preformed and deformed numerical model of the single loaded longline; c Relative forces for different angles of attack. Buck and Wiemann (unpublished date)

has a main joint, which is the technical limit for the depth of the connection point. This is located about $5 \mathrm{~m}$ below the water line (Fig. 11.30).

\subsubsection{Additional Forces Measurement}

To estimate the maximal forces in order to qualify the load sensor class some previous calculations were conducted. Figure 11.31a shows a schematic depiction of a single collector load system. Further, the load forces of the attached buoys were 

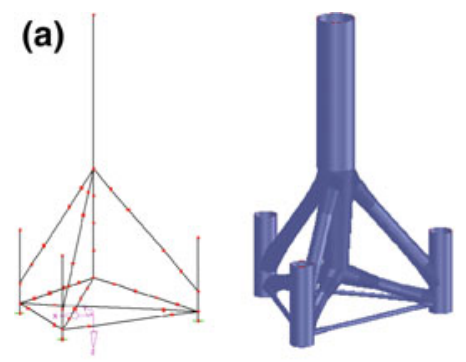

(b)

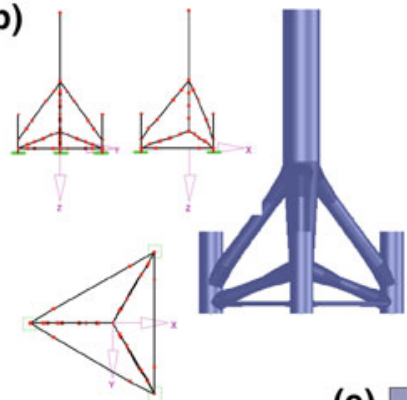

(e)
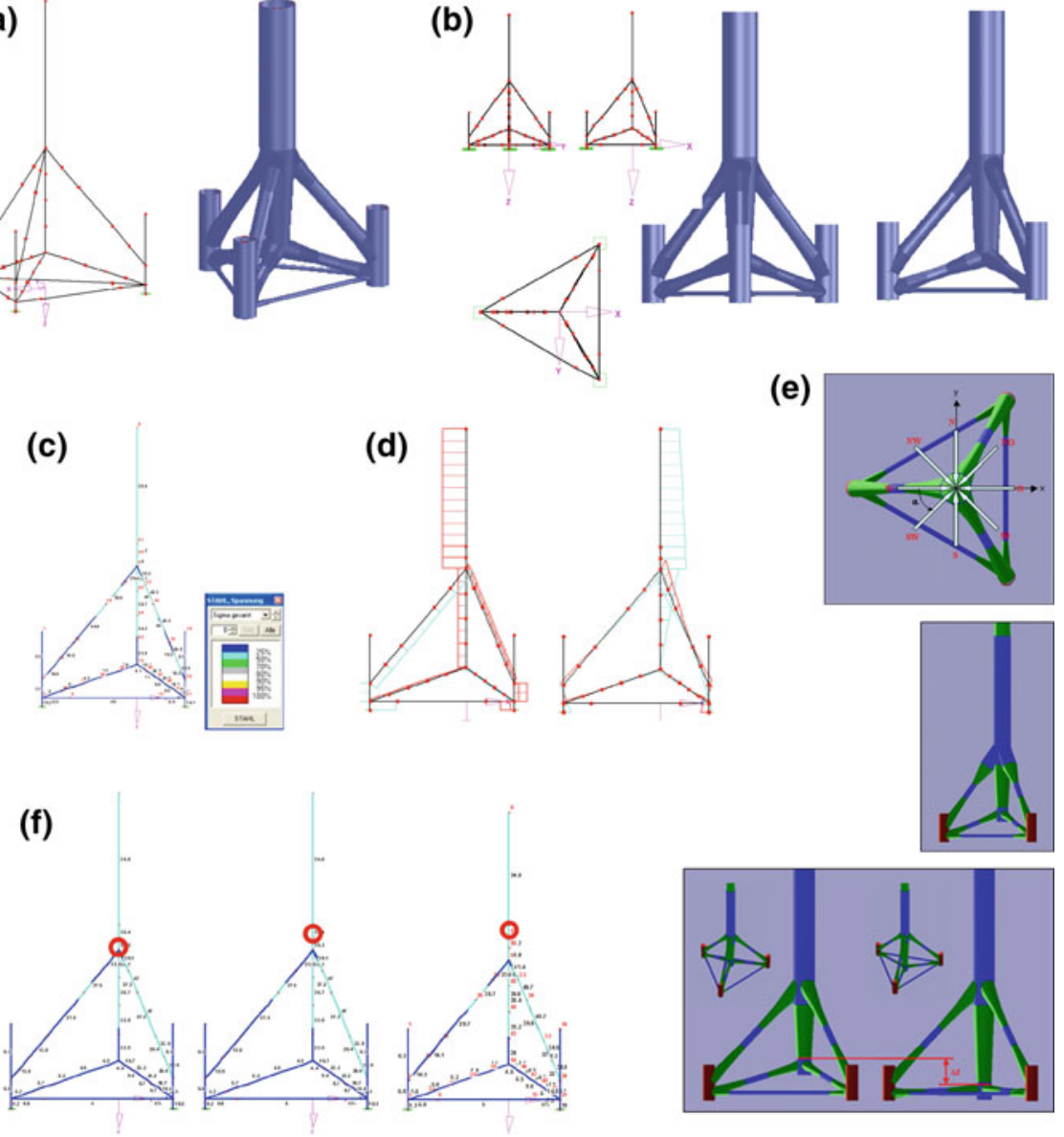

Fig. 11.29 a Representation of a beam model (left) and of a tube geometry (right) of a tripod foundation for offshore wind generators (4-5 MW class); $\mathbf{b}$ different views of a tripod foundation; c maximum tension utilization of steel at the various single components; $\mathbf{d}$ Representation of the progress of the transverse force (left) and of the progress of the momentum (right); e static system of a tripod; $\mathbf{f}$ representation of longline connection points at the tripod as well as the utilization of the maximum acceptable tension of the steel. Modified after Buck et al. 2006b, 2008a, b; Buck and Krause 2012

calculated similar to the collector (Fig. 11.31b). As the vertical forces were caused by the mass of the collector and the buoyancy the mass force was defined as

$$
F_{m}=m \cdot g
$$

with 

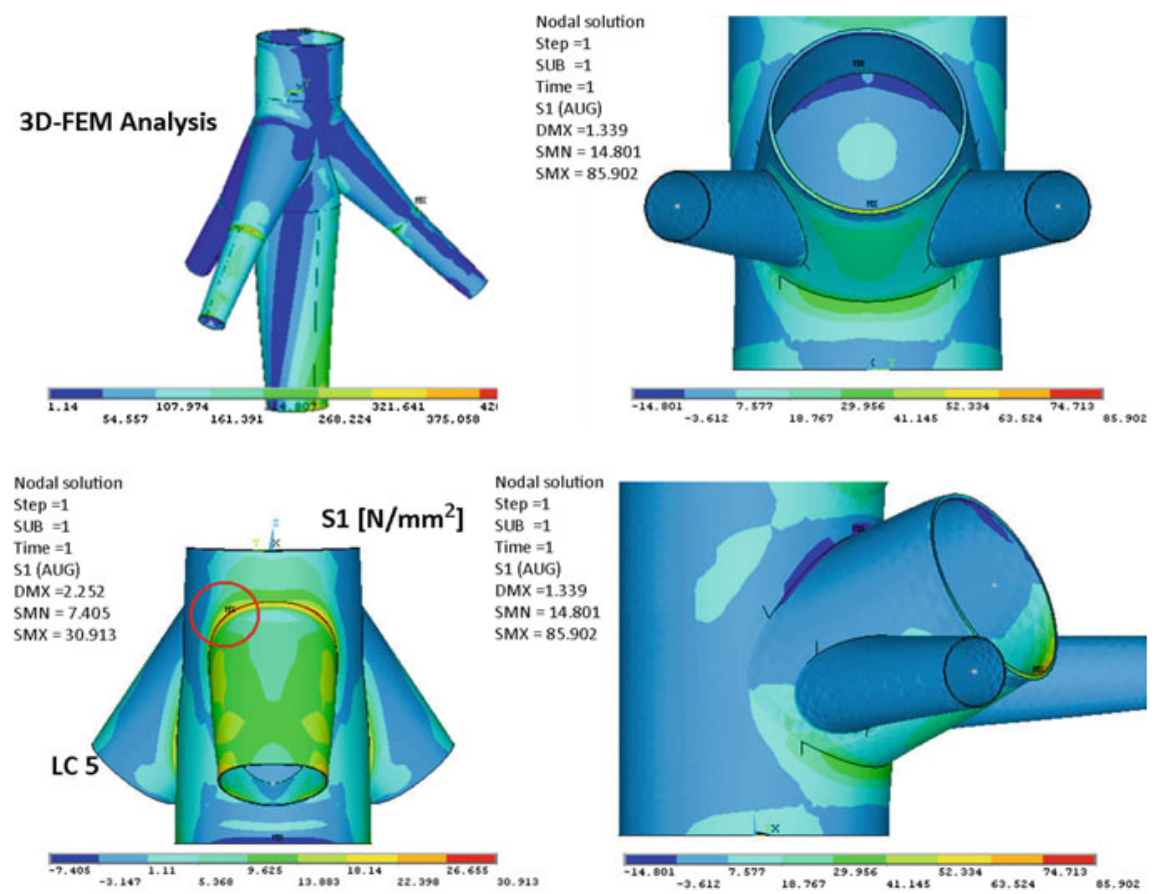

Fig. 11.30 Suggested connection points for the tripod construction including the tensions and load forces. Modified after Buck and Krause 2012

$$
\mathrm{m}=\mathrm{m}_{\mathrm{c}}+\mathrm{m}_{\mathrm{l}}+\mathrm{m}_{\mathrm{a}}
$$

where $m_{c}$ is the collector mass, $m_{l}$ the line mass and $m_{a}$ the additional mass. The buoyancy was calculated applying

$$
F_{b}=V \cdot \rho \cdot g
$$

where $V$ is the volume of the buoy, $\rho$ is the density of seawater and $g$ the gravity constant.

Given the resulting forces from the single collector and the buoy it was possible estimate the total load from the collectors and finally the longline system itself.

\subsubsection{Conclusion and Outlook}

The results of the first parametric study showed good correlation to theoretical results. However, for very small values of $h / l$ the difference between analytical and numerical values increases. This was mainly caused by length variation due to increasing strain for a tightened LL. The strain was not taken into account in the 
(a) Longline

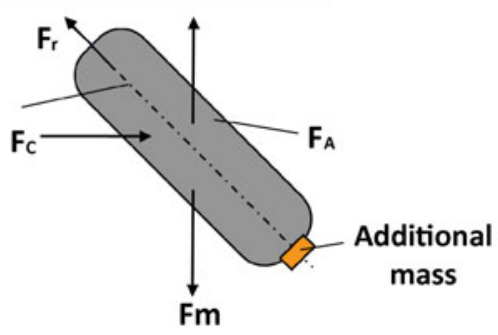

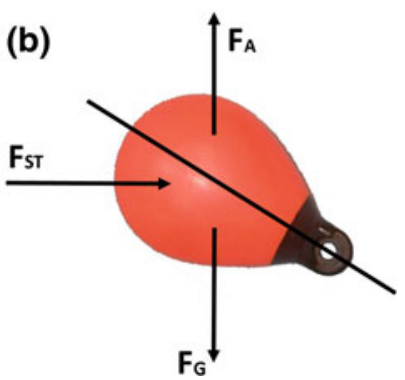

Fig. 11.31 a Model of collector loads for a single collector attached to a longline system; b Schematic diagram of a buoy and its forces. Modified after Buck et al. 2006b

analytical calculation. Hence, in the numerical calculation the calculated forces were smaller because the strain in the LL results in larger effective maximal effective sag. The rapprochement to relative force of one for $\beta$ approaching $30^{\circ}$ is suitable to the theoretic values.

The results present a numerical model with different parametric studies in order to assess the loads at the fixation of a longline for a worst case scenario. The model has been verified for the case of a single load point by analytical calculations. The parametric studies give an overview over the influence of the force angle and $h / l$ ratio parameters on the forces in the ends of the longline. This study also shows that in the case of high loads a load reduction could be achieved by an extension of the LL. Thus, large maximal sag leads to load reduction.

To provide detailed information for the additional loading on the support structure of offshore wind energy converters, a detailed examination of the sea states should be taken into account. Factors like wave height and direction as well as current speed and direction will influence the forces. To estimate the occurrence of worst-case scenarios, a dynamic analysis should be performed and would be useful for providing information about inertia forces.

\subsubsection{Seaweed Cultivation Devices}

In the German North Sea, macroalgal farming of brown algae in offshore environments was launched by the German Government in 1993 and conducted at the marine Station of the Biologische Anstalt Helgoland (BAH) off the island of Helgoland, North Sea (see also Sect. 3.1 "Offshore Aquaculture with Extractive Species: Seaweed and Bivalves"). One major component of this study was to develop an appropriate technical device to grow macroalgae. The system had to withstand the harsh environmental conditions of the German North Sea shelf, where maximum wind speeds can be $150-180 \mathrm{~km} / \mathrm{h}$ and wave amplitudes commonly 
reach 5-8 m during storms. Investigations were resumed in 2002-2004 aiming at using this new aquaculture technology in conjunction with offshore wind farms (Buck 2004; Buck and Buchholz 2004a).

To get more insight into the cultivation of plants under hostile conditions in multi-use with offshore wind farms, several known carrier designs for algal culture were built and deployed, subsequently resulting in the final modular construction named the "Offshore-Ring" (Fig. 11.32a-1; Fig. 11.33a-p; see also see also Sect. 3.1 "Offshore Aquaculture with Extractive Species: Seaweed and Bivalves"). The performance of the various test designs under offshore conditions, length changes and, where possible, the biomass yield of Sugar kelp Saccharina latissima (Laminaria saccharina) on these constructions were investigated at different locations. The results are of high importance for the future utilisation of exposed offshore locations in combination with offshore platforms, especially when considering multi-user concepts in offshore areas combining wind farm installations (e.g. Buck 2002; Krause et al. 2003; Buck et al. 2003, 2004).

Experimental offshore farming of Sugar kelp was first conducted in 1994 and 1995 at Helgoland (North Sea, Germany) as well as in 2001 and 2002 near the island of Sylt and in the outer estuary of the river Weser (17 nautical miles off the coast of the City of Bremerhaven). The study sites are characterized by various hydrographic features. Peak wind velocities of $\geq 6$ Beaufort and $\geq 8$ Beaufort were noted down during years of the experimental studies.

Four different cultivation systems were designed and deployed in the study area in order to find the most suitable design for offshore use (Buck and Buchholz 2004a). These included longline (Fig. 11.32e), ladder ("tandem longline") (Fig. 11.32f), grid (Fig. 11.32g) and a ring-shaped design (Figs. 11.32a and $11.33 \mathrm{a}-\mathrm{p}$ ) for attachment of algae seeded culture lines. Each of these different constructions varied in mooring design, floatation and culture units. Concrete blocks of 2.5, 4 and $4.5 \mathrm{t}$ were employed in a single, twin or radial mooring geometry in order to securely moor the carrier constructions. The ladder and grid constructions were oriented parallel to the main direction of the tidal current. Starting from the anchor stones chains with a service load (SL) of at least $8 \mathrm{t}$ were used to connect the concrete with the mooring line (SL $12 \mathrm{t}$ ). The service loads corresponded to a threefold collapse load. The mooring line itself held the culture unit, which was designed to float at or $1-1.5 \mathrm{~m}$ below the water surface. The floating system consisted of ball-like floats or pencil-like fenders, which were connected by ropes to the culture unit to provide sufficient buoyancy. All connections between ropes, chains, floats and concrete blocks contained triple rings (SL 6 t), shackles (SL 6.5 t), warbles (SL 6.5 t) and thimbles, in case of eyes at rope ends. The longline design consisted of a $50 \mathrm{~m}$ long, horizontal carrier rope anchored by a $4 \mathrm{t}$ twin mooring system. It served to fasten culture lines perpendicular to the water surface, each kept straight by a concrete weight $(2.5 \mathrm{~kg})$ (Fig. 11.32e). This method had been successfully employed by Kain and Dawes (1987) and Perez et al. (1992).

Between December 1994 and April 1995, a total of $140 \times 5 \mathrm{~m}$ long culture lines with young Saccharina sporophytes were transferred from the laboratory and 


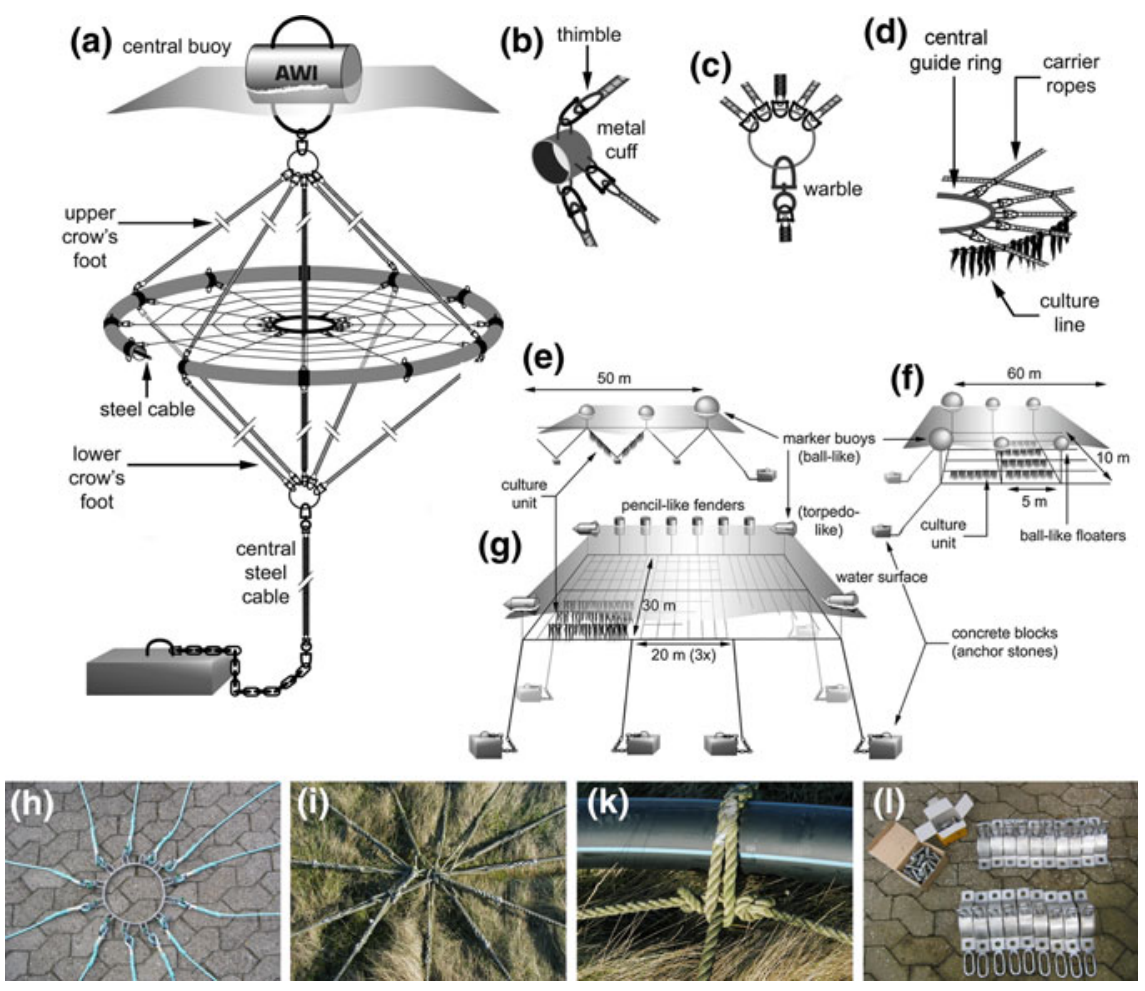

Fig. 11.32 a-i Development of system design to culture seaweed and invertebrates in offshore wind farms. a The successful ring design for the culture of Laminaria at offshore locations; major elements of the system design are magnified in $\mathbf{b}$ metal cuffs, to which the crow's feet and the ring tube are attached; $\mathbf{c}$ the transition between central steel cable of the mooring and that of the lower crow's foot, and $\mathbf{d}$ the central guide ring with attached carrier rope and culture line; e longline construction with perpendicular culture unit; $\mathbf{f}$ ladder construction, with culture lines knotted between the "steps"; $\mathbf{g}$ grid design with rectangular culture units; $\mathbf{h}$ central guide ring of the "Offshore-Ring" after modification; $\mathbf{i}$ central junction point for the carrier ropes in the first "Offshore-Ring" version; $\mathbf{k}$ interloops at the ring frame to connect the carrier ropes (first version) and $\mathbf{l}$ metal cuffs to connect carrier ropes (after modification): a-g Modified after Buck and Buchholz 2004a, h-l AWI/Prof. Dr. Bela H. Buck

knotted at $3 \mathrm{~m}$ intervals to the horizontal carrier rope. Later, two adjacent $3 \mathrm{~m}$ long culture lines were connected at their lower ends (V-shape). S. latissima on these lines were $2-3 \mathrm{~mm}$ at transplantation. The ladder design was $60 \mathrm{~m} \times 10 \mathrm{~m}$ in size and was positioned horizontally $1 \mathrm{~m}$ below the sea surface by 24 concrete weights (each $1 \mathrm{~kg}$ under water) and air-filled buoys on the surface (Fig. 11.32f). 1101 ball-shaped buoys at the corners of the ladder construction were meant to keep it afloat. It was suspended between four anchor stones ( $4.5 \mathrm{t}$ ) in a double twin mooring shape. $5 \mathrm{~m}$ long culture lines were knotted in between the "steps". Experience from the "ladder" went into the construction of a grid system. The grid 

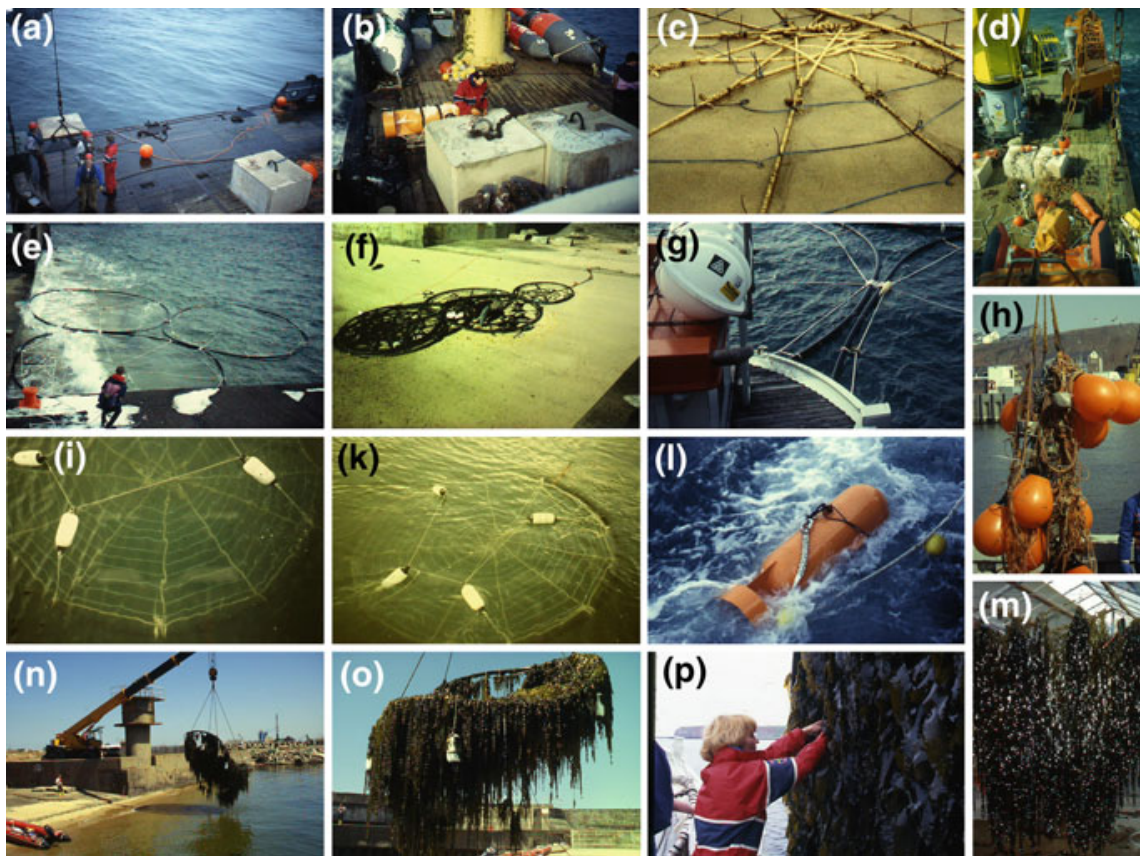

Fig. 11.33 a-p First offshore seaweed cultivation project in the mid-1990s. a Deployment of concrete blocks as mooring device using an offshore buoy layer; b buoy layer with mooring equipment; $\mathbf{c}$ central part of the first ring construction showing carrier ropes; $\mathbf{d}$ set-up of mooring devices for the first deployment of the "Offshore-Ring"; e first floating tests with ring devices and its potential combination; $\mathbf{f}$ small ring versions at the pier; $\mathbf{g}$ deployment of various ring devices in combination; $\mathbf{h}$ entanglement after a storm event; first "Offshore-Ring" several nautical miles off the Island of Helgoland with young Laminarian sporophytes in a $\mathbf{i}$ submerged and a $\mathbf{k}$ floating mode; $\mathbf{l}$ flow meter for the drag measurements offshore; $\mathbf{m}$ drying plants after harvest; $\mathbf{n}$ harvest of the first "Offshore-Ring" in the harbour of Helgoland; o preparation of Saccharina/Laminaria harvest of the ring formerly located at Helgoland Roads in the harbour of Helgoland. The ring was lifted from the water by a land-based crane; $\mathbf{p}$ control of the ring construction and length measurements of farmed plants. Images AWI/Dr. Cornelia Buchholz

construction had been in use off the Isle of Man (Kain 1991) and in Brittany (Perez et al. 1992). Based on the above and our own experiences, a grid system depicted in Fig. 11.32g was set up. The grid measured $60 \mathrm{~m} \times 30 \mathrm{~m}$ and was submerged at a depth of $1.2 \mathrm{~m}$. The grid was designed to hold $1400 \mathrm{~m}$ of culture line in an area of 0.18 ha. A radial mooring system was used with 10 concrete blocks $(2.5-4.5 \mathrm{t})$. The frame material employed tube was a "Herkules" rope, which is commonly used in commercial fisheries. This rope contains in its core several subcores, each made of six strands of steel. This way the rope was heavier than the surrounding seawater, which reduced the risk of potential damage at the weight attachment points. The inner supporting ropes of the construction were made of Polystar, a mixture of polypropylene and polyethylene, a material with excellent references in steel 
grades. Four metal torpedoes served as buoyancy devices at the corners, another 72 floats were pencil-like fenders with $23 \mathrm{~kg}$ buoyancy each. The final ring device (Patent No. PCT/DE2005/000234; Buck and Buchholz 2004b) had a total diameter of $5 \mathrm{~m}$ and consisted of polyethylene tubes with a $10 \mathrm{~mm}$ thick wall and a diameter of $110 \mathrm{~mm}$ that were welded to rings (Figs. $11.32 \mathrm{a}-\mathrm{d}, \mathrm{h}-\mathrm{l}$ and $11.33 \mathrm{a}-\mathrm{p}$ ). The rings were weighed down by a steel cable (30 $\mathrm{mm}$ in diameter) inserted into the tube and obtained their buoyancy through eight elongated fenders ( $23 \mathrm{~kg}$ buoyancy each). They consequently floated at a depth of 1.2-1.5 m. Carrier ropes were suspended radially and $80 \mathrm{~m}$ of culture line could be fastened like cobwebs on each ring. A crow's foot was used to fasten the ring on a common mooring system. Due to permanent chafing of the carrier ropes with the fender ropes and because the fenders themselves got entangled with each other a modified system was developed. This consisted of one centre buoy (300 kg buoyancy) with a connected reverse crow's foot and a centre guide ring to prevent chafing of the mooring line with the carrier ropes (Fig. 11.32a, d). Furthermore, all radial splices, which connected the carrier ropes to the polyethylene tubes, were replaced with metal cuffs (Fig. 11.32b). Three loops were welded to these cuffs, one to the centre to fix the carrier ropes and the other two to the bottom and the top of the cuff, to connect both crow's feet. An important feature common to all constructions was their ability to adjust the depth of culture lines to $1-1.5 \mathrm{~m}$ as this appeared to prevent possible PAR and UV damage to the young algae while providing enough light for successful photosynthesis. Moreover, the most turbulent upper meter of the water column could thus be avoided.

In the following, an overview of technical experience with the different culture devices in the offshore environments of the German North Sea is given. With the longline design, only 65 of the 140 culture lines, which were fastened on the longline system, have been retrieved and 20 of these were evaluated for further investigation. Due to very stormy weather the farm had not been visited very often. Every chance during calm weather was used to change the horizontal carrier rope and supply new culture lines. The study, however, revealed that the weights on the culture lines were not sufficiently heavy so that they were frequently tossed across the carrier line resulting in the removal of the young plants by friction and causing them to become entangled. Other culture lines, consisting of three twisted strands, were untwisted by the current and turbulences and consequently the individual strands were torn. Some improved performance of the longline was obtained by connecting pairs of only $3 \mathrm{~m}$ long culture lines at the lower end like a V-shape. Length data used here were taken from these lines. The ladder construction revealed problems pertaining to the durability of the frame material, the attached weights being potential breaking points. Moreover, the $110 \mathrm{~L}$ buoys at the corners were very instable and had to be exchanged several times. These drawbacks were taken into account during the development of the grid system. The grid system proved much more stable compared to the "ladder" even though the mooring ropes could not be adjusted to their optimal length to accommodate the full tidal differences. The use of elongated fenders instead of ball floats protected the construction by better riding the swell, which resulted in continuous vertical movement, while the balls used 
previously had resulted in jerking behaviour that created substantially more stress on all the materials. Culture lines were knotted into the grid from a small rowing boat, a procedure that needed smooth sea and calm weather and could only be managed during the period of slack tide (maximum $30 \mathrm{~min}$ ). $880 \mathrm{~m}$ of culture line were transferred to the grid and later harvested. Finally, the "Offshore-Ring" was the best design. So far, individual rings of $5 \mathrm{~m}$ diameter showed a superior performance in comparison to the other tested carrier constructions. They remained stable and in place during all weather conditions, provided their moorings were tended regularly, at least after storms, which imposed some wear on them. In addition, they allowed equipment with culture lines to be performed onshore, the rings subsequently being towed to their mooring locations and fastened relatively quickly during slack tide. With the ring construction the harvesting period could be prolonged by moving complete rings onshore. Moreover, sampling of the seaweed culture was more easily done due to the possibility of heaving up the ring construction with a ship's crane.

To conclude, our experience is that the major key conditions for offshore culture were fulfilled such as the pre-cultivation of healthy plants that were well attached to the culture lines. Another key factor, i.e., reduction of mechanical abrasion, was a major problem on the longline system, because of high turbulences. Longline systems are hence considered unsuitable for macroalgal culture under offshore North Sea conditions. The ladder system was more apt to damage than the improved grid system, e.g., at the fastening points of weights, and should therefore also be rejected in future considerations. A further problem of all carrier constructions except the rings was the necessity to fix them at permanent offshore sites. This led to the logistic and cost problems of efficient transfer of sporelings from the laboratory (or hatchery facility) to the grow-out location as well as appropriate tending of the carrier system under the prevailing rough weather conditions. Labour requirements were also enormous. Every single culture line had to be fastened to the carrier system from a small rowing boat, and this was only suitably done during slack tide. Work was seriously impaired by the difficulty of getting ship time and divers, while also waiting for calm seas and all of this at the 30 min of slack tide and during working hours. The ring construction using its present dimensions has proven stable in offshore conditions (Helgoland Farm, Helgoland Roads, and Roter Sand). The new ring construction, with a central steel cable and central buoy, reduced tractive power and tension in high velocity currents and when being moved for sampling or harvest (Fig. 11.32a-d, h-1). The two crow's feet with the metal cuffs greatly prevented torsion of the ring when lifted. The depth of a ring could be adjusted by insertion of steel ropes into its cavity and the buoyancy of the central buoy could also be adjusted by changing its size. This way the ring could be kept at an appropriate depth to avoid exposure to stressful surface turbulence and admit sufficient light for algal photosynthesis even with increasing weight of algae.

A major advantage of the ring system compared to the other systems was that the ring could be equipped onshore with $80-100 \mathrm{~m}$ of culture line and subsequently towed to the mooring site, where it could easily be moored by the ship's crew. The reverse took place at harvest time and was also most advantageous. The ring 
diameter of $5 \mathrm{~m}$ could be managed by cranes from relatively small vessels. This way the algae on the ring construction could be examined at most dates and at harvest while in the worst case it was at least possible to tow the ring into the harbour, where a larger crane could lift it onshore. The described characteristics and the modular nature of the ring construction promise to make it a sensible and effective choice to be used in aquaculture situations where offshore wind farms are located (Buck 2002; Krause et al. 2003; Buck et al. 2003, 2004; Buck and Buchholz 2004a). Moreover, one could transfer the technique to less developed countries using suitable materials, e.g. bamboo or rattan, and the craftsmanship of local people. However, lifetime and stability of these systems using materials in these countries will have to be tested before large-scale employment.

Concerning the most favourable location for aquaculture of macroalgae, our experiments suggest that fairly exposed sites with rough conditions are suitable, however, only if the carrying support structure is sufficiently rigid to withstand the rough to extreme conditions encountered in most of the trials. Aquaculture in sheltered waters must avoid shallow areas, like in the Sylt backwaters, because of possible contact with the seabed and the high siltation and suspended solid load which creates low light conditions. Any location selected for seaweed culture should have a minimum depth of 5-8 m. Offshore areas, such as "Roter Sand" and Helgoland Roads, seem to be well-suited for future commercial-scale seaweed culture.

\subsubsection{Fish Cages in Multi-use with Offshore Wind Turbine Foundations}

\subsubsection{Integrating a Fish Cage into a Tripod Foundation}

So far, no findings exist on the question how fish cages interact with offshore wind energy converters and how large additional forces could grow in the presence of waves (Goseberg et al. 2012). To investigate the potential multi-use of offshore wind turbine foundations with offshore submersible fish cages the offshore wind farm "Veja Mate" was taken as a case study site. Next to different foundation types, a tripile foundation of "Bard Engineering" was used to erect the $5 \mathrm{MW}$ turbines and towers (Fig. 11.34a-g). The advantage of the triple foundation in direct comparison to other foundation types is that due to its three-monopile character with a rigid platform on top it creates an open space under the platform above the water surface down to the seabed marked-off by the three foundation piles (Fig. 11.34d-g). The initial idea was to design different cages types to be installed exactly in this open space allowing submerging it towards the seafloor while also enabling it to be in a floating mode during maintenance and harvest procedures (Figs. 11.35a-d and 11.38a, b, e, f). 

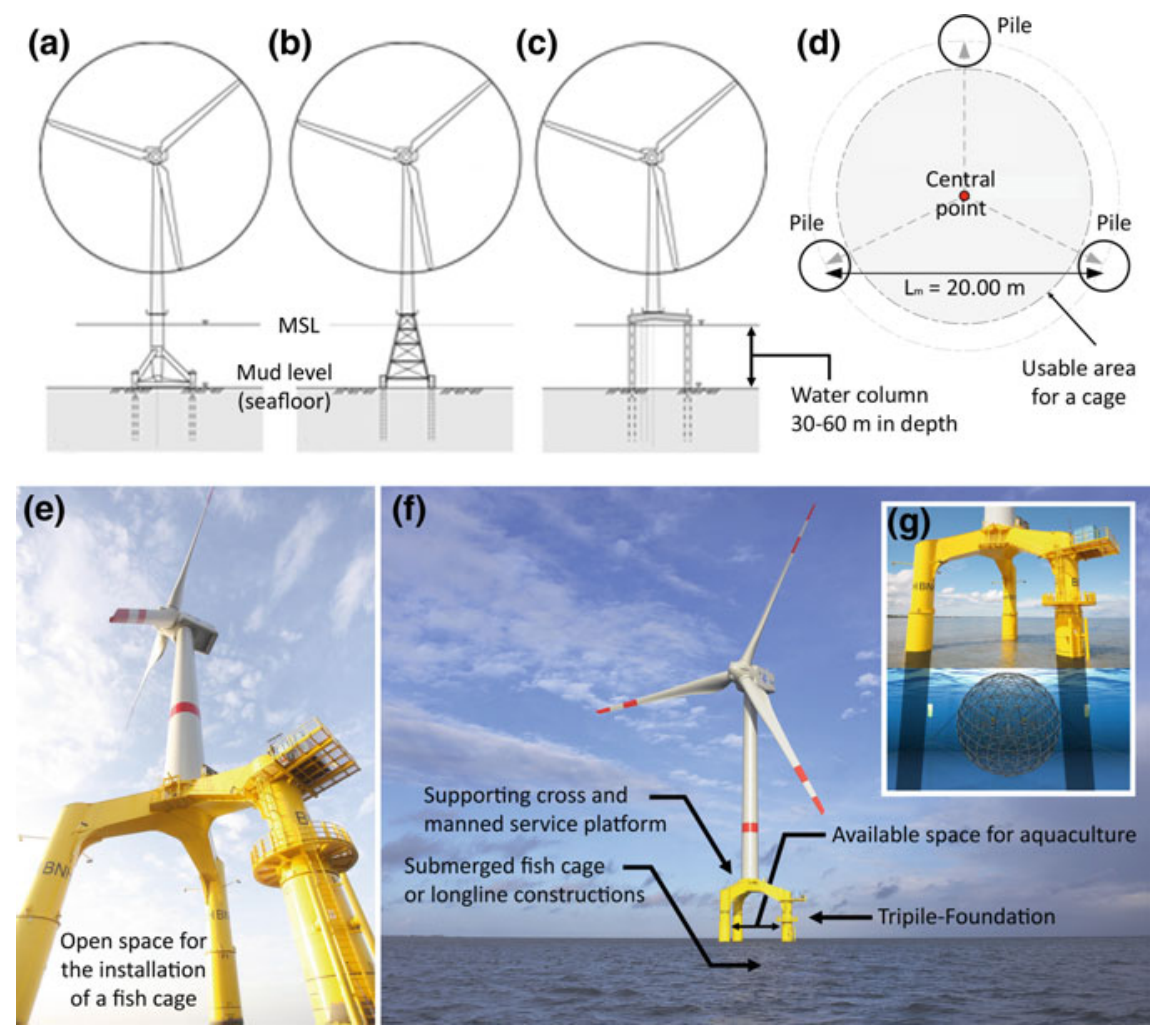

Fig. 11.34 a-e Support structures (foundations of offshore wind energy installations) and tripile constructions for the co-use for fish cages: a tripod; $\mathbf{b}$ jacket; $\mathbf{c}$ tripile; $\mathbf{d}$ usable horizontal section of the area under the tripile foundation; e shows the open space within a tripile foundation to be used for aquaculture purposes; $\mathbf{f}$ displays a lateral view of the "BARD-Wind-Turbine" and the access to the fish cage; $\mathbf{g}$ displays a photo animation and gives an idea how a fish farm, such as an "Aquapod", could be moored below. Modified after Buck and Krause 2012; Buck et al. 2012. Images (a-d) Dr. Nils Goseberg, (G) OFT 2010

In close cooperation with partners from wind industry, fishery and science it was investigated to which extend multi-use synergies among different stakeholders (wind, aquaculture) can be realized at a supporting structure of an offshore wind energy installation (Hundt et al. 2011). In this context, the technical design and the integration of cages in the support structure was put forward. Alternatively, if stand-alone and self-supporting structures can be set-up in the open field between wind turbine foundations moored on the seafloor and eventually partly to a foundation.

The investigations concentrated on the following aspects: (1) Fundamental development of a cage basis, (2) pre-design of the suggested fish cage(s) construction, (3) investigations on the designed cages in a current flume and a wave tank, and (4) design reiteration of the pre-designed cages following the current 


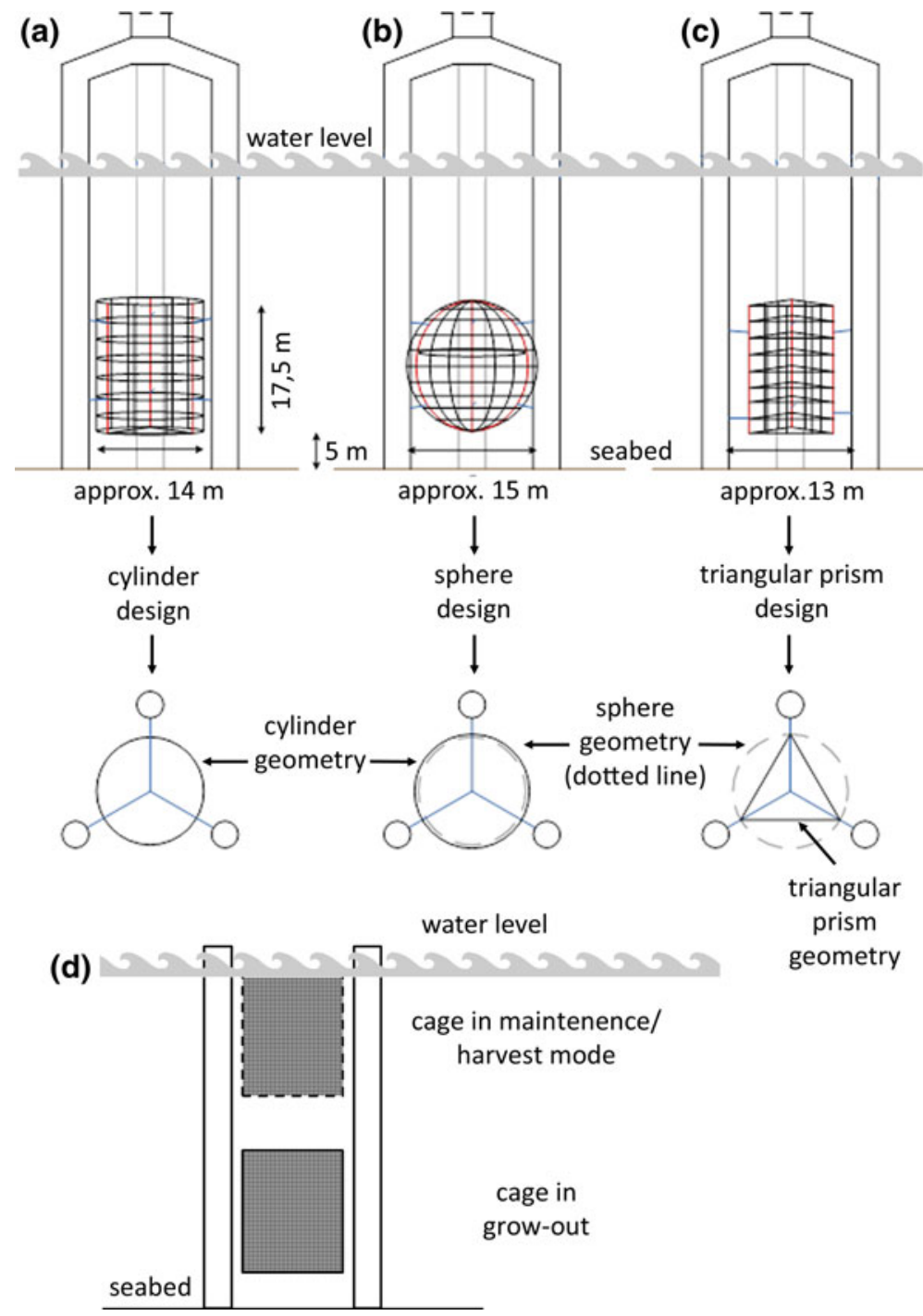

Fig. 11.35 a-b Support structures (tripile foundations of offshore wind energy installations), the integration of different cage designs and its geometric views. a Cylinder cage design; b sphere cage design; $\mathbf{c}$ triangular prism cage design; $\mathbf{d}$ operation modes (floating, submerged) of the cage in the tripile. Modified after Buck et al. (2012). Image a-c Jan Dubois

flume and wave tank results to optimise the final cage design. However, the evaluation of the potential impact of the additional loads due to the attached cage structures on the dimensioning of the support structure was not focused on. The basic data of the test site at "Veja Mate" are shown in the following table (Table 11.2). 
Table 11.2 Site specific data at the case study site "Veja Mate"

\begin{tabular}{|c|c|c|c|c|c|c|c|}
\hline \multicolumn{8}{|c|}{ Site specific data at the offshore wind farm "Veja Mate" } \\
\hline Position & \multicolumn{7}{|c|}{$\begin{array}{l}\text { (1) } 54^{\circ} 20^{\prime} 30.07^{\prime \prime} \mathrm{N} 05^{\circ} 49^{\prime} 43.30^{\prime \prime} \mathrm{E} \\
\text { (2) } 54^{\circ} 22^{\prime} 36.71^{\prime} \mathrm{N} 05^{\circ} 54^{\prime} 34.61^{\prime \prime} \mathrm{E} \\
\text { (3) } 54^{\circ} 16^{\prime} 29.11^{\prime \prime} \mathrm{N} 05^{\circ} 49^{\prime} 38.99^{\prime \prime} \mathrm{E} \\
\text { (4) } 54^{\circ} 16^{\prime} 29.44^{\prime \prime} \mathrm{N} 05^{\circ} 54^{\prime} 37.32^{\prime \prime} \mathrm{E}\end{array}$} \\
\hline Water depth $(\mathrm{m})$ & \multicolumn{7}{|c|}{$39-42$} \\
\hline $\begin{array}{l}\text { Significant wave heights divided in } \\
\text { three trimester }(\%)(\mathrm{m})\end{array}$ & 1 & 2 & 3 & 4 & 5 & 6 & $>6$ \\
\hline November-February & 17.4 & 48.3 & 31.7 & 15.4 & 0.8 & 0.4 & $<0.1$ \\
\hline March-June & 36.8 & 44.4 & 13.8 & 4.6 & 0.3 & 0.2 & $<0.1$ \\
\hline July-October & 39.2 & 40.7 & 13.6 & 4.5 & 1.5 & 0.6 & $<0.1$ \\
\hline Extreme events (m) & \multicolumn{7}{|c|}{$10.81 \mathrm{~m}$ within 50 years } \\
\hline Current velocity $\left(\mathrm{m} \mathrm{s}^{-1}\right)$ & \multicolumn{7}{|c|}{ Max. tidal current 0.98} \\
\hline
\end{tabular}

To proceed with the development of different cage models the area between the three piles of the tripile geometrically usable was taken into account for the maximum size of the cage (Figs. 11.34d and 11.35a-c). Additionally, the cage had to be planned in a size that would fit between the piles to get it in and out for installation, maintenance and repair. Therefore, next to the size of the cage the coupling between cage and piles had to be planned as well to get the maximum dimension of the entire cage construction. The following additional parameters and characteristics were taken into account during the fundamental development phase:

(1) simple cage design with only a few crossbars to ease construction and installation,

(2) the height of the cage depends on the depth of the water to allow fully submergence and also the draught (up to $8 \mathrm{~m}$ ) of the maintenance vessels when accessing the wind turbine (Figs. 11.35d 11.38a, b, e, f),

(3) the attachment mechanism (e.g. rails) mounted exteriorly of the cage to avoid any interference with the net,

(4) optimizing the coupling design symptoms of fatigue that were not primarily considered as the malfunction of the maximum load on it,

(5) the attachment device should not interfere with the sacrificial anode at the piles,

(6) the cage should be additionally fixed to the support cross and to an anchor at the seafloor,

(7) the coupling of the cage with the pile can be realized via rigid or flexible attachments or independently via an external mooring. The various options were reduced to a rigid attachment to the piles of the offshore wind energy foundation, as flexible couplings via ropes or cables could lead to an entanglement,

(8) to allow a preferably large surface area for flatfish to settle. Therefore, additional plane levels were integrated into the inner parts of the cage, which also supported the bracing of the cage and therefore supported structural stability, even if the conditions of production were more complicated as well as the loads on the entire cage induced through currents and waves, 
(9) to identify the overall loads the load forces of the cage structure and the load forces of the entire net harness (including the mesh size) were superposed.

Cylinder design: A cylinder cage design perfectly fits into the inner part of a tripile and the connection points from the cage to the piles are adjustable in height. The distance from the cage top to the cage bottom was calculated with $17.5 \mathrm{~m}$. Further, to avoid an additional scouring in the vicinity of the piles at the seafloor a distance of $5 \mathrm{~m}$ from the cage bottom to the seafloor in the submerged mode was provided. The resulting cage diameter was calculated being $14 \mathrm{~m}$ leading to a cage volume of about $2650 \mathrm{~m}^{3}$ (Figs. 11.35a and 11.36a-e).

The cylinder design was calculated with and without internal levels. The current regime within the entire foundation-cage construction would be changed

(a)

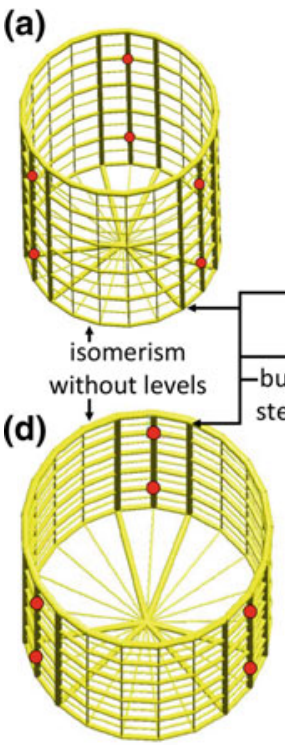

(g)

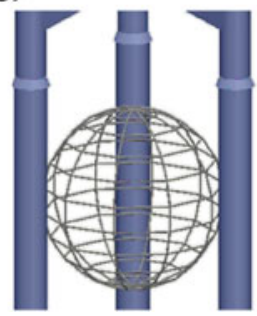

(b)
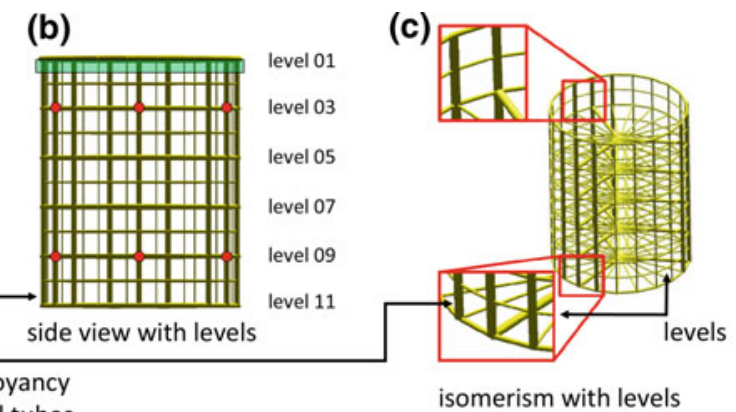

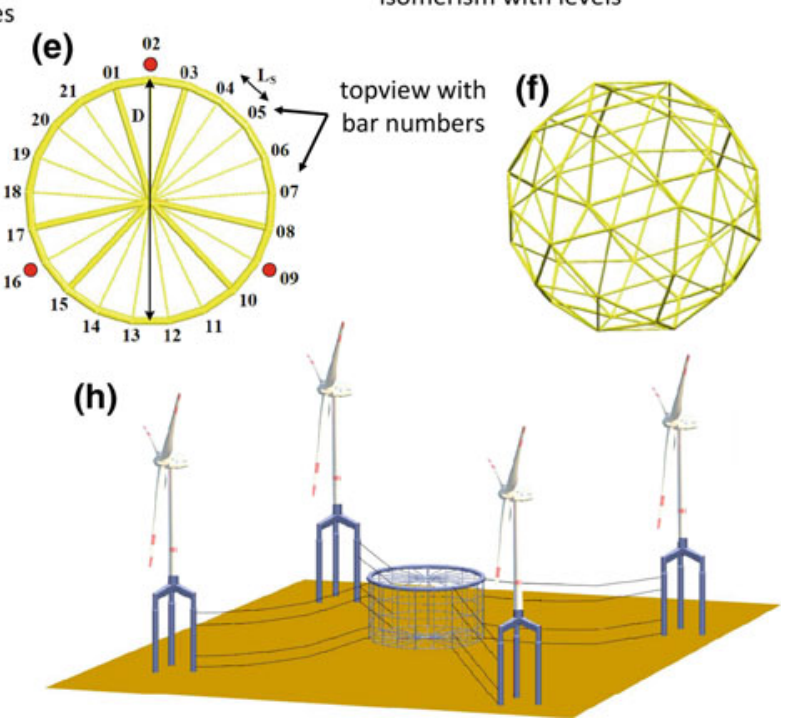

Fig. 11.36 $\mathbf{a}-\mathbf{h}$ Cage designs integrated into the tripile foundation as well as outside of the tripile. a-e Visualisation of cylinder-like cages with and without horizontal levels, support (bearing) points are displayed in red and the buoyancy device is shown in dark green; $\mathbf{f}$ cage design with a triangular bar interconnectedness of the spheres' surface; $\mathbf{g}$ cage design with meridional bar direction; $\mathbf{h}$ cage concept not integrated into a tripile foundation but installed in the centre of various wind turbines and connected to the foundations. Modified after Buck et al. 2012. Images Jan Dubois 
significantly which in turn could lead to more stress on the installation and the farmed candidates. The cage structure has additionally vertical steel pipes, which also act as buoyancy device.

Spherical design: The coordination of crossbars and the entire skeleton to design the spherical structure and its attachment device for the foundation piles simply depends on the height of the cage. We planned to connect the cage with the piles at least at six points to absorb axial forces and to avoid the generation of a kinematic positioning. The connections to the support structure were installed in the upper and lower third of the sphere (Figs. 11.35b and 11.36f, g). The cage volume of the sphere is approx. $1,700 \mathrm{~m}^{3}$.

As levels in the internal space would create wedge-shaped units in the upper and the lower third of the sphere, further developments would not include additional levels. Further, these levels would not explicitly improve the stability of the cage. The cage design with meridional bar direction (Fig. 11.36g) was rejected due to the sharp angles on the top and the bottom of the age as well as due to its poor load-bearing behaviour. Another design of the skeleton of the cage was the use of a triangular bar interconnectedness of the spheres' surface (Fig. 11.36f).

Triangular Prism: The height was calculated to be $17.5 \mathrm{~m}$ and an edge length of 13 m leading to a volume of about $1,250 \mathrm{~m}^{3}$ (Fig. 11.35b). This is a comparably small volume compared to the other cages, however, the advantage of this design is the reduced tensile loads on the horizontal crossbars through the prevailing bearing forces as the three edge cage piles spread the forces over the entire cage height. Another disadvantage of this cage design is the existence of the three edges along the entire cage height. In worst case scenarios with high waves and strong current velocities these edges could function as energy focussing zones leading to the fact that the fish could be pushed against the net, which in turn could lead to stress and interference of the fish.

Tripile cage designs: This cage design relies on the structure of the tripile as the foundation piles also function as the outer piles of the cage holding the net. In comparison to the cylinder cage the height of the tripile cage would be only $15 \mathrm{~m}$ as the distance from the cage bottom to the seafloor will be increased by $2.5-7.5 \mathrm{~m}$ to avoid any scour effects. The volume of the cage would be $3,000 \mathrm{~m}^{3}$.

Large-scale cage design: These large cages are designed with a volume of approx. $20,000 \mathrm{~m}^{3}$ and could be installed in the vicinity of the tripile and connected between 3 and 4 foundations (Fig. 11.36h).

\subsubsection{Impact of the Integrated Cage on the Support Structure}

To integrate a cage into the internal space of tripod foundation it is of the utmost importance to get more insight about the impact of the fish cage on the tripile-dynamics, such as an oscillatory instability of the foundation piles between the water surface and the seabed.

To start the laboratory experiments BARD Engineering constructed a model of the tripile, which was identical to the tripile used at the offshore wind farm 
"Veja Mata". This model was scaled down to a size of 1:40 and was used to integrate the new cage designs. After the first experiments were conducted in the wave flume of the Ludwig-Franzius-Institute for Hydraulic, Estuarine and Coastal Engineering we identified that the piles could under extreme conditions tend to local vibrations (Fig. 11.37a). This effect was even intensified on the foundation piles when integrating the cage models (Fig. 11.37b-d). Additionally, we found that rigid constructions would lead to a static fatigue of the connection devices between the cage and the piles due to the constraining force resulting from the differential deformation of the piles of the tripile. A solution would be a more flexible coupling element (e.g. spring bars) as well as a certain clearance between the different installations to avoid that all three piles at the same time transfer the forces through their vibration on the cage (Figs. 11.37e-g and $11.38 \mathrm{c}, \mathrm{d}$ ).

\subsubsection{Supporting Devices}

\subsubsection{Offshore Seed Collector and Grow-Out Devices}

In order to find suitable offshore locations, where the biological background conditions were suitable for both wind and aquaculture farms, in Project No. 2 "Open Ocean Aquaculture" and 3 "Roter Sand" a number of offshore wind farm sites within the German Bight were surveyed in 2002. Subsequently, nine locations 10-40 nautical miles off the German North Sea coast were selected for further investigation (Fig. 11.7a). Site criteria for this survey were the vicinity to a planned wind farm, the distance from the coast, the water depth, the water quality, and the substratum. In January 2003, the selected offshore locations were equipped with test moorings to investigate the potential of offshore seaweed, mussel and oyster farming. For this purpose an offshore seed collector as well as grow out device for extractive species was developed (Fig. 11.39a, b).

The mooring's marker buoy had a buoyancy of $300 \mathrm{~kg}$ and was connected to a 2 ton concrete block with a $22 \mathrm{~mm}$ steel wire and a heavy buoy chain (Fig. 11.39a). At $3 \mathrm{~m}$ below the surface a $1 \times 1 \mathrm{~m}$ metal frame was fixed to the wire, providing a holding unit for two spat collectors clamped into the frame. The depth was chosen because of multi-annual data (Walter and Liebezeit 2001; Joschko et al. 2008) indicating little settlement in depths $<4 \mathrm{~m}$. Each collector consisted of a polypropylene carrier rope $(10 \mathrm{~mm})$ with four inserted transverse elements to enlarge the surface area. The elements were made of $15 \mathrm{~cm}$ long pieces of the same polypropylene rope, which were frayed manually in 1100 single fibres to produce a bow-tie-like bundle. This type of collector is equivalent to the type used by Tortell (1976) and Dare et al. (1983) and has proven successful in its ability to attract mussel spat in tens of thousands of individuals per meter (Walter and Liebezeit 2003). Once a month if possible (February, March, April, May, July, September), samples were collected on a 5-day cruise using the research vessels $R V$ Heincke, $R V$ Uthörn, and RB Remzy. All 

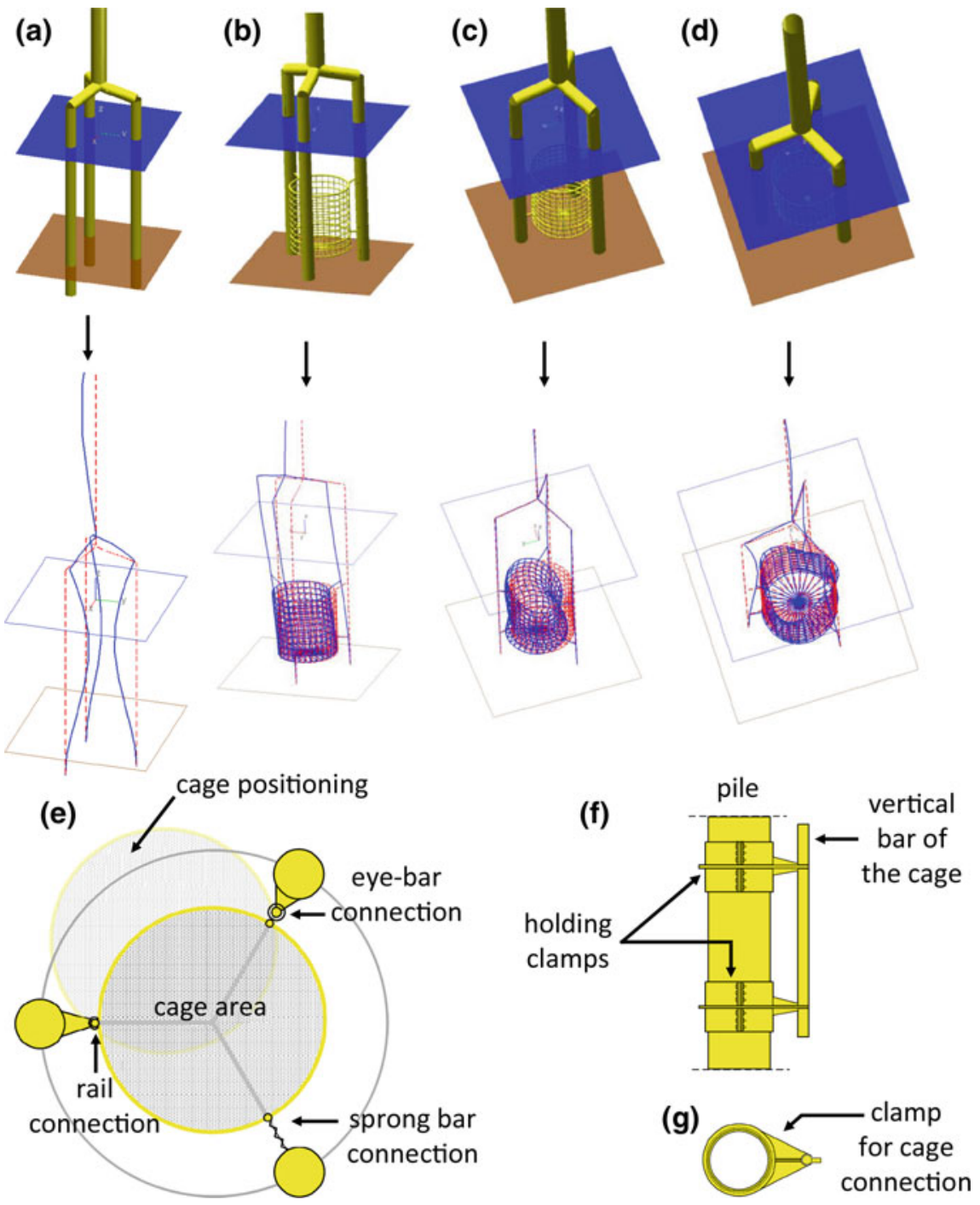

Fig. 11.37 a-g Vibration of the tripile and the connected cylinder design cage and connection points. a bending with local vibration (tripile without cage); b-d bending with local vibration (tripile with cylinder cage) showing cumulative effects; e top view including different connections from cage to tripile; $\mathbf{f}$ pile with connecting clamps; $\mathbf{g}$ top view of a clamp. Modified after Buck et al. 2012. Images Jan Dubois

moorings were deployed adjacent to proposed wind farms. For safety reasons they were placed at least 1 nautical mile from the wind farm areas.

At a later stage a second version of an offshore test device for mussel seed collection was developed and tested during the Project No. 5 "MytiFit". Figure $11.39 \mathrm{c}-\mathrm{e}$ shows the new version of the test device. 
(a)

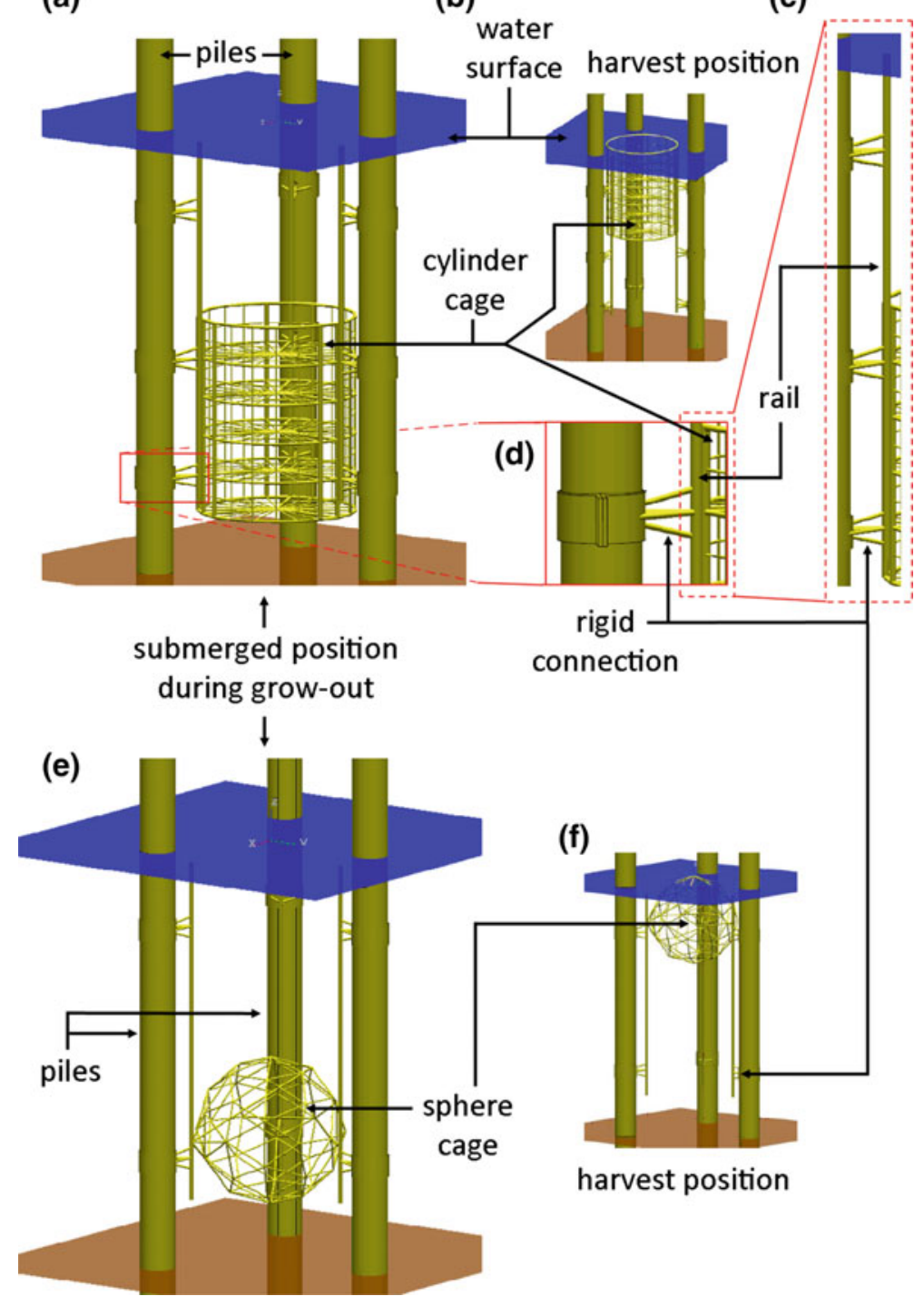

Fig. 11.38 a-f Cage connections and cage positions during maintenance/harvest and grow-out. a cylinder cage in grow-out position; $\mathbf{b}$ cylinder cage in maintenance and harvest position; $\mathbf{c}$ and d enlargements of the cage-rail-pile connection; e sphere cage in grow-out position; $\mathbf{f}$ sphere cage in maintenance and harvest position; Modified after Buck et al. 2012. Images Jan Dubois

\subsubsection{Underwater Inspection Device}

The underwater inspection device is a camera system, which helps the farmer to inspect his longline or tube system and being independent in this need to order a 

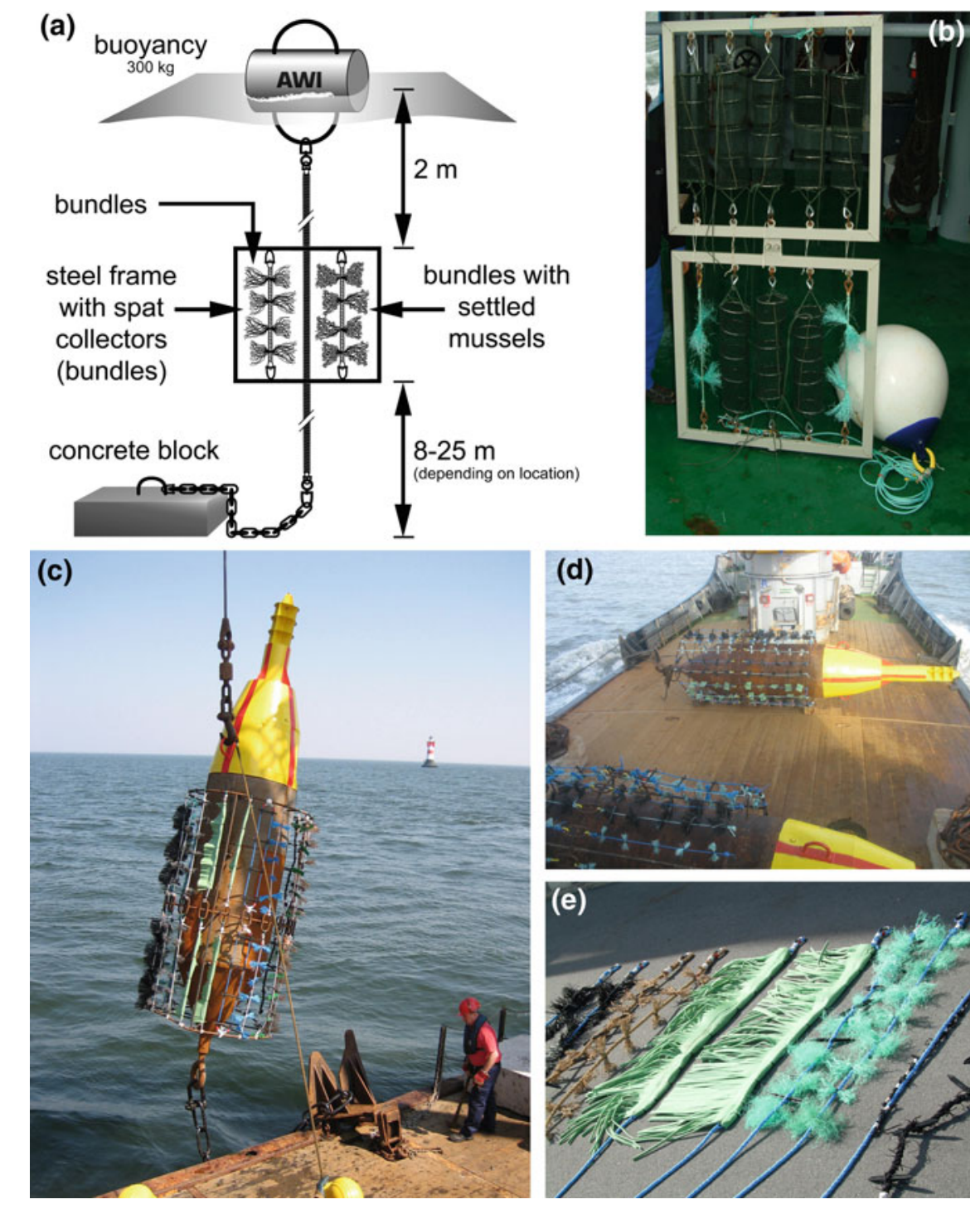

Fig. 11.39 a-e Spat collecting and grow-out devices used for offshore multi-use projects. a Offshore spat collector "First Generation" with holding supports for seed collectors and mussel spat (modified after Buck 2017); b Same mooring device for offshore oyster tests (Photo AWI/Prof. Dr. Bela H. Buck); c Offshore spat collector "Second Generation" (modified after Brenner et al. 2007); d New collector buoys during transfer at sea (Photo: AWI/Thomas Manefeld); e Collector types tested at the offshore wind farm site (Photo: AWI/Thomas Manefeld)

scientific diving team (Buck and Wunsch 2005; Patent: DE 102005020 070). The camera device was developed to allow the farmer to inspect the culture candidate suspended in the water column, while at the same time taking samples 

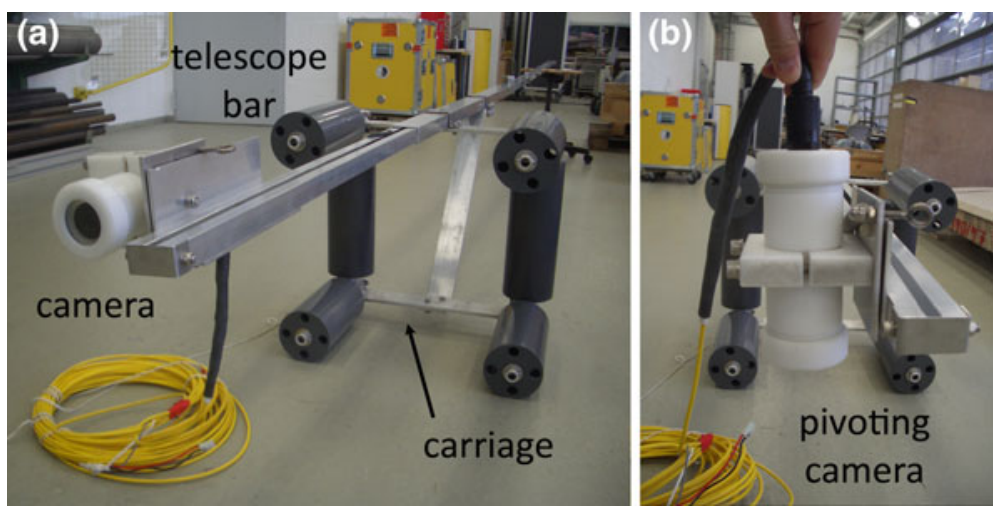

Fig. 11.40 a-b Inspection device for under water constructions including a positioning system. a Shows the complete device with the camera and the carriage, which wheels over the offshore mussel longline and tube system for inspection; b displays the pivoting equipment for the digital camera (Photos AWI/Prof. Dr. Bela H. Buck, modified after Buck and Wunsch 2005; Patent: DE $102005020070)$

(Fig. $11.40 \mathrm{a}, \mathrm{b}$ ). The camera was mounted to a pivoting arm to enable $360^{\circ}$ view and was adjustable to the depth of the backbone of the longline. The complete inspection system was used to wheel over the longline or to move a small carriage adapted to the width of a long tube. The development of the device was conducted during the Project No. 3 "Roter Sand" and was modified in Project No. 6 "AquaLast".

\subsubsection{Automated Saccharina Seeding Tank}

To ease the cultivation of Saccharina during lab-phase and to allow a several $100 \mathrm{~m}$ long seeding rope as substrate for the sporophyte various "curtain"-systems were developed (see also Fig. 11.3c). Here, a tank with rotating drums was set-up to ease handling, allow a constant seeding while at the same time enable the use of long ropes, thus avoiding the interconnecting of several short pieces of substrate (Fig. 11.41a, b). However, the main purpose of this system is that the plants experience a certain current due to the rotation and therefore adapt to a minimum current. The advantage is that due to this current, which can be increased by accelerating the rotation velocity of the drums, leading to an adaptation of the holdfast of the plants to more hostile environments. When transferring the plants at sea in high energy environments plants will not detach from its substrate (Buck and Buchholz 2005). 

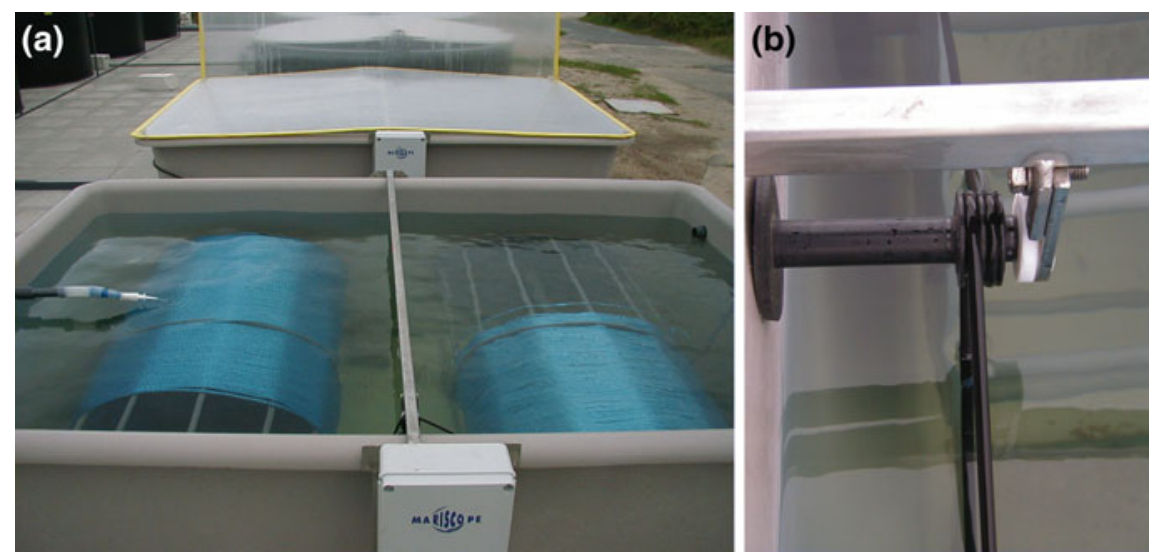

Fig. 11.41 a-b Automated seeding and on-growing device for Laminaria sp. culture. a Tank with rotating drums equipped with the seeding line. $\mathbf{b}$ Transmission shaft for the rotation with a power unit aside of the tank (Photos AWI/Prof. Dr. Bela H. Buck)

\subsection{Stakeholder Attitudes, Perceptions and Concerns}

While early studies mostly focussed on technological feasibility, environmental impacts, and profitability, the perceptions of stakeholders in the offshore realm have experienced increasing attention in the North Sea context. A number of studies have collected and analysed stakeholder attitudes, their interests and concerns over the past decade (Michler-Cieluch et al. 2009a, b; Michler-Cieluch and Kodeih 2008; Michler-Cieluch and Krause 2008; Vollstedt 2011; Wever et al. 2015; Michler-Cieluch 2009) (Projects No. 4 "Coastal Futures", Project No. 13 "Open Ocean Multi-Use"). Many of the stakeholders from the fishery and offshore wind industries, public administration, environmental groups and the research community have been part of the ongoing offshore research process since its very beginnings and still remain to date. Table 11.3 gives an overview of the most relevant actor groups in this context.

In the early process of identifying key stakeholders in the offshore realm, it became apparent that the types of actors involved in, or affected by offshore ventures clearly differ from stakeholders in coastal areas, and so do their interests and concerns with respect to offshore uses (Krause et al. 2003; Michler-Cieluch 2009).

Coastal areas have a long history of a great variety of uses, so user patterns and stakeholder networks have naturally grown over a long time period. Offshore areas to the contrary have only recently experienced intense utilisation due to technological advancements. This resulted in conflicts, as new types of use emerged or intensified, while other uses are marginalized or even banned. The offshore wind energy sector has turned into a powerful, international player that has benefitted immensely from the current political agenda in Germany. Other users, such as fisheries, are pushed out of large areas of the ocean. Within this highly contested 
Table 11.3 Overview of stakeholder groups and corresponding institutions (modified after Vollstedt 2011)

\begin{tabular}{|c|c|}
\hline Stakeholder group & Detailed description of stakeholder group \\
\hline Fisheries & $\begin{array}{l}\text { - Fisheries association } \\
\text { - Fishing companies } \\
\text { - Mussel and aquaculture farms and producer }\end{array}$ \\
\hline Public administration & $\begin{array}{l}\text { - Regional and national public authorities concerned with nature } \\
\text { conservation, agriculture, fisheries, renewable energy and } \\
\text { environmental protection } \\
\text { - Water and shipping directorates } \\
\text { - Public authorities involved in maritime Spatial planning, ICZM } \\
\text { and authorization of offshore wind farms }\end{array}$ \\
\hline Offshore wind energy & $\begin{array}{l}\text { - Regional and national wind farm companies concerned with } \\
\text { planning, construction, maintenance and service of offshore } \\
\text { wind farms } \\
\text { - Wind farm associations }\end{array}$ \\
\hline $\begin{array}{l}\text { Environmental } \\
\text { organisations }\end{array}$ & $\begin{array}{l}\text { - Regional, national and international organizations engaged with } \\
\text { nature conservation, protection of the marine environment and } \\
\text { environmental protection }\end{array}$ \\
\hline Fish industry & $\begin{array}{l}\text { - Producer of frozen fish products for consumption } \\
\text { - Associations concerning fish processing, fish wholesale and fish } \\
\text { importers }\end{array}$ \\
\hline Marine technique & $\begin{array}{l}\text { - Companies and institutes involved in planning and construction } \\
\text { of maritime technology }\end{array}$ \\
\hline $\begin{array}{l}\text { Promotion of economic } \\
\text { development }\end{array}$ & $\begin{array}{l}\text { - Regional companies involved in business development and } \\
\text { project investment }\end{array}$ \\
\hline Research institutes & - Research institutes related to aquaculture and fishery \\
\hline
\end{tabular}

socio-political landscape, it is of overriding importance to understand the mind-sets of the actors involved, appreciate potential (beneficiary as well as harmful) impacts of their activities and interests, and identify, if possible, "win-win" solutions.

Recent studies point to a generally supportive attitude of the majority of stakeholders towards spatial and/or operational integration of marine aquaculture and offshore wind energy (Wever et al. 2015; Michler-Cieluch and Kodeih 2008; Vollstedt 2011). Many stakeholders that were consulted believe that the combination of a limited number of sustainable marine uses - such as offshore wind energy and fish farming - appears as an attractive solution to increasing, and competing demands for limited ocean space. Figure 11.42 displays the general acceptance of co-use of different interest groups as compiled by Michler-Cieluch and Kodeih (2008).

However, when it comes to the details of a hypothetical co-management scenario highly controversial attitudes, perceptions, concerns, and interests surface. Of overriding concern to many of the stakeholders are potentially harmful impacts of offshore aquaculture systems to the marine environment. In particular environmental agencies and organisations, but also researchers from a range of disciplines, are highly concerned especially about the impacts of nutrients on the benthic 


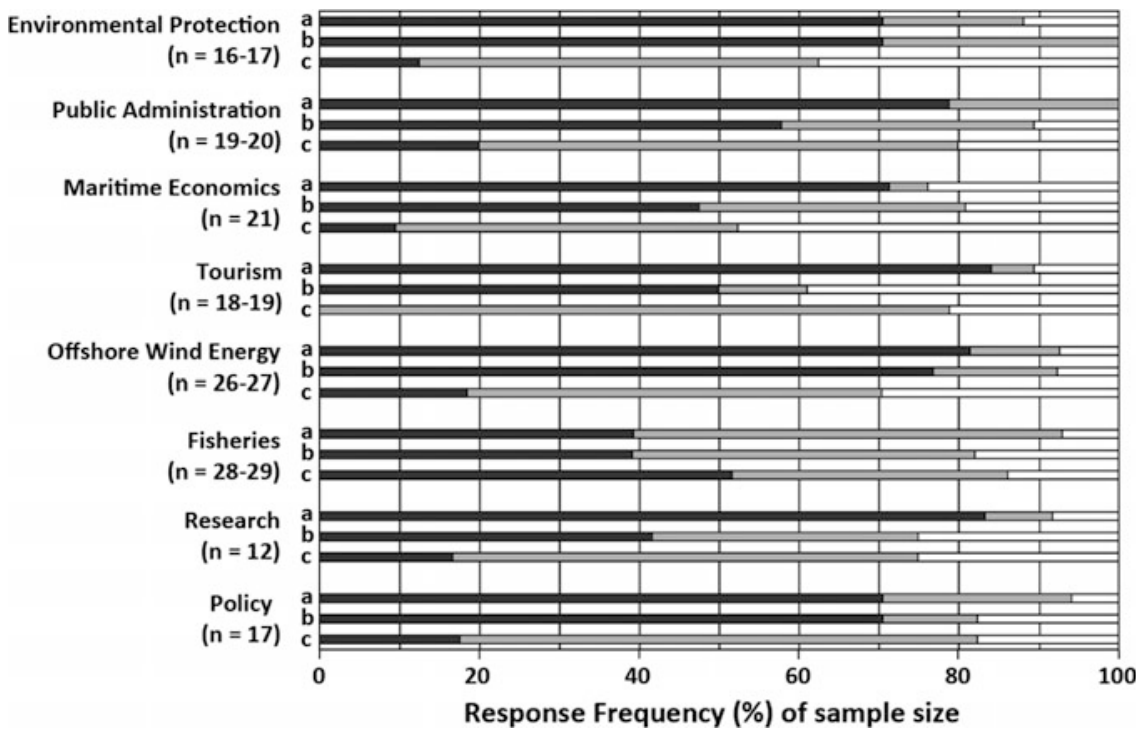

Fig. 11.42 Responses of various stakeholders to the statements: "A concurrent cultivation of mussels and seaweed in offshore wind farms is...: (a) "... a reasonable co-use of those marine areas occupied by wind farms." (Cramer's $\mathrm{V}=0.33$ ); b “... reduces conflicts between interest groups due to the twofold use of the same marine area." (Cramer's $\mathrm{V}=0.28$ ); c “... negatively affects security in offshore wind farms." (Cramer's V $=0.32$ ). $n$ sample size; black bars agree, grey bars disagree, white bars do not know. Modified after Michler \& Kodeih (2008)

environment and pelagic fauna. The need for locale-specific nutrient budgeting and carrying capacity analyses, and further research into the possible role of IMTA systems were clearly articulated throughout the process (Wever et al. 2015). Other concerns relate to transmission of diseases and genetic change of wild populations by fish escapes (Vollstedt 2011). Environmental impacts of open offshore systems clearly need to be evaluated and appropriately quantified as part of the site selection process (Buck et al. 2012; Pogoda et al. 2015). However, while the specific environmental concerns may be alleviated as more precise, on the ground information on impacts becomes available, to some stakeholders the mere accumulation of ocean uses is a threat from the environmental protection point of view. In fact, while offshore wind farms themselves are subject to environmental concerns (such as increased noise levels, risk of collisions, changes to benthic and pelagic habitats, alterations to food webs, and pollution from increased vessel traffic, see e.g. Bailey et al. 2014 and Köller et al. 2006), some environmentalists believe in beneficial effects of single-use wind farms, in which fishing is prohibited, such as reduced pressure on fish stocks and recuperation of the benthic environment. Additional uses such as aquaculture would rescind such effects (Wever et al. 2015).

Turning to the potentially most involved actor groups - the offshore wind farm developers and operators, and the fisheries sector-a critical attitude is prevailing. Both sectors are highly sceptical with respect to the economic, technological, 
Table 11.4 Compilation of the strengths, weaknesses, opportunities, and threats (SWOT-analysis), which identify and assemble internal and external favouring or inhibitory factors (potentialities and restrictions) of interrelated O\&M activities of offshore wind farms and mariculture installations (modified after Michler-Cieluch et al. 2009a)

\begin{tabular}{|c|c|c|}
\hline & Potentialities & Restrictions \\
\hline \multirow[t]{6}{*}{ Internal } & Strength & Weaknesses \\
\hline & $\begin{array}{l}\text { - Development of a flexible, collective } \\
\text { transportation scheme }\end{array}$ & $\begin{array}{l}\text { - Little to no interest in joint } \\
\text { planning process }\end{array}$ \\
\hline & - Sharing of high-priced facilities & $\begin{array}{l}\text { - Little willingness to engage into } \\
\text { new fields of activity }\end{array}$ \\
\hline & - Rationalization of operating processes & $\begin{array}{l}\text { - Ambiguous assignment of rights } \\
\text { and duties }\end{array}$ \\
\hline & \multirow{2}{*}{$\begin{array}{l}\text { - Shortening of adaptive learning process } \\
\text { for any offshore works by making use of } \\
\text { available experience and knowledge }\end{array}$} & $\begin{array}{l}\text { - Problems of interfering } \\
\text { operations }\end{array}$ \\
\hline & & $\begin{array}{l}\text { - Lack of motivating force due to } \\
\text { doubtful mutual cost benefit }\end{array}$ \\
\hline \multirow[t]{6}{*}{ External } & Opportunities & Threats \\
\hline & - Available working days coincide & $\begin{array}{l}\text { - Unfavourable accessibility of } \\
\text { wind farm location inhibits joint } \\
\text { O\&M }\end{array}$ \\
\hline & $\begin{array}{l}\text { - Transportation and lifting devices are } \\
\text { indispensable }\end{array}$ & $\begin{array}{l}\text { - Lack of regulatory framework } \\
\text { supporting co-management } \\
\text { arrangements }\end{array}$ \\
\hline & $\begin{array}{l}\text { - Availability of a wide range of expertise } \\
\text { (hard and soft skills) }\end{array}$ & $\begin{array}{l}\text { - No access rights within wind } \\
\text { farm area for second party }\end{array}$ \\
\hline & \multirow{2}{*}{$\begin{array}{l}\text { - Lack of legislation in EEZ favours } \\
\text { implementation of innovative concepts }\end{array}$} & - Unsolvable problems of liability \\
\hline & & - Dissimilar lease tenures \\
\hline
\end{tabular}

operational and biological feasibility of such an endeavour (Wever et al. 2015; Vollstedt 2011). Michler-Cieluch et al. (2009a) identified a number of potential synergies and benefits relating to functional aspects such as joint use of transportation infrastructure, and organizational features such as the prospect to combine offshore working pattern, both of which hold the potential to reduce costs (e.g. for security systems or by vessel sharing) for both participating parties. Table 11.4 compiles potentials and restrictions related to interrelated operation and maintenance activities of offshore wind farms and aquaculture installations. However, considering the variety of technological designs in offshore wind energy installations currently on the market, and the range of potential, yet to be developed technical solutions for offshore aquaculture installations as described in the Chap. 4 "Technologies", a reliable estimation of financial benefits and overall economic viability needs to be done on a case-to-case basis. Even though the offshore wind energy sector is a highly innovative and dynamic sector that has been described as willing to take risks (Byzio et al. 2005), at this point in time the technical, legal, actuarial and operational concerns still appear to prevail (Michler-Cieluch and Kodeih 2008; Michler-Cieluch and Krause 2008). 
The fisheries sector from the outset faces a different situation: while the offshore wind energy sector is privileged with stable and outspoken political commitments and to-date exclusive user rights for vast ocean areas, the fisheries sector is losing ground. This development however has not resulted in any noticeable efforts of the fisheries sector to diversify into marine farming so far. In fact, local fishermen appear rather reluctant to the idea of engaging with marine farming (Wever et al. 2015; Michler-Cieluch 2009). Neither do they possess the specific knowledge of marine farming, nor the sufficient investment capital, nor do they seem to be willing to move away from their original profession. By some fisheries representatives, the efforts to engage fishermen into alternative occupations are perceived as lip service to avert from the fact that the expansion of offshore wind energy goes hand in hand with the closing of fishing grounds, thus threatening the very existence of the fisheries sector.

Earlier stakeholder efforts focused on the potential role of nearshore aquaculturists, in particular mussel farmers, in offshore mariculture operations (Michler-Cieluch and Kodeih 2008). Similarly to the fishermen, the local mussel farmers also generally appeared reluctant to the idea of expanding their businesses into offshore waters. Here again the disbeliefs in economic efficiency and technical feasibility, and a generally low readiness to assume risks were identified as the main causes for a sceptical attitude towards offshore mariculture. Moreover, offshore mariculture was found to be perceived as "intruder" that could displace traditional ways of fishing from the Wadden Sea. The fisheries sector thus felt as a "two-fold loser" that is threatened not only by the loss of fishing grounds due to the expansion of offshore wind farms, but also the loss of their occupational identity if forced into offshore farming in order to secure income. Table 11.5 displays selected supportive, as well as opposing statements from fisheries and offshore wind energy representatives.

These results seem surprising, as both fisheries and nearshore aquaculture sectors possess developable equipment as well as valuable skills and knowledge to work in open waters, and both sectors, for different reasons, are confronted with the need to extend and diversify their businesses. They reveal the Achilles heel of socioeconomic studies so far: the lack of a clearly identified target group. It is not yet clear who would actually be willing and capable to develop and operate a marine aquaculture facility in offshore waters. In fact, due to the remoteness of offshore installations, operations would have to rely heavily on automated processes. Stakeholders have repeatedly raised their worries that the technology would be attractive only to large, possibly foreign investors and would hardly generate any income or employment effects to the region (Wever et al. 2015). It is also not clear under what kind of arrangement the two very heterogeneous actor groups (wind farm operators and aquaculture operators) with substantially different interests and concerns could be brought together in a co-management scheme. Financial and operational benefits from sharing a common facility and space may only be attained when a high degree of cooperation between the co-users is achieved, not only 
Table 11.5 Statements made by representatives of the offshore wind farm and fisheries actor group towards potential 'Wind Farm-Mariculture Integration' (modified after Michler-Cieluch and Kodeih 2008)

\begin{tabular}{|c|c|}
\hline Actor Group & Statements \\
\hline \multicolumn{2}{|l|}{ Fisheries } \\
\hline $\begin{array}{l}\text { Statements in } \\
\text { support }\end{array}$ & $\begin{array}{l}\text { "It is no alternative for the mussel fishery sector but an additional } \\
\text { possibility. Synergetic effects are always desirable" } \\
\text { "Could open up interesting possibilities and have advantages for both } \\
\text { wind farmers and fishermen" }\end{array}$ \\
\hline $\begin{array}{l}\text { Critical } \\
\text { statements }\end{array}$ & $\begin{array}{l}\text { - "There are no reliable original data" } \\
\text { "Loss of fishing grounds remains unchanged for the fisheries sector. } \\
\text { Mariculture of this kind is not economical and no alternative to sea } \\
\text { fishing" } \\
\text { "Too little mussel spat available in the region, I think it will stay a } \\
\text { fantasy" } \\
\text { "It only serves to show wind farms in a better light and to enhance public } \\
\text { acceptance" }\end{array}$ \\
\hline \multicolumn{2}{|c|}{ Offshore wind energy } \\
\hline $\begin{array}{l}\text { Statements in } \\
\text { support }\end{array}$ & $\begin{array}{l}\text { - "New innovative idea. For sure there are many open questions to be } \\
\text { resolved such as technical feasibility or cross-linking of branches" } \\
\text { "Additional uses are welcome, also for the purpose of increasing } \\
\text { acceptance among fishermen" } \\
\text { "Maximization of the economic value of ocean territory from an } \\
\text { ecological point of view" }\end{array}$ \\
\hline $\begin{array}{l}\text { Critical } \\
\text { statements }\end{array}$ & $\begin{array}{l}\text { - "I don't see any added value to the manufacturers/suppliers of wind } \\
\text { turbines or to the operators. The use of offshore wind energy has nothing } \\
\text { to do with mariculture" } \\
\text { - "Attaching [mariculture devices] to turbine foundations could be a } \\
\text { problem and requires third party certification" } \\
\text { "The problem will be to make sure that operation and maintenance of the } \\
\text { wind turbines is not impeded" }\end{array}$ \\
\hline
\end{tabular}

during operation and maintenance, but already in the early stages of technological development. Lack of social ties and common identity make collective action more difficult to organize. Appropriate institutional design of co-managed facilities must compensate for the absence of tight social networks and long traditions of collaboration (Michler-Cieluch 2009). Figure 11.43 displays some of the key framework requirements for ensuring sound cooperative work between the two actors. Further research is clearly needed to identify the target group and their specific requirements for operation, and infer common ground and modes of operation between the co-users.

The methodology used to obtain the presented information shown is thoroughly described in Michler-Cieluch and Kodeih (2008). 

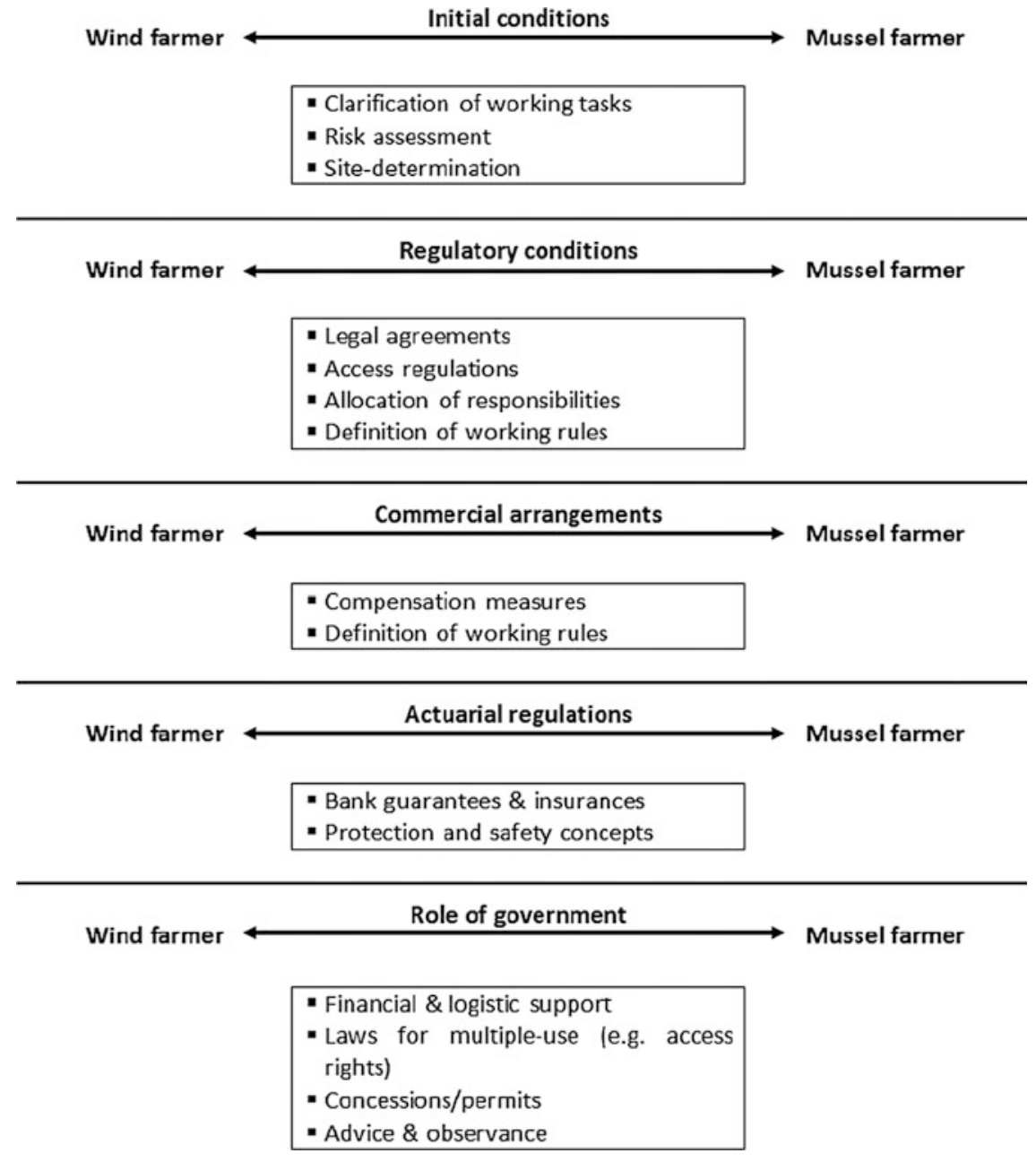

Fig. 11.43 Framework requirements for managing 'wind farm-mariculture integration' (modified after Michler-Cieluch and Krause 2008)

\subsection{Economic Calculations}

For the last 25 years, total mussel production in the German North Sea varied from 5000 to 50,000 annual tons. As these mussels were produced by using the on bottom-culture technique, the farmer depends on the bioavailability of seed mussels obtained from wild beds in the coastal sea. Walter and Liebezeit (2001, 2003) commenced research into whether or not suspended culture techniques could be used to obtain seed mussels in a nearshore areas of the German Bight. They found that spat can be obtained even in years with a low spat fall when using the floating 
longline technique, commonly described as off-bottom culture (Hickman 1992). Due to conservation measures applied to nearly $98 \%$ of the German North Sea coast, the development and expansion of the mussel aquaculture sector is limited insofar as the current area of mussel culture plots will not be enlarged (CWSS 2002). As already described previously in this book, moving off coastal areas to the open ocean, where offshore wind farms are planned, is a potential solution (Buck 2002, 2007). Advantages of performing mussel cultivation activities within offshore wind farm territories are manifold, such as the placement of mariculture devices in defined corridors between wind farm turbines as well as sharing infrastructure for regular servicing and joined multi-use sources of transportation. This provides an opportunity for both enterprises to share these high-priced facilities (Michler-Cieluch et al. 2009b). Further, charter contracts for specially designed mussel harvesting vessels could be aimed as a solution for transporting wind farm technicians to the offshore location at times of planned, preventive operation and maintenance activities (Michler-Cieluch et al. 2009b). Altogether, the viability of a mussel cultivation enterprise within offshore wind farming areas depends on various factors such as (1) the technological and biological feasibility, (2) the legislative and regulatory constraints, (3) the environmental sustainability of farming aquatic organisms, and (4) the profitability of this potential commercial operation (see review by Buck et al. 2008b). As for some offshore aquaculture projects on pilot scale, the economic part is often unrepresented or even ignored. Therefore, this sub-chapter, which is the summary of the Project No. 8 "MytiMoney" (Fig. 11.1), provides a first insight into financial considerations associated with moving mussel cultivation close to German offshore wind farms, aiming to demonstrate the commercial potential from an economic perspective of a new enterprise that has not yet become established even on a pilot scale (Fig. 11.44a).

In the following the most relevant parameters that have an impact on potential commercial exploitation, an investment appraisal, an enterprise budget analysis, a break-even analysis, and a sensitivity analysis of various scenarios to evaluate economic profitability of mussel cultivation offshore are outlined.

\subsubsection{Basic Data}

The offshore wind farm, which acts as a case study site, is called Nordergründe (see Fig. 11.8) and is located close to the offshore lighthouse "Roter Sand". Site-specific data are shown in Table 11.6 and Fig. 11.44a-c.

The economic analysis consists of an investment appraisal by calculating the following: (1) net present values (NPV), (2) the internal rate of return (IRR), (3) an enterprise budget analysis, (4) a break-even analysis, (5) and a sensitivity analysis of changes of the most important parameters (all numbers are in real terms, taxes were not considered; see also e.g. Hatch and Tai 1997; D’Souza et al. 2004; Engle et al. 2005; Pomeroy et al. 2006; Whitmarsh et al. 2006; Liu and Sumaila 2007). According to the operating life expectancy of main components of the complete 
(a)

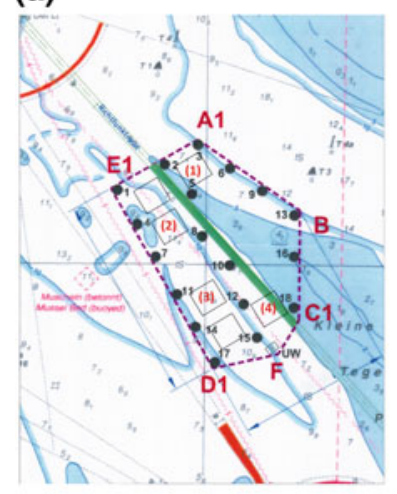

(b)

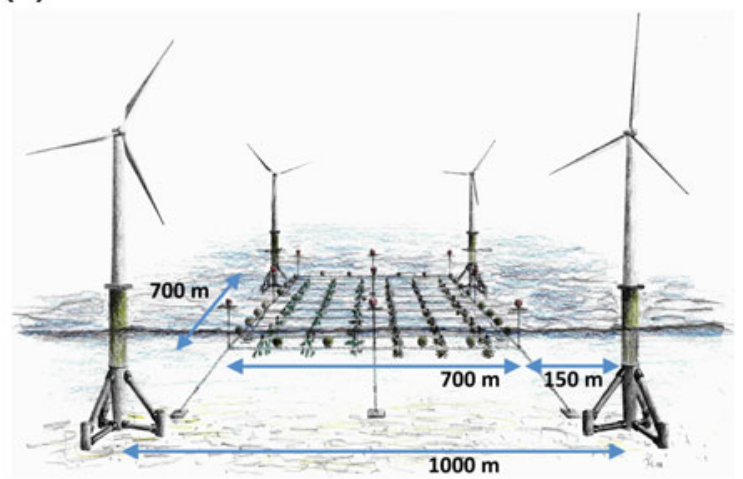

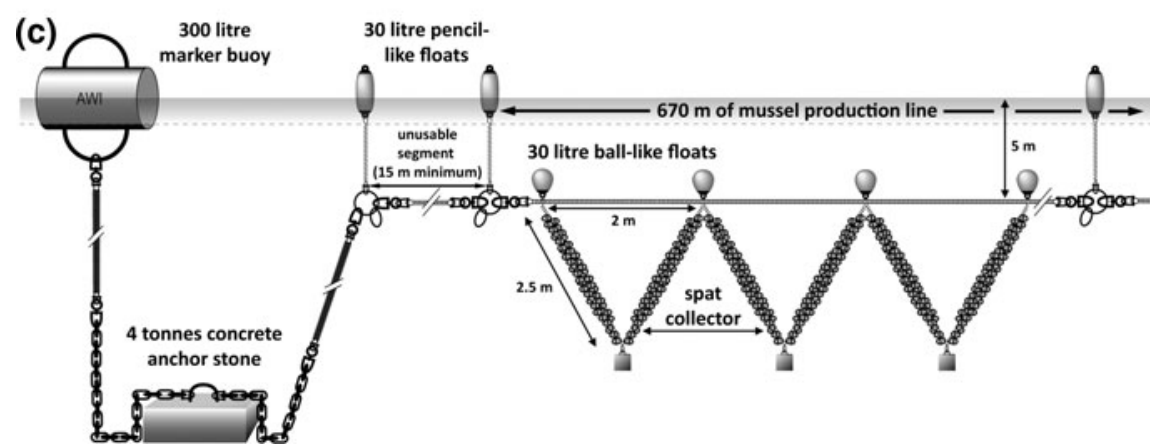

Fig. 11.44 a Map of the planned wind farm Nordergründe displaying 18 offshore wind turbines (numbers without brackets) and six single mussel plots designated by the wind farm company (bird's eye view). Four of these six designated plots were calculated according to our mussel cultivation projections (numbers in brackets). b Presents a design of a single mussel plot within a group of four wind turbines (not to scale) (modified after Buck et al. 2010). c Example of a submerged longline system design with a V-shaped spat collector harness. In this image only a part of the $700 \mathrm{~m}$ long longline is presented (not to scale). Modified after Buck et al. 2010

longline device, the enterprise budget for a four-year life cycle was calculated. Additionally, a new vessel as well as the possibility of using existing capacities of the mussel farmer community in Lower Saxony will be taken into consideration. This led to four different scenarios. First, a basic scenario for the farming of consumption mussels with a new appropriate vessel as well as a new land facility was assumed. In a further scenario, the above-mentioned existing capacities of mussel farmers were addressed. The economic analysis was organized as follows: (1) basic parameters for farm size, culture technology and biomass gain are described (Table 11.6); (2) time schedule of the farm set-up and harvest operations were presented; (3) basic data on costs and investment were specified; and (4) finally a sensitivity analysis was outlined. 
Table 11.6 Site-specific data of the offshore wind farm-aquaculture multi-use concept at the offshore lighthouse "Roter Sand" (modified after Buck et al. 2010, based on Buck 2004 and Buck et al. 2008a, b)

\begin{tabular}{|c|c|}
\hline \multicolumn{2}{|l|}{ Basic data } \\
\hline Distance to shore (City of Bremerhaven) & 17 nautical miles \\
\hline Number of planned wind turbines/power & 18/5 MW-class \\
\hline Salinity & $\begin{array}{l}20-33 \% \text { (due to tidal current and the influence of } \\
\text { the Weser estuary) }\end{array}$ \\
\hline Depth & $10-15 \mathrm{~m}$ \\
\hline Condition of the sea bottom & Soft bottom (Wadden Sea) \\
\hline Turbidity and light & High sediment load (due to the Wadden Sea) \\
\hline Wave climate & exposed \\
\hline Current velocity & $0-1.2 \mathrm{~m} \mathrm{~s}^{-1}$ (depending on the tide) \\
\hline Significant wave heights & $0-6 \mathrm{~m}$ \\
\hline Nutrients & Eutrophic situation \\
\hline Water temperature & $1.5-18^{\circ} \mathrm{C}$ \\
\hline Wind velocities & Up to 8 Beaufort \\
\hline Distance between turbines & Approx. $1,000 \mathrm{~m}$ \\
\hline $\begin{array}{l}\text { Minimum spacing between turbines and } \\
\text { any aquaculture co-use }\end{array}$ & $150 \mathrm{~m}$ \\
\hline $\begin{array}{l}\text { Size of aquacultural area (single mussel } \\
\text { plot) }\end{array}$ & $\begin{array}{l}700 \times 700 \mathrm{~m} \\
\left(490,000 \mathrm{~m}^{2}=0.49 \mathrm{~km}^{2}=49 \mathrm{ha}=121 \text { acre }\right)\end{array}$ \\
\hline Number of single mussel plots & $4(196$ ha $=484$ acre $)$ \\
\hline $\begin{array}{l}\text { Total length of the collector harness per } \\
\text { longline }\end{array}$ & $\begin{array}{l}1675 \mathrm{~m}(335 \mathrm{~V} \text {-shaped collector pairs having each } \\
\text { a length of } 2 \cdot 2.5 \mathrm{~m}=5 \mathrm{~m} \text {, } \\
71 \cdot 1675 \mathrm{~m}=118,925 \mathrm{~m} \text { per single mussel plot }\end{array}$ \\
\hline $\begin{array}{l}\text { Biomass of mussels per meter of } \\
\text { collector }\end{array}$ & $\begin{array}{l}10-15 \mathrm{~kg}(16.75 \text { metric tons } \cdot \text { longline } \\
\left.1190 \text { metric tons } \cdot \text { plot }^{-1}\right)\end{array}$ \\
\hline
\end{tabular}

\subsubsection{Data for the Economic Analysis}

(1) See Table 11.6

(2) As the best and safest working conditions are to maximize onshore activities (Sørensen et al. 2001), the setup of all longline devices should take place on land-based facilities and transferred to the aquaculture site during spring to allow settlement in May of the same year. It was planned to install two full mussel plots, which were scaled up in the following year, which would then be equivalent to four mussel plots in operation. Exchange of longline devices after its operating life expectancy can automatically be done during or after maintenance or harvest procedures. Consumption mussels reach market size after approximately 1.5 years; therefore, the farm will operate at full scale in the second year, which results in a form of shifting cultivation (Bartlett 1956). While only in the first year of the enterprise no mussels can be harvested due to their growth period to reach market size, in the following years two plots can be 
harvested biennially each year (6 harvests in four years). Once the longline is transferred at sea, deployed and ready for cultivation the production undergoes two cycles: Spat collection (April-June) in year one and maintenance of longlines to remove fouling organisms and modify buoyancy (August-May) in year one as well and grow-out to consumption size within 15-18 months (market size: $<5.5 \mathrm{~cm}$ ) and harvest in August-November in the second year.

(3) All costs were itemized by scenarios of production for consumption mussels (Buck et al. 2010 also calculate seed mussel production). Cost calculations were based on data gathered from existing traditional nearshore mussel cultivation activities. Some nearshore cultivation plots have a distance of 10-55 nautical miles to the port of trans-shipment, which is within the scale of the planned offshore site (17 nautical miles) (BSH 2016). Offshore operations are more labour and time intensive than nearshore sites. Much of the labour is for maintenance that includes deploying or retrieving of moorings or other parts of the construction harness, which may lead to generally higher operation and production costs. However, some production steps necessary for nearshore operations cease to exist offshore, which in turn leads to cost reduction. The annual fixed costs consist of depreciation, licenses, motor overhaul, interest on fixed capital and miscellaneous costs like insurance premium and administrative cost. Interest rate was assumed to be $7 \%$. Variable costs are fuel expenses, wages, repairs and maintenance, miscellaneous costs and interest on variable costs. Fuel was assumed to cost $0.55 € \operatorname{liter}^{-1}$, wages are calculated with $3,333 €$ month $^{-1}$. When using existing capacities of mussel farming in Lower Saxony, an investment for retrofitting at the beginning of the enterprise will be required. In the scenarios where new capacities have to be established, investment into a new appropriate vessel as well as into a new land facility was considered. All other costs are assumed to be similar to those used for the basic scenario.

(4) A sensitivity analysis was calculated to explore the effects of changes in the key parameters that reflect uncertainty, such as the biomass gain and/or the development of costs and prices. Here, NPV and IRR for different mussel prices, different biomass gain, different developments of single cost components as well as an increase in overall costs were calculated as well as different discount rates on NPV.

\subsubsection{Calculation and Results}

Following the data of the Federal Agency for Agriculture and Food (2007) and the State Fisheries Agency, Bremerhaven, Germany (SFA) (2008), the average market price per $\mathrm{kg}$ of consumer mussels has been relatively stable until 1975 (below $\left.0.2 € \mathrm{~kg}^{-1}\right)$. Afterwards, the price has been subject to fluctuations ranging between 
0.50 and $1.96 € \mathrm{~kg}^{-1}$. According to the development of the market price of Blue mussels, a price of $1.0 € \mathrm{~kg}^{-1}$ of mussels was used in the base scenario (SFA 2008). Thus, a single longline could have a production value of $16,750 €$ $(1,000 € \times 16.75$ metric tons $)$ and a single mussel plot of approx. 1,190,000 $€$ $(1,000 € \times 1190$ metric tons).

The cost of longlines including the complete harness is the sum of various individual costs and levels around $15.80 €$ meter $^{-1}$ of longline (including collectors, mooring constructions, connecting pieces for the entire longline device, such as shackles, swivels, rings as well as the complete buoyancy). Costs were calculated by Sahr (2006) using the equations for the definition of key cost data published in Pelz (1974). This leads to an overall investment cost of approximately 835,500 € single mussel plot ${ }^{-1}$ every four years. In line with the estimates of Whitmarsh et al. (2006) the operating life expectancy is assumed to be four years for longlines and collectors, six years for buoyancy, and 10 years for anchors. A vessel adapted for performing offshore operations is needed. In the base scenario, an investment in a new vessel (45 m class, $430 \mathrm{GRT}, 500 \mathrm{~kW}$ ) for around 4 million $€$ (Sahr 2006), including all necessary equipment for longline cultivation, was assumed. This case also includes a complete motor overhaul after 10 years with 385,000 $€$ (assuming motor costs to be $17.5 \%$ of total vessel investment and retrofitting to be $55 \%$ of the amount of 17.5\%; Sahr 2006). Because the mussel farmer community already disposes of mussel farming cutters used for bottom culture, we also calculated the NPV with the assumption of using existing capacities of mussel farmers. Investment will then be reduced to the retrofitting of the vessel only, which was calculated with costs of about 750,000 € (Sahr 2006). Capital investment costs include the costs of a land facility for the purpose of equipment storage and for carrying out land-based activities, such as tying and repairing collectors and other equipment. Investment costs for a land facility are assumed to be 1,500,000 € Licensing costs for a single mussel plot at the offshore site Nordergründe is based upon the scale of charges and fees of the State of Lower Saxony (NKüFischO 2006). Following the fees for mussel license areas, only the bureaucratic work load will be charged, which was calculated by the State Fisheries Agency (SFA) in Bremerhaven with a nonrecurring charge of approximately $1,000 €$ (personal communication with Brandt from SFA). Miscellaneous fixed costs (e.g., insurance premiums) are assumed to be $5 \%$ of depreciation leading to a total sum of $151,127 €$ in four years. Interest on fixed capital is $232,951 €$ for a four-year period. Total fixed costs were $3,560,817 €$.

\subsubsection{Operation Costs}

The experience of the bottom-culture aquaculturists indicates that approximately 70 days per year are needed for labour at four culture plots, amounting altogether to 280 offshore working days in four years. Taking into account $61.8 \%$ of full load engine performance in a $24 \mathrm{~h}$ day, fuel costs per day at sea are estimated to be $1200 €$ (Gloy 2006; Sahr 2006). This totals $84,000 €$ per year or $336,000 €$ in four 
years. Two full positions and two seasonal employees are required per year. The latter are employed only in times of the heaviest workload in the 6 months from spring to autumn. Labour costs total $479,952 €$ in a four-year period. Costs of maintenance and repairs, estimated as $10 \%$ of the yearly depreciation, are $302,254 €$. Miscellaneous variable costs are estimated to be 5\% of depreciation, total $151,127 €$ in four years. Interest on operating capital sums to $88,853 €$ in four years. Total variable costs were $1,358,186 €$.

\subsubsection{Enterprise Budget Analysis}

Costs and receipts of two case-scenarios were calculated for consumption mussels. Scenario 1: Production of consumption mussels with Investment into a new vessel. This is the base scenario assuming a four million $€$ investment into a new vessel for farming of mussels for consumption. A general overhaul of the motor is necessary after 10 years and is calculated with 385,000 €. Net returns for an average four year period sum to $4,594,996 €$. Scenario 2: Production of consumption mussels using free capacities of existing mussel farmers. For this scenario, retrofitting costs for the vessel are about 750,000 €. No land-based facility is included. This leads to net returns of approximately $6,022,000 €$ in four years, which is 1.3 times higher than in the base scenario.

\subsubsection{Productivity Measures}

Break-even yield and break-even price were calculated to estimate the minimum level of biomass production and the minimum price per $\mathrm{kg}$ mussel to enable the enterprise to cover cost. Assuming a biomass of $10 \mathrm{~kg}$ meter $^{-1}$ (consumer mussels) the break-even price is $0.52 €$ when a new vessel and land facility is taken into calculation. Using existing equipment, a break-even price of $0.37 €$ results. In the case of seed mussels the break-even price varies between 0.34 and $0.49 €$. Break-even yield for the consumer mussel scenarios lies between $3.67 \mathrm{~kg}$ and $5.17 \mathrm{~kg}$ per meter longline, respectively, assuming a mussel price of $1 € \mathrm{~kg}^{-1}$. In the seed mussel scenario the break-even yields range from 3.42 to $4.92 \mathrm{~kg}$. Actual prices and yields observed at field experiments are higher than the break-even values. This indicates the profitability of both practices, while the consumer mussel production is clearly more above those criterions for economic viability.

\subsubsection{Investment Appraisal}

Assuming the operating life expectancy of a new vessel to be 20 years, we calculate the NPV of cash flows over 20 years with a discount rate of $7 \%$ in the basic model. This rate is chosen according to Liu and Sumaila (2007), who argue that the most frequently used discount rate by Nature Resources Canada is within a range of 
5-10\%. D'Souza et al. (2004) used 7, 9 and 11\%, while Whitmarsh et al. (2006) limits the discount rate to $8 \%$. Due to the sensitivity of the NPV to the discount rate, values ranging from 6 to $9 \%$ were used. In the base scenario, the price for one $\mathrm{kg}$ of mussels was assumed to be $1.0 €$. Net present value amounts to 5,667,073€, with an IRR of $14.73 \%$. When using existing capacities of mussel farming in Lower Saxony, an investment of about $750,000 €$ for retrofitting of the vessel at the beginning of the enterprise will be required. All other costs are assumed to be similar to those from the basic scenario. NPV levels around 9,622,937 $€$ and an IRR of $28.11 \%$. Economically, the most promising enterprise is the production of consumer mussels if existing equipment can be used. But also in the case of a new vessel and a new land facility profits are likely, since the IRR levels at $14.73 \%$. This should be in most cases higher than the costs of capital.

\subsubsection{Sensitivity Analysis}

A sensitivity analysis was carried out to assess the economic feasibility, if key parameters of the economic analysis are changing. As the biomass harvested was assumed to be at a low level, the positive impact of a 25 and $50 \%$ biomass increase was estimated for consumer mussels as well as an increase of $10 \%$ for seed mussel yield. Fuel costs were increased by 10 and $20 \%$ per year, wages by $3 \%$ per year, longline costs by $5 \%$ per year and total costs by $5 \%$ per year. Discount rates were varied from $5 \%$ over 6 to $8 \%$. The mussel price was changed by $10 \%$ in case of consumer mussels and by $20 \%$ in case of seed mussels. The results are shown in Table 8 . The overall result shows the capacity of the production of consumer mussels with existing equipment to withstand cost increases quite well. In case of a new vessel and new land facility NPV remains positive except for an overall cost increase of $5 \%$ per year. All calculated discount rates leave NPV to be positive.

\subsubsection{Final Conclusion}

Assuming a baseline production of 2380 tons of consumption mussels per year (2 plots) the results of the economic study show that the base scenario is clearly beyond the break-even point. Varying parameter values, such as investment costs concerning longlines, new vessels or retrofitting, operating costs like wages and fuel, biomass yield, market price, total cost increases, and different discount rates, show different levels of feasibility. Offshore mussel production for consumption is profitable, but profits are less with a new vessel and a new land facility and higher in the scenarios without a new vessel and a new land facility, respectively. The NPV and IRR are large enough that this business can be recommended as long as there are existing capacities. Of course, all businesses can become profitable and respectively more profitable if costs can be reduced and revenues increased. 
The lack of practical experience of culturing mussels in exposed environments precludes estimating effects of economic risks.

\subsection{Ownership Issues}

\subsubsection{Modes of Cooperation}

The relevant government policy as a central framing condition must be part of any analysis of likely management scenarios for an integrated wind energy-mariculture facility. In the North Sea area, the here presented concept is ahead of the current institutionalized regulatory system. Indeed, a systematic regulation addressing this multi-use concept in the context of industry support is yet lacking. While current legislation may preclude concurrent economic activity within offshore wind farms, that likely can be interpreted as a de facto law absent any regulatory consideration on this multi-use issue. However, given the strong push for spatial efficiency and multi-use concepts in the maritime waters in the EU and elsewhere (Krause et al. 2003; Lutges and Holzfuss 2006), it can be expected that more comprehensive regulatory frameworks will develop in due time. Krause et al. (2011) identified three likely avenues under which an integrated mariculture-wind energy facility may be organized. These are not exhaustive, or mutually exclusive from each other, but rather provide a straightforward method for categorizing potential outcomes. In the following, a brief synopsis of these three different ownership scenarios of multi-use in the offshore realm is provided.

\subsubsection{Sole Owner}

At the extreme end, a sole owner situation could be envisaged, in which a multiple use business plan could be enacted by a sole company without any cooperation. This set-up may accommodate especially the interests of the wind energy producers, who would have easier access to the financial resources needed. In view of the current complexity of drafting and following a contract with an outside firm makes this sole owner approach highly appealing. Indeed, from an economic point of view, governance structures that have better transaction cost economizing properties are preferable. Additionally, transaction cost economics suggests that full vertical integration completely resolves issues related to hold-ups and misaligned incentives (Williamson 1979, 1981; Johnson and Houston 2000).

Undeniably, the potential for further net revenue via mariculture may be alluring to a wind energy firm, especially in the light that the area occupied by wind turbines is roughly $1-3 \%$ of the total area of an offshore wind farm (Mee 2006). Economies of scope may act thus as a financial catalyst, i.e. simultaneously producing two products with a lower average cost than if undertaken separately. 
Undertaking this economic decision as a sole firm partly however rests on the ability of the wind energy producer to culture products at a similar or lower average cost than if they had negotiated a contract or formed a joint venture with a firm who specializes in mariculture. The lack of knowledge on the different modes of conduct in the mariculture section could act however, as a major impediment to such sole ownership scenario of a wind farm enterprise. Thus, while a sole ownership approach may initially appear promising, the degree of risk involved in operating two very different businesses at the same location is high. The relative risk of internalizing both productive activities can be somewhat combatted by the degree to which personnel with specialized knowledge could be brought into oversee and conduct these operations. Current lines of research are assessing the economic merits of a joint mariculture-wind energy facility and will help illuminate the viability of such a venture from multiple perspectives (Griffin and Krause 2010).

\subsubsection{Negotiated Contract}

Forming alliances is a common commercial strategy that is employed to organize and mitigate activities that are riskier than a firm's average inside project. These alliances occur more in riskier industries (Robinson 2008). Expanding to an industry-level analysis, Robinson (2008) found that alliance intensity across industries is positively associated with the risk difference between the two industries. This dynamic could play an important role in alliance formation versus single firm management of a multi-use facility. Therefore negotiated contracts are a alternative path to mitigate and manage the risk associated to an integrated facility. Such categories of agreement may cover a multitude of different settings, such as a joint venture or a consortium or any form of subcontracts. Central hereby is the fact that the outlined interdependence between firms must provide benefit to each party (Pareto-improving) and be perceived as fair by the participating entities. Continued cooperation between parties must be sustainable by the underlying game structure (Grandori and Soda 1995). Alliance between firms that both hold unique capabilities that neither partner could efficiently provide alone, have the highest potential for coordination. Michler-Cieluch and Krause (2008) showed that under such an umbrella there is sufficient scope for such wind farm-mariculture cooperation in terms of operation and maintenance activities.

However, the process of drawing up a contract that delineates the lines of cooperation between firms is fraught with challenges. Hold-up hazards increase when complexity and uncertainty make writing and enforcing contracts difficult (Williamson 1979), and when products require asset-specific investments, two conditions that hold in this case. Only when there are offsetting economic benefits and sufficient efficiency scope to doing so firms are compelled to engage in integrated organisational structures over simple contracts or sole ownership (Johnson and Houston 2000). Such economic benefits pertain to any of the previously outlined benefits from cooperation, such as reduced production costs, organisational efficiencies, or pooling risk- but these benefits are not guaranteed. Because of the 
parties' inability to write an a priori comprehensive agreement that covers all future contingencies, Nielsen (2010) argued that all alliance contracts are necessarily incomplete. Thus, these contracts may enhance or prohibit desired outcomes. In order to be successful, all stakeholders involved in such joint cooperation agreements must be informed and clear about their expectations, rights and duties involved from the onset if being engaged in such multiple use setting.

Regarding the predictors of success in joint ventures and other alliances, an amount of considerable research exists. Johnson and Houston (2000) find that only joint ventures between firms in related businesses are likely to generate operating synergies. Thus, combinations of dissimilar firms can reduce value by contributing to bureaucracy and lack-of-focus. Beamish (1994) finds that the good intentions and rational motives behind alliances are often not congruent with the strategic direction of either firm on its own. This inconsistency can lead to poor performance and instability. Indeed, Kumar (2007) finds that in incidences where firms with asymmetric resource endowments enter into a joint venture, asymmetric wealth gains arise via the negative wealth transfer effects of resource appropriation by the firm with more valuable resources. Therefore, initial collaborative research between sectors prior to the design and execution of a commercial agreement by act as avenue to overcome this potential pitfall Michler-Cieluch et al. (2009a). In the German case study, our interviews and survey work suggests that the stakeholders in a potential mariculture-wind energy facility may be amenable to some type of contracted agreement. Respondents have suggested that they would be open to the idea of contracting out culturing activities at the site of an offshore wind farm as a prior joint research initiative and feasibility study. It does seem unlikely though at this point that a contracted solution could occur in the absence of some intervening third body (Michler-Cieluch et al. 2009a). However, an advisory or some other external independent mediating group or entity that helps to coordinate and facilitate the entire process generally improves the chances of reaching a successful agreement (Noble 2000).

\subsubsection{Legislated}

In the third ownership option, a legislative prescription could attain desired policy goals of spatial efficiency in the ocean area. The use of mandates, subsidies, tariffs, and other policy tools can change the incentives of the current economic environment to make the multi-use concept economically viable in cases where it may not be to date very appealing or in places where finding a direct commercial market solution for multi-use in the offshore setting is not possible. Increasingly, policy makers may find policy instruments as a palatable solution for achieving policy goals, especially as there is a growing focus on coastal zone management and the efficient and equitable use of coastal resources in the EU, US, and elsewhere (Krause et al. 2003, Lutges and Holzfuss 2006; Rhode Island Coastal Resources Management Council 2010). Mariculture can offer expanded employment opportunities to rural peripheral regions and displaced fishermen in the area of a wind 
energy facility. Furthermore, it has the potential to make wild harvest fisheries more productive if mariculture areas act as nurseries for wild fish (Mee 2006). Indeed, multi-use layering of economic activities can maximize the value of offshore resources while reducing conflict between stakeholder groups. Since regulators have already shown they are comfortable with using legislation to spur growth in the offshore wind energy industry, such type of legislative promoting a multi-use concept would not be an uncommon step. Indeed, a clear, coherent, and stable regulatory framework is a bare minimum when firms make financial decisions in the inherently risky offshore marine environment. Managers need to be able to predict with some certainty the expected outcomes of changes in strategy, be it an internal decision or the decision to form an external alliance. To the contrary, fragmentation in the structure of State decision making is shown to lead to more elaborate and costly inter-organisational networks (Carroll et al. 1988). However, the decision to actively foster cooperation on a multi-use concept should largely be dependent on market conditions, which must be somewhat accommodated for by the legislation. The latter may be driven by the recognition of the potential social benefits available from multi-use facilities. Williamson (1981) stated that "there are so many different types of organisations because transactions differ so greatly and efficiency is only realized if governance structures are tailored to the specific needs of each type of transaction." The legislative ownership discussion this far have attempted to frame the potential cooperation in a multi-use setting in the context of the broader social, political, and economic spheres. Next, the discussions also acknowledge and illuminate the perceptions and characteristics of the particular industries themselves. It appears clear that uncertainty and risk are large components of this discussion. These were reinforced and frequently voiced by the survey respondents in the German case study. It can be expected that the likelihood and form of collaboration in the near future will be shaped by how well this risk and uncertainty is addressed.

\subsection{Regulation of Aquaculture Within the German Bight}

The EEZ is a special area-it is not a state territory even if a coastal state has there sovereign rights and jurisdiction. This is an area where three legal systems come together: international law, law of the European Union and national law (Buck et al. 2003). There are no commercial aquaculture operations in the German EEZ and no approval procedure has been completed so far. Additionally, some sites are not suitable for aquaculture, especially because of nature conservation and shipping. 


\subsubsection{Mariculture in the German Exclusive Economic Zone}

Mariculture in the Exclusive Economic Zone (EEZ) could be in the future an interesting completion of fishery, not least because of overfishing of natural stocks. Nevertheless, its legal questions are still not fully answered (for an overview of legal frame of mariculture see Kersandt 2012 as well as in BLFRG 2012; ECR 2006, 2007, 2008; EC 2000, 2008, 2011; SAG 1965; VüAs 1997).

\subsubsection{The System of Law in the EEZ}

The EEZ cannot be considered as a part of the state territory. It is a sui generis zone and the coastal state can only use it and regulate its use as outlined in the relevant provisions of the United Nations Convention on the Law of the Sea (Dahm et al. 1989; Gündling 1983). This effects the first restriction for the German law-maker. Furthermore, Germany as a member of the European Union, has to respect the European law. Although the EEZ is no sovereign state territory, the EU is allowed to issue the law: The EU has legislative authority in the area outside the members' territory, where the international public law gives such authority to the state, e.g. fisheries on the High Sea (Grabitz et al. 2010). Some directives and regulations refer to aquaculture, e.g. regulation concerning use of alien and locally absent species in aquaculture, directive on animal health requirements for aquaculture animals, products thereof and on the prevention of diseases or regulation on conditions for market placing and the import of aquaculture animals. Some general (i.e., not specific to aquaculture) rules are relevant to aquaculture, e.g. Marine Strategy Framework Directive, Water Framework Directive or EIA Directive.

The legislative authority usually belongs to the Federal Republic of Germany and not to the German States (Länder). It depends on the jurisdictional provisions of Article 74 GG, e.g. the law relating to economic matters (no. 11), deep-sea and coastal fishing (no. 17), and protection of nature and landscape management (no. 29) or management of water resources (no. 32).

\subsubsection{The Approval Procedure}

The basis for the approval procedure of aquaculture in the EEZ is Marine Facilities Ordinance (SeeAnlV), which is based on Federal Maritime Responsibilities Act. The agency deciding on the approval of mariculture in the EEZ is Federal Maritime and Hydrographic Agency (Bundesamt für Seeschifffahrt und Hydrographie, BSH). Aquaculture, as any other facility that is not purposed to produce or transmit energy, needs an approval. For energy projects, a plan approval procedure is mandatory. The approval, different than the plan approval, doesn't have the "concentration effect": the applicant needs to get all necessary permits on his own 
(Dahlke 2002). Especially provisions of the German Federal Nature Conservation Act (Bundesnaturschutzgesetz - BNatSchG) are here determined, e.g. those about protected species (Art. $44 \mathrm{ff}$. BNatSchG), protected habitats (Art. $30 \mathrm{ff}$. BNatSchG) and Natura 2000 areas (Art. 31 ff. BNatSchG) (BNatSchG 2009).

An approval is a non-discretionary administrative act, i.e., it has to be granted when there are no reasons for denying approval (Dahlke 2002). According to Sect. 7 SeeAnlV the approval has to be denied when

- it is likely to impair the safety and efficiency of navigation or poses a threat to the marine environment or

- the requirements of regional planning or overriding military or other public or private predominant concerns are against the approval.

Before the approval has been granted the Federal Waterways and Shipping Agency (former Waterways and Shipping Directorate) has to give a declaration of agreement. It can only be denied if the facility impairs the safety and efficiency of navigation and it is not possible to prevent or compensate the detrimental effects through conditions or requirements, Sect. 8 SeeAnlV.

The term "marine environment" is explained in Sect. 5 subsection 6 no. 2 SeeAnlV. It refers to the definition of "pollution of the marine environment" in Article 1 (1) no. 4 UNCLOS. The approval is to be denied when the pollution gives rise to concern. Aquaculture projects in the EEZ can require environmental impact assessment. The Environmental Impact Assessment Act, which implements the EIA Directive, intends the examination only for intensive fish farming and not for other candidates like mussels or seaweeds. Whether the assessment is mandatory or not depends on the yearly fish amount: it is mandatory if this amount is larger than $2500 \mathrm{t}$. Otherwise, there is a general $(500 \mathrm{t}-2500 \mathrm{t})$ or site-related $(250 \mathrm{t}-500 \mathrm{t})$ preliminary examination of the environmental compatibility to undertake. Depending on the result, the assessment is to the end or the whole EIA has to be done.

\subsubsection{The Sites for Mariculture Facilities}

Spatial Planning Ordinance for the German EEZ in the North Sea (also in the Baltic Sea) regulates targets and principles of spatial planning. Marine aquaculture is identified as a meaningful economic sector in the future. Negative impacts of the mariculture on the marine environment shall be avoided. Facilities for mariculture shall be established preferably in combination with existing installations, Sect. 3.6.1 (1) and (2) Spatial Plan North Sea. Spatial planning has an effect on the site for mariculture facilities. In some areas, e.g. in shipping priority areas, measures and projects which are not compatible with the character of this area are not permitted, as stated in Sect. 3.1.1 (1) Marine Spatial Plan North Sea. In the reservation areas, other uses are also allowed, but the main use is given special consideration. This needs to be taken into account in a comparative evaluation assessment with other 
spatially significant planning tasks, measures and projects. Corresponding rules are provided for the Baltic Sea.

There are also other sites where mariculture is not allowed. In Natura 2000 areas, which are protected areas under national law, mariculture facilities are prohibited. 2005 the Eastern German Bight became a nature conservation area under German law, other sitesDogger Bank, Sylt Outer Reef and Borkum Reef Ground-were nominated to the European Council. In Sect. 4 subsection 2 no. 1 of designating ordinance mariculture facilities are prohibited. It is likely that other ordinances will have the same regulation.

\subsubsection{Approval procedure of offshore multi-use installations}

Changing marine utilization patterns represent considerable challenge to society and governments. Indeed, the ongoing intense competition for ocean space leads and has led inevitably to disputes. As a case in point, the somewhat private ownership of ocean space, which usually is assigned via central government authorities, has fostered the raise of "client mentalities" of the ocean pioneers. This has resulted in a complex mix of ownership, associated commons and private property. Thus, the central question remains how to operationalise the multi-use dimension of offshore installations within marine spatial planning?

Centralized authority planning, such as showcased by the existing permitting procedure in the offshore realm in Germany that is charged by one lead agency (Federal Maritime and Hydrographic Agency) has given way to new forms of governing - tendency to define issues at only one scale and only one installation at time. Indeed, in the case of Germany, a highly comprehensive regulatory framework for offshore wind energy, but only a weak and uncertain framework for offshore aquaculture installations is in place. For the latter, technological as well as ecological standards are yet needed. In Fig. 11.45 we present a permitting procedure that possibly integrate multi-use installations within the same suite of permitting process. This is showcased by the integration of offshore wind farm installations and open ocean aquaculture. By acknowledging throughout the process the different demands, potential impacts and outcomes of each partner within a multi-use system, the permitting process could be streamlined and efficient. By this, the permit process would become more specific articulating societal choices about goals and their related social values in a multi-use context. Open issues pertain to e.g. who should be included in a balanced jurisdiction and what should that jurisdiction do? What criteria are relevant to opt for open ocean aquaculture and what are the implications of such criteria and how to include cross-border users? E. g. regions, where offshore wind farms are planned, are also important fishing regions of German, Belgian, Danish and Dutch fishermen.

In summary, the current gap between oceans as commons and ocean as private property as well as diverging views and pictures leads to a contested sea space. 


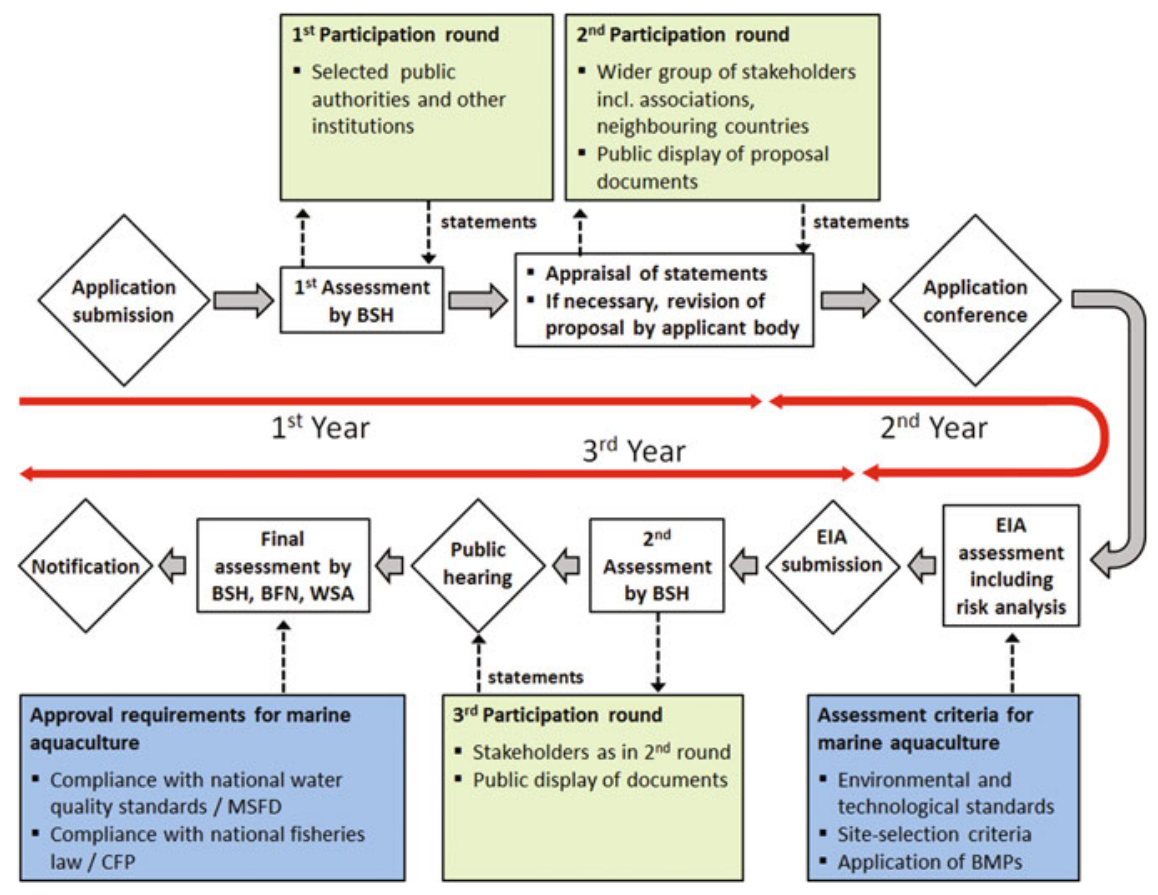

Fig. 11.45 Potential approval procedure of multi-use offshore installations (here exemplified by offshore wind farm and offshore aquaculture) in the German EEZ according to the Marine Facilities Ordinance. BFN = Bundesamt für Naturschutz (Federal Agency for Nature Conservation), BMP $=$ Best Management Practice, $\mathrm{BSH}=$ Bundesamt für Seeschifffahrt und Hydrographie (Federal Maritime and Hydrographic Agency of Germany), CFP = Common Fisheries Policy, EIA = Environmental Impact Assessment, MSFD = Marine Strategy Framework Directive, WSA = Wasser- und Schifffahrtsdirektion (Waterways and Shipping Office) (modified after Wever 2011)

A more holistic, integrated approach to ocean management that acknowledges the interconnectedness of human and natural systems is timely. However, there is a high risk of failing in the current window-of-opportunity to integrate open ocean aquaculture within the emerging management of the marine realm. What is at odds is the management discourse of the politically powerful vs. newcomers, reaffirming the socially constructed nature of knowledge.

\section{References}

Abad, M., Ruiz, C., Martinez, D., Mosquera, G., \& Sánchez, J. L. (1995). Seasonal variations of lipid classes and fatty acids in flat oyster, Ostrea edulis, from San Cibran (Galicia, Spain). Comparative Biochemistry and Physiology, 110, 109-118. 
Ahn, O., Petrell, R. J., \& Harrison, P. J. (1998). Ammonium and nitrate uptake by Laminaria saccharina and Nereocystis luetkeana originating from a salmon sea cage farm. Journal of Applied Phycology, 10, 333-340.

Bailey, H., Brookes, K. L., \& Thompson, P. M. (2014). Assessing environmental impacts of offshore wind farms: Lessons learned and recommendations for the future. Aquatic Biosystems, 2014(10), 8.

Bartlett, H. H. (1956). Fire, primitive agriculture, and grazing in the tropics. In W. L. Thomas (Ed.), Man's role in changing the face of the earth (pp. 692-720). Chicago and London: The University of Chicago Press.

Bartsch, I., Wiencke, C., Bischof, K., Buchholz, C., Buck, B. H., Eggert, A., et al. (2008). The genus Laminaria sensu lato: Recent insights and developments. European Journal of Phycology, 43, 1-86.

BLFRG. (2012). Basic law for the federal Republic of Germany in the revised version published in the Federal Law Gazette Part III, classification number 100-1, as last amended by the Act of 11.7.2012, Federal Law Gazette I, 1478.

Beamish, P. (1994). Joint vetures in LDCs: Partner selection and performance. Management International Review, 34, 60-74.

Beninger, P. G., \& Lucas, A. (1984). Seasonal variations in condition, reproductive activity, and gross biochemical composition of two species of adult clam reared in a common habitat: Tapes decussates L. (Jeffreys) and Tapes philippinarum (Adams \& Reeve). Journal of Experimental Marine Biology and Ecology, 79, 19-37.

Bilio, M. (2008). Controlled reproduction and domestication in aquaculture. The current state of the art. Aquaculture Europe Part I-IV, 33, 1-24.

Boghen, A. (1991). Cold-Water aquaculture in Atlantic Canada. New Brunswick: Canadian Institute for Research on Regional Development.

Brenner, M. (2009). Site selection criteria and technical requirements for the offshore cultivation of Blue mussels (Mytilus edulis L.). PhD Thesis. Jacobs University Bremen, Germany.

Brenner, M., \& Buck, B. H. (2010). Attachment properties of blue mussels (Mytilus edulis L.) byssus threads on culture-based artificial collector substrates. Aquacultural Engineering, 42, 128-139.

Brenner, M., Buck, B. H., \& Köhler, A. (2007). New concepts for the multi-use of offshore wind farms and high quality mussel cultivation. Global Aquaculture Advocate, 10, 79-81.

Brenner, M., Buchholz, C., Heemken, O., Buck, B. H., \& Köhler, A. (2012). Health and growth performance of the blue mussel (Mytilus edulis L.) from two hanging cultivation sites in the German Bight: a nearshore - offshore comparison. Aquaculture International, 20, 751-778.

Bridger, C. J., \& Costa-Pierce, B. A. (2003). Open ocean aquaculture: From research to commercial reality. Baton Rouge, Louisiana, USA: The World Aquaculture Society.

BSH. (2016). Bundesamt für Seeschiffahrt und Hydrographie (Federal Maritime and Hydrographic Agency), Maps of North Sea Stakeholders, CONTIS-Geodata (Continental Shelf Information System). Germany: Hamburg and Rostock.

Browne, L. (2001). Mariculture of the edible red alga Palmaria palmata. PhD thesis, Queen's University Belfast.

Buchholz, C., \& Lüning, K. (1999). Isolated, distal blade discs of the brown alga Laminaria digitata form sorus, but not discs, near to the meristematic transition zone. Journal of Applied Phycology, 11, 579-584.

Buck, B. H. (2000). Open Ocean Aquaculture und Offshore-Windparks: Eine Machbarkeitsstudie über die multifunktionale Nutzung von Offshore-Windparks und Offshore-Marikultur im Raum Nordsee. Reports on Polar and Marine Research, 412. Alfred Wegener Institute for Polar and Marine Research, Bremerhaven, Germany.

Buck, B. H. (2001). Combined utilisation of wind farming and mariculture in the North Sea. Biennial Report of Science Highlights at the Alfred Wegener Institute Helmholtz Centre for Polar and Marine Research, 33-39.

Buck, B. H. (2002). Open Ocean Aquaculture und Offshore-Windparks: Eine Machbarkeitsstudie über die multifunktionale Nutzung von Offshore-Windparks und Offshore-Marikultur im Raum 
Nordsee. Reports on Polar and Marine Research, 412. Alfred Wegener Institute for Polar and Marine Research, Bremerhaven, Germany.

Buck, B. H. (2004). Farming in a high energy environment: potentials and constraints of sustainable offshore aquaculture in the German Bight (North Sea). PhD thesis, University of Bremen, Germany.

Buck, B. H. (2007). Experimental trials on the feasibility of offshore seed production of the mussel Mytilus edulis in the German Bight: Installation, technical requirements and environmental conditions. Helgoland Marine Research, 61, 87-101.

Buck, B. H. (2017). Mytilid larval appearance and settlement at offshore wind farm sites in the German Bight - a trial to estimate multi-use potentials for bivalve seed collection and cultivation. Helgoland Marine Research.

Buck, B. H., \& Buchholz, C. M. (2004a). The offshore-ring: A new system design for the open ocean aquaculture of macroalgae. Journal of Applied Phycology, 16, 355-368.

Buck, B. H., \& Buchholz, C. M. (2004b). Support device for the cultivation of macro organisms in marine waters. Patents: PCT/DE2005/000234.

Buck, B. H., \& Buchholz, C. M. (2005). Response of offshore cultivated Laminaria saccharina to hydrodynamic forcing in the North Sea. Aquaculture, 250, 674-691.

Buck, B. H., \& Krause, G. (2012). Integration of aquaculture and renewable energy systems. In R. A. Meyers (Ed.), Encyclopaedia of sustainability science and technology (Vol. 1, pp. 511533). Springer Science + Business Media LLC.

Buck, B. H., \& Wunsch, M. (2005). Inspection device for under water constructions including a positioning system. Patent: DE 102005020070.

Buck, B. H., Ebeling, M., \& Michler-Cieluch, T. (2010). Mussel cultivation as a co-use in offshore wind farms: Potentials and economic feasibility. Aquaculture Economics and Management, 14, 255-281.

Buck, B. H., Krause, G., \& Rosenthal, H. (2004). Extensive open ocean aquaculture development within wind farms in Germany: The prospect of offshore co-management and legal constraints. Ocean Coastal Management, 47, 95-122.

Buck, B. H., Krause, G., Rosenthal, H., \& Smetacek, V. (2003). Aquaculture and environmental regulations: The German situation within the North Sea. In A. Kirchner (Ed.), International marine environmental law: Institutions, implementation and innovation. International environmental law and policies series of Kluwer Law international 64 (pp. 211-229). The Hague: Kluwer.

Buck, B. H., Walter, U., Rosenthal, H., \& Neudecker, T. (2006a). The development of Mollusc farming in Germany: Past, present and future. World Aquaculture Magazine, 6-11, 66-69.

Buck, B. H., Berg-Pollack, A., Assheuer, J., Zielinski, O., \& Kassen, D. (2006b). Technical realization of extensive aquaculture constructions in offshore wind farms: consideration of the mechanical loads. In Proceedings of the 25th International Conference on Offshore Mechanics and Arctic Engineering, OMAE 2006: Presented at the 25th International Conference on Offshore Mechanics and Arctic Engineering, 4-9 June 2006, Hamburg, Germany.

Buck, B. H., Thieltges, D., Walter, U., Nehls, G., \& Rosenthal, H. (2005). Inshore-offshore comparison of parasite infestation in Mytilus edulis: Implications for open ocean aquaculture. Journal of Applied Ichthyology, 21, 107-113.

Buck, B. H., Krause, G., Michler-Cieluch, T., Brenner, M., Buchholz, C. M., \& Busch, J. A. (2008a). Meeting the quest for spatial efficiency: Progress and prospects of extensive aquaculture within offshore wind farms. Helgoland Marine Research, 62, 269-281.

Buck, B. H., Zielinski, O., Assheuer, J., Wiemann, K., Hamm, C., \& Kassen, D. (2008b). Technische Umsetzung von extensiven Marikulturanlagen in Windparks: Betrachtung der mechanischen Lasten (Technical realisation of extensive aquaculture in offshore wind farms: Calculation of mechanical loads). Project Report FV 174.

Buck, B. H., Dubois, J., Ebeling, M., Franz, B., Goseberg, N., Krause, G., et al. (2012). Projektbericht multiple nutzung und co-management von offshore-strukturen: Marine aquakultur und offshore windparks - Open Ocean Multi-Use (OOMU). Gefördert durch das BMU—Förderkennzeichen 325206. Projektleitung: IMARE GMBH Bremerhaven—Germany. 
BNatSchG. (2009). Bundesnaturschutzgesetz, Federal Law Gazette I, 2542/2009, last amended by Federal Law Gazette I, 3154.

Byzio, A., Mautz, R., \& Rosenbaum, W. (2005). Energiewende in schwerer See? Konflikte um die Offshore-Windkraftnutzung. München: Oekom.

Caers, M., Coutteau, P., \& Sorgeloos, P. (2000). Impact of starvation and of feeding algal and artificial diets on the lipid content and composition of juvenile oyster (Crassostrea gigas) and clams (Tapes philippinarum). Marine Biology, 136, 891-899.

Carroll, G., Goodstein, J., \& Gyenes, A. (1988). Organisations and the state: Effects of the institutional environment on agricultural cooperatives in hungary. Administrative Science Quarterly, 33, 233-256.

Chambers, M. D., \& Howell, W. H. (2006). Preliminary information on cod and haddock production in submerged cages off the coast of New Hampshire, USA. ICES Journal of Marine Science, 63, 385-392.

Chopin, T., Buschmann, A. H., Halling, C., Troell, M., Kautsky, N., Neori, A., et al. (2001). Integrating seaweeds into marine aquaculture systems: A key towards sustainability. Journal of Phycology, 37, 975-986.

Corey, P., Kim, J. K., Duston, J., \& Garbary, D. J. (2014). Growth and nutrient uptake by Palmaria palmata integrated with Atlantic halibut in a land-based aquaculture system. Algae, 29, 35-45.

CWSS. (2002). Shellfish fisheries. An overview of policies for shellfish fishing in the Wadden Sea. Wilhelmshaven (Germany): Common Wadden Sea Secretariat.

Dahlke, C. (2002). Genehmigungsverfahren von Offshore-Windenergieanlagen nach der Seeanlagenverordnung. $N u R, 8,472-479$.

Dahm, G., Delbrück, J., \& Wolfrum, R. (1989). Völkerrecht, Band I/1: Die Grundlagen. Die Völkerrechtssubjekte. Berlin: de Gruyter.

Daniel, T. L. (1984). Unsteady aspects of aquatic locomotion. American Zoology, 24, 121-134.

Daniels, H. V., \& Watanabe, W. O. (2010). Practical flatfish culture and stock enhancement. New Jersey: Wiley Blackwell.

Dare, P. J., Edwards, D. B., \& Davies, G. (1983). Experimental collection and handling of spat mussels (Mytilus edulis L.) on ropes for intertidal cultivation. London: Ministry of Agriculture Fisheries and Food, Directorate of Fisheries Research.

Davenport, J., \& Chen, X. (1987). A comparison of methods for the assessment of condition in the mussel (Mytilus edulis L.). Journal of Molluscan Studies, 53, 293-297.

Davies, I. M., Greathead, C., \& Black, E. A. (2008). Risk analysis of the potential interbreeding of wild and escaped farmed cod (Gadus morhua Linnaeus). Reports and studies-Joint group of experts on the scientific aspects of marine. Environmental Protection, 76, 112-132.

De la Parra, A. M., García, O., \& Fuencisla, S. J. (2005). Seasonal variation on the biochemical composition and lipid classes of the gonadal and storage tissues of Crassostrea gigas (Thunberg, 1794) in relation to the gametogenic cycle. Journal of Shellfish Research, 24, 457467.

Denny, M. W. (1988). Biology and the mechanics of the wave-swept environment. New York: Princeton University Press.

Denny, M. W., Daniel, T. L., \& Koehl, M. A. R. (1985). Mechanical limits to size in wave-swept organisms. Ecological Monographs, 55, 69-102.

Diederich, S., Nehls, G., van Beusekom, J. E. E., \& Reise, K. (2004). Introduced Pacific oysters (Crassostrea gigas) in the northern Wadden Sea: Invasion accelerated by warm summers? Helgoland Marine Research, 59, 97-106.

D’Souza, G., Miller, D., Semmens, K., \& Smith, D. (2004). Mine water aquaculture as an economic development strategy: Linking coal mining, fish farming, water conservation and recreation. Journal of Applied Aquaculture, 15, 159-172.

EC. (2000). Directive 2000/60/EC of the European Parliament and of the Council of 23 October 2000 establishing a framework for Community action in the field of water policy, OJ L 327, December 22 2000, 1-73. 
EC. (2008). Directive 2008/56/EC of the European Parliament and of the Council of 17 June 2008 establishing a framework for community action in the field of marine environmental policy, OJ L 164, June 25 2008, 19-40.

EC. (2011). Directive 2011/92/EU of the European Parliament and of the Council of 13 December 2011 on the assessment of the effects of certain public and private projects on the environment, OJ L 335, 17.12.2011, 1-14; see also Directive 2014/52/ of the European Parliament and of the Council of 16 April 2014 amending Directive 2011/92/EU on the assessment of the effects of certain public and private projects on the environment, OJ L 124, April 25 2014, 1-18.

ECR. (2006). European Council Directive 2006/88/EC of 24 October 2006 on animal health requirements for aquaculture animals and products thereof, and on the prevention and control of certain diseases in aquatic animals, OJ L 328, November 24 2006, 14-56.

ECR. (2007). European Council Regulation No 708/2007 of 11 June 2007 concerning use of alien and locally absent species in aquaculture, OJ L 168, June 28 2007, 1-17.

ECR. (2008). European Commission Regulation No 1251/2008 of 12 December 2008 implementing Council Directive 2006/88/EC as regards conditions and certification requirements for the placing on the market and the import into the Community of aquaculture animals and products thereof and laying down a list of vector species, OJ L 337, December 162008 , 41-75.

Engle, C. R., Pomerleau, S., Fornshell, G., Hinshaw, J. M., Sloan, D., \& Thompson, S. (2005). The economic impact of proposed effluent treatment options for production of trout Oncorhynchus mykiss in flow-through systems. Aquacultural Engineering, 32, 303-323.

FAO. (2004). Food and Agricutlure Organization of the United Nations. Cultured aquatic species information programme. Salmo salar. FAO Fisheries and Aquaculture Department. Retrieved October 12, 2016, from http://www.fao.org/fishery/culturedspecies/Salmo_salar/en

FAO. (2005). Food and Agricutlure Organization of the United Nations. Cultured Aquatic Species Information Programme. Dicentrarchus labrax. FAO Fisheries and Aquaculture Department. Retrieved October 12, 2016, from http://www.fao.org/fishery/culturedspecies/Dicentrarchus_ labrax/en

Federal Agency for Agriculture and Food. (2007). Der Markt für Fischereierzeugnisse in der Bundesrepublik Deutschland im Jahre 2006: Bericht über die Versorgung der Bundesrepublik Deutschland mit Fischereiprodukten aus Eigenproduktion und Importen sowie die Exportsituation. Hamburg, Germany: Bundesanstalt für Landwirtschaft und Ernährung Referat 523 - Fischwirtschaft.

Fei, X. (2004). Solving the coastal eutrophication problem by large scale seaweed cultivation. Hydrobiologia, 512, 145-151.

Fiedler, G., Heuer, R., Koch, L., \& Steinberg, R. (2011). Windenergieanlagengeräusche als Stressor. Projektierung Biotechnologie WS 2010/11. University of Applied Sciences Bremerhaven (Germany).

Fraser, A. J., Tocher, D. R., \& Sargent, J. R. (1985). Thin-layer chromatography-Flame ionization detection and the quantification of marine neutral lipids and phospholipids. Journal of Experimental Marine Biology and Ecology, 88, 91-99.

Gallager, S. M., \& Mann, R. (1986). Growth and survival of larvae of Mercenaria mercenaria (L.) and Crassostrea virginica (Gmelin) relative to broodstock conditioning and lipid content of eggs. Aquaculture, 56, 105-121.

Gloy, C. (2006). Wirtschaftliche Bewertung einer kombinierten WindenergiegewinnungSaatmuschel-Konsummuschelproduktion im Offshore-Bereich (Abschätzung von Kosten-Nutzen). Bremerhaven: CG Gloy.

Goseberg, N., Franz, B., \& Schlurmann, T. (2012), The potential co-use of aquaculture and offshore wind energy structures. In Proceedings of the Sixth Chinese-German Joint Symposium on Hydraulic and Ocean Engineering (CGJOINT 2012) (Vol. 6, pp. 597-603), Keelung: National Taiwan Ocean University.

Grabitz, E., Hilf, M., \& Nettesheim, M. (2010-2015). Das Recht der Europäischen Union. Munich, Germany: Beck. 
Grandori, A., \& Soda, G. (1995). Inter-firm networks: Antecedents, mechanisms and forms. Organisational Studies, 16, 183-214.

Griffin, R., \& Krause, G. (2010). Economics of wind farm-mariculture integration. Working Paper, Department of Environmental and Natural Resource Economics, University of Rhode Island.

Grote, B. (2016). Bioremediation of aquaculture wastewater: evaluating the prospects of the red alga Palmaria palmata (Rhodophyta) for nitrogen uptake. Journal of Applied Phycology. doi:10.1007/s10811-016-0848-x

Grote, B., \& Buck, B. H. (2017). The IMTA-approach for nutrient balanced aquaculture: Evaluating the potential of turbot (Scophthalmus maximus) and dulse (Palmaria palmata) from onshore RAS to offshore wind farm environments. Aquaculture.

Gündling, L. (1983). Die 200 Seemeilen-Wirtschaftszone: Entstehung eines neuen Regimes des Meeresvölkerrechts. Berlin, Germany: Springer.

Guiry, M. D., \& Blunden, G. (1991). Seaweed resources in Europe: Uses and potential. Chichester, UK: Wiley.

Hatch, U., \& Thai, C. F. (1997). A survey of aquaculture production economics and management. Aquaculture Economics \& Management, 1, 13-27.

Hesley, C. (1997). Open ocean aquaculture: Chartering the future of Ocean farming. In Proceedings of an International Conference, April 23-25, 1997, Maui, Hawaii. UNIHI-Seagrant-CP-98-08, University of Hawaii Sea Grant College Program: Maui.

Hickman, R. W. (1992). Mussel cultivation. In E. Gosling (Ed.), The mussel Mytilus: Ecology, physiology, genetics and culture (pp. 465-510). Amsterdam/London: Elsevier.

Howell, W. H., \& Chambers, M. D. (2005). Growth performance and survival of Atlantic halibut (Hippoglossus hippoglossus) growth in submerged net pens. In Proceedings of the Contributed Papers of the 21 super(st) Annual, AAC (pp. 35-37), St. Andrews, NB (Canada), Aquaculture Canada super(OM) 2004.

Hundt, M., Goseberg, N., Wever, L., Ebeling, M., Schlurmann, T., \& Dubois, J. (2011). Multiple Nutzung und co-management von Offshore Strukturen: Marine Aquakultur und Offshore Windparks, Tagungsband, 8. FZK Kolloquium. Maritimer Wasserbau und Küsteningenieurwesen. Forschungszentrum Küste (FZK). Gemeinsame Einrichtung der Leibniz Universität Hannover und der technischen Universität Braunschweig, 8, 127-140.

Indergaard, M., \& Minsaas, J. (1991). Animal and human nutrition. In M. D. Guiry \& G. Blunden (Eds.), Seaweed resources in Europe: Uses and potential (pp. 21-64). Chichester, New York, Brisbane: John Wiley \& Sons.

Jensen, Ø., Dempster, T., Thorstad, E. B., Uglem, I., \& Fredheim, A. (2010). Escapes of fishes from Norwegian sea-cage aquaculture: Causes, consequences and prevention. Aquatic Environmental Interaction, 1, 71-83.

Jobling, M. (1988). A review of the physiological and nutritional energetics of cod, Gadus morhua L., with particular reference to growth under farmed conditions. Aquaculture, 70, 1-19.

Johnson, S., \& Houston, M. (2000). A reexamination of the motives and gains in joint ventures. Journal of Finanyial and Quantitative Analysis, 35, 67-85.

Joschko, T. J., Buck, B. H., Gutow, L., \& Schröder, A. (2008). Colonisation of an artificial hard substrate by Mytilus edulis in the German Bight. Marine Biology Research, 4, 350-360.

Kain, J. M. (1979). A view of the genus Laminaria. Oeeanography Marine Biology Annual Review, 17, 101-161.

Kain, J. M. (1991). Cultivation of attached Seaweeds. In M. D. Guiry \& G. Blunden (Eds.), Seaweed resources in Europe: Uses and potential (pp. 309-377). Chichester, UK: Wiley.

Kain, J. M., \& Dawes, C. P. (1987). Useful European seaweeds: Past hopes and present cultivation. Hydrobiologia, 151(152), 173-181.

Kersandt, P. (2012). Rechtliche Rahmenbedingungen der Aquakultur im Meeres- und Küstenbereich von Nord- und Ostsee. In T. Bosecke, P. Kersandt \& K. Täufer (Eds.), Mereesnaturschutz. Erhaltung der Biodiversität und andere Herausforderungen im „Kaskadensystem“ des Rechts (pp. 181-206). Berlin: Springer.

Köller, J, Köppel, J., \& Peters, W. (Eds.) (2006). Offshore wind energy-Research on environmental impacts. Springer. 
Korsøen, O. J. (2011). Biological criteria for submergence of physostome (Atlantic salmon) and physoclist (Atlantic cod) fish in sea-cages. Dissertation, The University of Bergen, Bergen.

Krause, G., Buck, B. H., \& Rosenthal, H. (2003). Multifunctional use and environmental regulations: potentials in the offshore aquaculture development in Germany. In A. Sjoestroem (Ed.), Rights and Duties in the Coastal Zone, Proceedings of the Multidisciplinary Scientific Conference on Sustainable Coastal Zone Management Rights and Duties in the Coastal Zone, 12-14 June 2003. Sweden: Stockholm.

Krause, G., Griffin, R. M., \& Buck, B. H. (2011). Perceived concerns and advocated organisational structures of ownership supporting 'Offshore Wind Farm - Mariculture Integration'. In G. Krause (Ed.), From turbine to wind farms: Technical requirements and spin off products (pp. 203-218). Rijeka, Croatia: InTech, Open Access Publisher.

Krause, G., Brugere, C., Diedrich, A., Troell, M., Ebeling, M. W., Ferse, S. C., et al. (2015). A Revolution without people? Closing the people-policy gap in aquaculture development. Aquaculture, 447, 44-55.

Krone, R. (2012a). Artificial habitat in polyhedron for crustaceans in marine soft bottoms and application (Künstliches Habitat in Polyederform für Krebstiere auf marinen Weichböden und Anwendung). German Patent DE102010049049B3.

Krone, R. (2012b). Offshore wind power reef effects and reef fauna roles. Dissertation, University Bremen.

Krone, R., \& Krämer, P. (2011). Device for colonizing and harvesting marine hardground animals, (Vorrichtung zur Ansiedelung und Ernte von marinen Hartbodentieren); German Patent DE102009058278B3; United States patent US020110139083A1.

Krone, R., \& Krämer, P. (2012). Transportable device for colonizing and harvesting invertebrates and its use, (Transportierbare Vorrichtung zur Ansiedlung und Erntung von wirbellosen Tieren und Anwendung davon. German Patent DE102009049083B3; Canadian patent CA000002764735A1; international patent WO002011042003A1.

Krone, R., \& Schröder, A. (2011). Wrecks as artificial lobster habitats in the German Bight. Helgoland marine research. doi: 10.1007/s10152-010-0195-2

Krone, R., Schmalenbach, I., \& Franke, H. D. (2013). Lobster settlement at the offshore wind farm Riffgat, German Bight (North Sea). WinMon. BE Conference, Environmental impact of offshore wind farms, Royal Belgian Institute of Natural Sciences, Brussels, Belgium, 26 November 2013-28 November 2013.

Krone, R., Schröder, A., \& Krämer, P. (2012). Device for developing habitats in the underwater area of an offshore construction, (Vorrichtung zur Habitaterschließung im Unterwasserbereich eines Offshore-Bauwerks). German Patent DE102010021606B4; international patent WO002011147400A3.

Kumar, M. V. (2007). Asymmetric wealth gains in joint ventures: Theory and evidence. Finance Research Letters, 4, 19-27.

Laing, I., Walker, P., \& Areal, F. (2006). Return of the native-Is European oyster (Ostrea edulis) stock restoration in the UK feasible? Aquatic Living Resources, 19, 283-287.

Lanari, D., D’Agaro, E., \& Ballestrazzi, R. (2002). Growth parameters in European sea bass (Dicentrarchus labrax L.): Effects of live weight and water temperature. Italian Journal of Animal Science, 1, 181-185.

Langan, R., \& Horton, F. (2003). Design, operation and economics of submerged longline mussel culture in the open ocean. Bulletin of the Aquaculture Association of Canada, 103, 11-20.

Le Gall, L., Pien, S., \& Rusig, A. M. (2004). Cultivation of Palmaria palmata (Palmariales, Rhodophyta) from isolated spores in semi-controlled conditions. Aquaculture, 229, 181-191.

Liu, Y., \& Sumaila, R. U. (2007). Economic analysis of netcage versus sea-bag production systems for salmon aquaculture in British Columbia. Aquaculture Economics \& Management, 11, 371-395.

Løvstad-Holdt, S., \& Kraan, S. (2011). Bioactive compounds in seaweed: functional food applications and legislation. Journal of Applied Phycology, 23, 543-597. 
Lutges, S., \& Holzfuss, H. (2006). Integrates coastal zone management in Germany: Assessment and steps towards a national ICZM strategy. German Federal Ministry for the Environment, Nature Conservation and Nuclear Safety.

Lüning, K. (1979). Growth strategies of three Laminaria species (Phaeophyceae) inhabiting different depth zones in the sublittoral region of Helgoland (North Sea). Marine Ecology Progress Series, 1, 195-207.

Lüning, K. (1990). Seaweeds: Their environment, biogeography, and ecophysiology. Chichester, New York, Brisbane: Wiley.

Lüning, K. (2001). SEAPURA: Seaweeds purifying effluents from fish farms, an EU project coordinated by the Wattenmeerstation Sylt, Wadden Sea Newsletter, 20-21.

Lüning, K., \& Pang, S. J. (2003). Mass cultivation of seaweeds: current aspects and approaches. Journal of Applied Phycology, 15, 115-119.

Lüning, K., Wagner, A., \& Buchholz, C. (2000). Evidence for inhibitors of sporangium formation in Laminaria digitata (Phaeophyceae) during the season of rapid growth. Journal of Phycology, 36, 1129-1134.

Matos, J., Costa, S., Rodrigues, A., Pereira, R., \& Sousa-Pinto, I. (2006). Experimental integrated aquaculture of fish and red seaweeds in Northern Portugal. Aquaculture, 252, 31-42.

Matthiessen, G. C. (2001). Oyster culture. London: Wiley-Blackwell.

Mc Hugh, D. J. (2003). A guide to the seaweed industry. FAO Fisheries Technical Papers T441.

Mee, L. (2006). Complementary benefits of alternative energy: Suitability of offshore wind farms as aquaculture sites. Report of Project 10517, commissioned by Seafish.

Michler-Cieluch, T. (2009). Co-management processes in integrated coastal management-The case of integrating marine aquaculture in offshore wind farms. Hamburg: University of Hamburg, Department of Integrative Geography.

Michler-Cieluch, T., \& Krause, G. (2008). Perceived concerns and possible management strategies for governing wind farm-mariculture integration. Marine Policy, 32, 1013-1022.

Michler-Cieluch, T., \& Kodeih, S. (2008). Mussel and seaweed cultivation in offshore wind farms: an opinion survey. Coastal Management, 36, 392-411.

Michler-Cieluch, T., Krause, G., \& Buck, B. H. (2009a). Reflections on integrating operation and maintenance activities of offshore wind farms and mariculture. Ocean and Coastal Management, 52, 57-68.

Michler-Cieluch, T., Krause, G., \& Buck, B. H. (2009b). Marine aquaculture within offshore wind farms: Social aspects of multiple use planning. GAIA, 18, 158-162.

Mittendorf, K., Nguyen, B., \& Zielke, W. (2001). User manual waveloads-A computer program to calculate wave loading on vertical and inclined tubes. Institut für Strömungsmechanik und Elektron. Rechnen im Bauwesen, Universität Hannover. Retrieved October 12, 2016, from

Moksness, E., Kjorsvik, E., \& Olsen, Y. (2004). Culture of cold-water marine fish. London: Wiley-Blackwell.

Molenaar, F. J., \& Breeman, A. M. (1997). Latitudinal trends in the growth and reproductve seasonality of Delesseria sanguinea, Membranoptera alata and Phycodrys rubens (RHODOPHYTA). Journal of Phycology, 33, 330-343.

Morgan, K. C., \& Simpson, F. J. (1981). The cultivation of Palmaria palmata. Effect of light intensity and temperature on growth and chemical composition. Botanica Marina, 24, 547552.

Morgan, K. C., Wright, J. L., \& Simpson, F. J. (1980a). Review of chemical constituents of the red alga Palmaria palmata (dulse). Economic Botany, 34, 27-50.

Morgan, K. C., Shacklock, P. F., \& Simpson, F. J. (1980b). Some aspects of the culture of Palmaria palmata in greenhouse conditions. Botanica Marina, 23, 765-770.

Morison, J. R., O‘Brien, M. P., \& Schaaf, S. A. (1950). The force exerted by surface waves on piles. Petroleum Transactions, AIME 2846, 189, 149-157

Neori, A., Chopin, T., Troell, M., Buschmann, A. H., Kraemer, G. P., \& Halling, C. (2004). Integrated aquaculture: Rationale, evolution and state of the art emphasizing seaweed biofiltration in modern mariculture. Aquaculture, 231, 361-391. 
Newkirk, G. F., Muise, B., \& Enright, C. T. (1995). Culture of the Belon oyster, Ostrea edulis, in Nova Scotia. In A. D. Boghen (Ed.), Cold-water aquaculture in Atlantic Canada. Moncton, Canada: Canadian Institute for Research on Regional Development.

Nielsen, B. (2010). Strategic fit, contractual, and procedural governance in alliances. Journal of Business Research, 63, 682-689.

NKüFischO. (2006). Niedersächsische Küstenfischereiordnung, Nds. GVB1. S. 108_VORIS 79300.

Noble, B. (2000). Institutional criteria for co-management. Marine Policy, 24(1), 69-77.

OFT. (2010). Aquapod-A submergible fish cage. Searsmont, USA: Ocean Farm Technologies.

Özbilgina, H., \& Glass, C. W. (2004). Role of learning in mesh penetration behaviour of haddock (Melanogrammus aeglefinus). ICES Journal of Marine Science: Journal du Conseil, 61, 11901194.

Pang, S. J., \& Lüning, K. (2004). Tank cultivation of the red alga Palmaria palmata: Effects of intermittent light on growth rate, yield and growth kinetics. Journal of Applied Phycology, 16, 93-99.

Pang, S. J., \& Lüning, K. (2006). Tank cultivation of the red alga Palmaria palmata: Year-round induction of tetrasporangia, tetraspore release in darkness and mass cultivation of vegetative thalli. Aquaculture, 252, 20-30.

Pazos, A. J., Ruíz, C., García-Martín, O., Abad, M., \& Sánchez, J. L. (1996). Seasonal variations of the lipid content and fatty acid composition of Crassostrea gigas cultured in El Grove, Galicia, N.W. Spain. Comparative Biochemistry and Physiology, 114, 171-179.

Pelz, P. (1974). Rationalisierung aus unternehmerischer Sicht: Vorbereitung und technischwirtschaftliche Beurteilung. In P. Pelz (Ed.), Die Priorität der Rationalisierung im Unternehmen (pp. 58). Düsseldorf/Berlin, Germany: Verein Deutscher Ingenieure, VDI-Bildungswerk.

Person-Le Ruyet, J., Buchet, V., Vincent, B., Le Delliou, H., \& Quemener, L. (2006). Effects of temperature on the growth of pollack (Pollachius pollachius) juveniles. Aquaculture, 251, 340-345.

Perez, P., Kaas, R., Campello, F., Arbault, S., \& Barbaroux, O. (1992). La culture des algues marines dans le monde. Nantes, France: IFREMER.

Petrell, R. J., \& Alie, S. Y. (1996). Integrated cultivation of salmonids and seaweeds in open systems. Hydrobiologia, 326, 67-73.

Pogoda, B. (2012). Farming the High Seas: Biological performance of the offshore cultivated oysters Ostrea edulis and Crassostrea gigas in the North Sea. Dissertation, Marine Zoology of the Department of Biology \& Chemistry, University of Bremen.

Pogoda, B., Buck, B. H., \& Hagen, W. (2011). Growth performance and condition of oysters (Crassostrea gigas and Ostrea edulis) farmed in an offshore environment (North Sea, Germany). Aquaculture, 319, 484-492.

Pogoda, B., Grote, B., \& Buck, B. H. (2015). Aquakultur-Site-Selection für die nachhaltige und multifunktionale Nutzung von marinen Gebieten in stark genutzten Meeren am Beispiel der Nordsee-Offshore Site-Selection. Gefördert durch das BMELV-Förderkennzeichen GZ: 511-06.01-28-1-73.009-10.

Pogoda, B., Buck, B. H., Saborowski, R., \& Hagen, W. (2013). Biochemical and elemental composition of the offshore-cultivated oysters Ostrea edulis and Crassostrea gigas. Aquaculture, 400, 53-60.

Pogoda, B., Jungblut, S., Buck, B. H., \& Hagen, W. (2012). Infestation of oysters and mussels by mytilicolid copepods: Differences between natural coastal habitats and two offshore cultivation sites in the German Bight. Journal of Applied Ichthyology, 28(5), 756-765.

Polk, M. (1996). Open Ocean Aquaculture. In Proceedings of an International Conference, May 8-10, 1996, Portland, Maine. UNHMP-CP-SG-96-9, Portland, New Hampshire/Maine Sea Grant College Program.

Pomeroy, R. S., Parks, J. E., \& Balboa, C. M. (2006). Farming the reef: Is aquaculture a solution for reducing fishing pressure on coral reefs? Marine Policy, 30, 111-130. 
Raman-Nair, W., \& Colbourne, D. B. (2003). Dynamics of a mussel longline system article in aquacultural. Engineering, 27, 191-212.

Rhode Island Coastal Resources Management Council. (2010). Rhode Island Ocean Special Area Management Plan.

Rick, H. J., Rick, S., Tillmann, U., Brockmann, U., Gaertner, U., Duerselen, C., et al. (2006). Primary productivity in the German bight (1994-1996). Estuaries and Coasts, 29, 4-23.

Robinson, D. (2008). Strategic alliances and the boundaries of the firm. The Review of Financial Studies, 21, 649-681.

Rosenberg, R., \& Loo, L. O. (1983). Energy flow in a Mytilus edulis culture in western Sweden. Aquaculture, 35, 151-167.

Rosenlund, G., \& Skretting, M. (2006). Worldwide status and perspective on gadoid culture. ICES Journal of Marine Science, 63, 194-197.

Ruíz, C., Martinez, D., Mosquera, G., Abad, M., \& Sánchez, J. L. (1992). Seasonal variations in condition, reproductive activity and biochemical composition of the flat oyster, Ostrea edulis, from San Cibran (Galicia, Spain). Marine Biology, 112, 67-74.

SAG. (1965). Seeaufgabengesetz of 24.5.1965, Federal Law Gazette 1965 II p. 833, last amended by Act of 19.10. 2013, Federal Law Gazette I p. 3836.

Sahr, J. (2006). Wind und Meer: Küstenproduktion von morgen. Anregungen für Marikultur in Offshore Windparks. Bremerhaven: CG Gloy.

Sanderson, J. C., Dring, M. J., Davidson, K., \& Kelly, M. S. (2012). Culture, yield and bioremediation potential of Palmaria palmata (Linnaeus) Weber \& Mohr and Saccharina latissima (Linnaeus) C.E. Lane, C. Mayes, Druehl \& G.W. Saunders adjacent to fish farm cages in northwest Scotland. Aquaculture, 354-355, 128-135.

Scarratt, D. (1993). A handbook of northern Mussel culture. Montague: Island Press.

Schmalenbach, I., \& Krone, R. (2011). Secondary use of offshore wind farms-Settlement of juvenile European lobsters (Homarus gammarus). IMARE-Conference "Marine Resources and Beyond", 5-7 September 2011, Bremerhaven, Germany.

Schmalenbach, I., Mehrtens, F., Janke, M., \& Buchholz, F. (2011). A mark-recapture study of hatchery-reared juvenile European lobsters, Homarus gammarus, released at the rocky island of Helgoland (German Bight, North Sea) from 2000 to 2009. Fisheries Research, 108, 22-30.

SFA. (2008). Annual data for mussel harvest in Lower Saxony (Germany) in the years 1950-2007 provided by the State Fisheries Agency Bremerhaven (Germany).

Smaal, A. C., Kater, B. J., \& Wijsman, J. (2009). Introduction, establishment and expansion of the Pacific oyster Crassostrea gigas in the Oosterschelde (SW Netherlands). Helgoland Marine Research, 63, 75-83.

Sørensen, H. C., Hansen, J., \& Vølund, P. (2001). Experiences from the establishment of Middelgrunden $40 \mathrm{MW}$ offshore wind farm. In Proceedings of the European Wind Energy Conference, 2-6 July, Copenhagen, Denmark: EWEA.

Stelzenmüller, V., Diekmann, R., Bastardie, F., Schulze, T., Berkenhagen, J., Kloppmann, et al. (2016). Co-location of passive gear fisheries in offshore wind farms in the German EEZ of the North Sea: A first socio-economic scoping. Journal of Environmental Management, 183, 794 805. doi dx.doi.org/10.1016/j.jenvman.2016.08.027.

Stickney, R. R. (1998). Joining forces with industry—open ocean aquaculture. In Proceedings of the Third Annual International Conference, May 10-15, Corpus Christi, Texas. TAMU-SG-99-103, Corpus Christi, Texas Sea Grant College Program.

Sturrock, H., Newton, R., Paffrath, S., Bostock, J., Muir, J., Young, J., et al. (2008). Prospective analysis of the aquaculture sector in the EU. Part 2: Characterisation of emerging aquaculture systems. Seville, Spain: Institute for Prospective Technological Studies.

Subandar, A., Petrell, R. J., \& Harrison, P. J. (1993). Laminaria culture for reduction of dissolved inorganic nitrogen in salmon farm effluent. Journal of Applied Phycology, 5, 455-463. doi:10. 1007/BF02182738

Thieltges, D. W., Krakau, M., Andresen, H., Fottner, S., \& Reise, K. (2006). Macroparasite community in molluscs of a tidal basin in the Wadden Sea. Helgoland Marine Research, 60, 307-316. 
Tortell, P. (1976). A new rope for mussel farming. Aquaculture, 8, 383-388.

Treasurer, J. W., Sveier, H., Harvey, W., Allen, R., Cutts, C. J., Mazorra de Quero, C., et al. (2006). Growth, survival, diet, and on-growing husbandry of haddock Melanogrammus aeglefinus in tanks and netpens. ICES Journal of Marine Science, 63, 376-384.

Troell, M., Rönnbäck, P., Halling, C., Kautsky, N., \& Buschmann, A. (1999). Ecological engineering in aquaculture: Use of seaweeds for removing nutrients from intensive mariculture. Journal of Applied Phycology, 11, 89-97.

VüAs. (1997). Verordnung über Anlagen seewärts der Begrenzung des deutschen Küstenmeeres of 23.01.1997, Federal Law Gazette I p. 57, last amended by Ordinance of 29.8.2013 Federal Gazette of 30.08.2013.

Vollstedt, B. (2011). The role of perceptions and networks in multiple marine resource use: Integrating aquaculture and offshore wind farms in the North Sea. Master thesis University Kiel.

Walne, P. R., \& Mann, R. (1975). Growth and biochemical composition in Ostrea edulis and Crassostrea gigas. In H. Barnes (Ed.), Proceedings of 9th EMBS Aberdeen (pp. 587-607).

Walter, U., \& Liebezeit, G. (2003). Efficiency of blue mussel (Mytilus edulis) spat collectors in highly dynamic tidal environments of the Lower Saxonian coast (southern North Sea). Biomolecular Engineering, 20, 407-411.

Walter, U., \& Liebezeit, G. (2001). Abschlußbericht des Projektes: Nachhaltige Miesmuschel-Anzucht im niedersächsischen Wattenmeer durch die Besiedlung natürlicher und künstlicher Substrate. Forschungszentrum Terramare.

Walter, U., Buck, B. H., \& Rosenthal, H. (2002). Marikultur im Nordseeraum: Status Quo, Probleme und Tendenzen. In J. L. Lozán, E. Rachor, \& K. Reise (Eds.), Warnsignale aus Nordsee \& Wattenmeer: eine aktuelle Umweltbilanz (pp. 122-131). Hamburg: Büro Wiss. Auswertungen.

Weiss, M., \& Buck, B. H. (2017). Blue Mussel (Mytilus edulis) Meat as a Partial Fish Meal Replacement for the Diet in Turbot Aquaculture. Journal of Applied Ichthyology.

Weiss, M., Wittke, S., Greim Fish Consulting, WeserWind, Louis Schoppenhauer GmbH \& Co. KG. (2012). NutriMat: Nutritional material from fouling organisms-Analyse der Nutzungsmöglichkeiten von biologischem Aufwuchs von künstlichen Hartsubstraten für die Gewinnung alternativer Protein- und Lipidressourcen. Bremerhaven, Germany: Imare.

Werner, A., \& Dring, M. (2011). Aquaculture explained no 27. BIM-Irish Sea Fisheries Board: Cultivating Palmaria palmata.

Wever, L. (2011). The emergence of multi-use ocean governance: Potentials and constraints for offshore windfarm-mariculture integration in Germany. International Conference "Marine Resources and Beyond 2011", September 5-7 2011, Bremerhaven, Germany. Book of Abstracts. 46 p.

Wever, L., Buck, B. H., \& Krause, G. (2014). Lessons from stakeholder dialogues on marine aquaculture in offshore wind farms: Perceived potentials, constraints and research gaps. Marine Policy, 51, 251-259.

Whitmarsh, D. J., Cook, E. J., \& Black, K. D. (2006). Searching for sustainability in aquaculture: An investigation into the economic prospects for an integrated salmon-mussel production system. Marine Policy, 30, 293-298.

Whyte, J. N. C., Englar, J. R., \& Carswell, B. L. (1990). Biochemical composition and energy reserves in Crassostrea gigas exposed to different levels of nutrition. Aquaculture, 90, 157172.

Wildish, D. J., \& Kristmanson, D. D. (1984). Importance to mussels of the benthic boundary layer. Canadian Journal of Fisheries and Aquatic Sciences, 41, 1618-1625.

Wildish, D. J., \& Kristmanson, D. D. (1985). Control of suspension feeding bivalve production by current speed. Helgoländer Wiss Meeresunters, 39, 237-243.

Williamson, O. (1979). Transaction-cost economics: The governance of contractual relations. Journal of Law and Economics, 22, 233-261. 
Williamson, O. (1981). The economics of organisation: The transaction cost approach. American Journal of Sociology, 87, 548-577.

Wiltshire, K. H., \& Manly, B. F. J. (2004). The warming trend at Helgoland Roads, North Sea: Phytoplankton response. Helgoland Marine Research, 58, 269-273.

Open Access This chapter is licensed under the terms of the Creative Commons Attribution 4.0 International License (http://creativecommons.org/licenses/by/4.0/), which permits use, sharing, adaptation, distribution and reproduction in any medium or format, as long as you give appropriate credit to the original author(s) and the source, provide a link to the Creative Commons license and indicate if changes were made.

The images or other third party material in this chapter are included in the chapter's Creative Commons license, unless indicated otherwise in a credit line to the material. If material is not included in the chapter's Creative Commons license and your intended use is not permitted by statutory regulation or exceeds the permitted use, you will need to obtain permission directly from the copyright holder. 